Florida International University

FIU Digital Commons

FIU Electronic Theses and Dissertations

University Graduate School

$3-22-2011$

\title{
Comparison of Repeated and Two Non-Repeated Readings Conditions on Reading Abilities of Students with Emotional and/or Behavioral Disabilities
}

Raul Escarpio

Florida International University, scarp@mac.com

DOI: $10.25148 /$ etd.FI1 1050303

Follow this and additional works at: https://digitalcommons.fiu.edu/etd

\section{Recommended Citation}

Escarpio, Raul, "Comparison of Repeated and Two Non-Repeated Readings Conditions on Reading Abilities of Students with Emotional and/or Behavioral Disabilities" (2011). FIU Electronic Theses and Dissertations. 379.

https://digitalcommons.fiu.edu/etd/379 


\title{
FLORIDA INTERNATIONAL UNIVERSITY \\ Miami, Florida
}

\section{COMPARISON OF REPEATED AND TWO NON-REPEATED READINGS CONDITIONS ON READING ABILITIES OF STUDENTS WITH \\ EMOTIONAL AND/OR BEHAVIORAL DISABILITIES}

\author{
A dissertation submitted in partial fulfillment of the \\ requirements for the degree of \\ DOCTOR OF EDUCATION \\ in \\ EXCEPTIONAL STUDENT EDUCATION
}

by

Raul Escarpio

2011 
To: Dean Delia Garcia

College of Education

This dissertation, written by Raul Escarpio, and entitled Comparison of Repeated and Two Non-Repeated Readings Conditions on Reading Abilities of Students with Emotional and/or Behavioral Disabilities, having been approved in respect to style and intellectual content, is referred to you for judgment.

We have read this dissertation and recommend that it be approved.

Elizabeth Cramer

Lynne Miller

Diana Valle-Riestra

Patricia M. Barbetta, Major Professor

Date of Defense: March 22, 2011

The dissertation of Raul Escarpio is approved.

\begin{tabular}{r}
$\begin{array}{r}\text { Dean Delia Garcia } \\
\text { College of Education }\end{array}$ \\
\hline Interim Dean Kevin O'Shea \\
University Graduate School
\end{tabular}

Florida International University, 2011 
(C) Copyright 2011 by Raul Escarpio

All rights reserved. 


\section{DEDICATION}

I dedicate this work to Aileen, our son, and our little one on the way. Thanks for always being so patient and inspiring me to do my best. You are a blessing to me and I will be forever grateful for all of your support throughout this process. I love you all. Thank You, Lord Jesus for all Your blessings especially Your love for my family and me. 


\section{ACKNOWLEDGMENTS}

I would like to thank the members of my committee Major Professor Dr. Patricia M. Barbetta, Dr. Elizabeth Cramer, Dr. Lynne Miller, and Dr. Diana Valle-Riestra for their honesty, input, and support. In particular, I want to extend a special thank you to Dr. Barbetta, who provided me with much needed feedback and tough love at each and every turn. Thank you for teaching me and helping me to appreciate the value of single subject design in the classroom. Thank you also to Dr. Linda Bliss, Dr. Ann Nevin and Dr. Louie Rodriguez for their guidance and support throughout the program. Finally, a special thank you to Dr. Valle-Riestra who was instrumental in my formation and development as a doctoral student. This project would not have been completed without them.

I would like to thank Dr. Katrina G. Landa for the countless times she was available to answer any questions or concerns. Additionally, I would like to thank the administration, staff, and students of Ruth Owens Krusé Educational Center for their support in completing this dissertation but especially those in the elementary program

who were very helpful throughout this study. Thanks to my family (Dad, Mari, Orly, Leo, Sonia, and Carlos), friends (Escala, Chacon, Rodriguez, Gonzalez, Jimenez, Santamaria, and Lopez), and the rest of Marriages in Victory for all your prayers and encouragement throughout those long nights and weekends spent away from you.

Finally, I would like to thank my late mother, Mercedes, who always believed I could complete this study even when (at times) I didn't. You may not be around in person to see this study come to fruition, but you were the major catalyst to this study being completed. Thank you for your faith in me. I miss you and love you very much. 


\title{
ABSTRACT OF THE DISSERTATION \\ COMPARISON OF REPEATED AND TWO NON-REPEATED READINGS \\ CONDITIONS ON READING ABILITIES OF STUDENTS WITH EMOTIONAL \\ AND/OR BEHAVIORAL DISABILITIES
}

\author{
by \\ Raul Escarpio \\ Florida International University, 2011 \\ Miami, Florida \\ Professor Patricia M. Barbetta, Major Professor
}

Students with emotional and/or behavioral disorders (EBD)present considerable academic challenges along with emotional and/or behavioral problems. In terms of reading, these students typically perform one-to-two years below grade level (Kauffman, 2001). Given the strong correlation between reading failure and school failure and overall success (Scott \& Shearer-Lingo, 2002), finding effective approaches to reading instruction is imperative for these students (Staubitz, Cartledge, Yurick, \& Lo, 2005).

This study used an alternating treatments design to comparethe effects of three conditions on the reading fluency, errors, and comprehension of four, sixth-grade students with EBD who were struggling readers. Specifically, the following were compared: (a) Repeated readings in which participants repeatedly read a passage of about 100-150 words, three times, (b) Non-repeated readings in which participants sequentially read an original passage of about 100-150 words once, and (c) Equivalent non-repeated readings in which participants sequentially read a passage of about 300-450 words, equivalent to the number of words in the repeated readings condition. Also examined 
were the effects of the three repeated readings practice trials per sessions on reading fluency and errors. The reading passage difficulty and length established prior to commencing were used for all participants throughout the standard phase. During the enhanced phase, the reading levels were increased 6 months for all participants, and for two (the advanced readers), the length of the reading passages was increased by $50 \%$, allowing for comparisons under more rigorous conditions.

The results indicate that overall repeated readings had the best outcome across the standard and enhanced phases for increasing readers' fluency, reducing their errors per minute, and supporting fluency answers to literal comprehension questions correctly as compared to non-repeated and equivalent non-repeated conditions. When comparing nonrepeated and equivalent non-repeated readings, there were mixed results. Under the enhanced phases, the positive effects of repeated readings were more demonstrative.

Additional research is needed to compare the effects of repeated and equivalent non-repeated readings across other populations of students with disabilities or varying learning styles. This research should include collecting repeated readings practice trial data for fluency and errors to further analyze the immediate effects of repeatedly reading a passage. 


\section{TABLE OF CONTENTS}

CHAPTER

PAGE

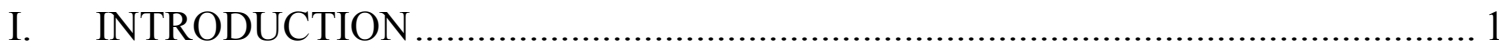

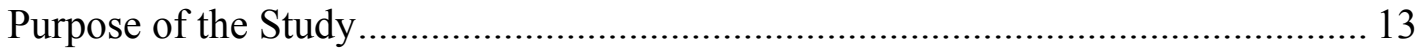

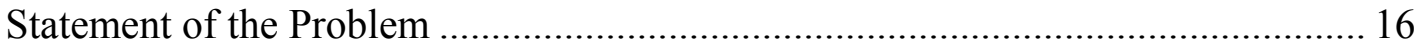

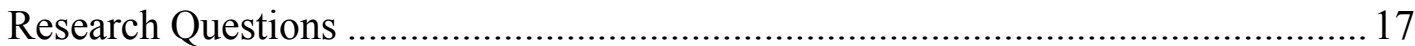

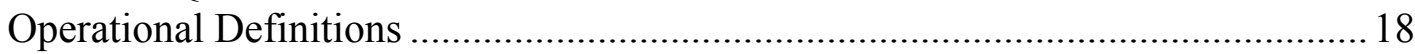

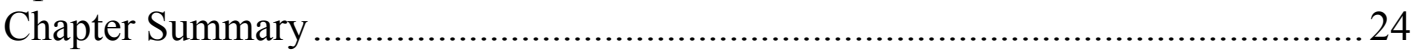

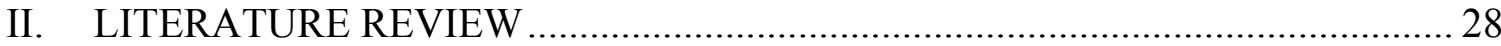

Characteristics of Students Who Do and Do Not Read Well .................................. 28

Students With Emotional and/or Behavioral Disorders and Academics................... 30

Students With Emotional and/or Behavioral Disorders and Reading ........................ 33

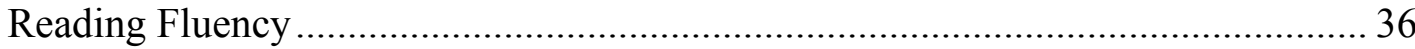

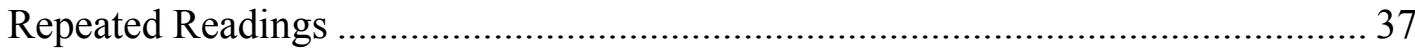

Students With Emotional and/or Behavioral Disorders and

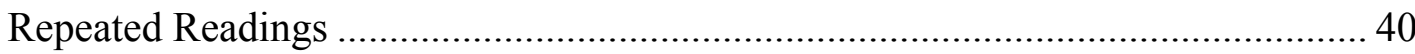

Active Student Responding and Opportunities to Respond ..................................... 46

Repeated Readings and Equivalent Non-Repeated Readings by Number of

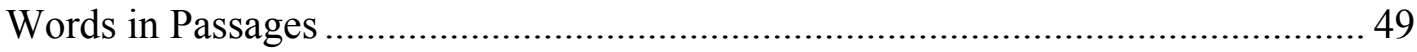

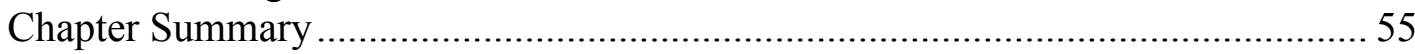

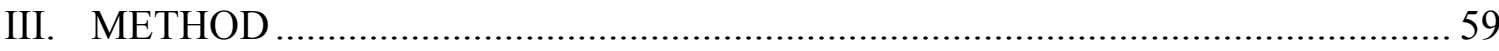

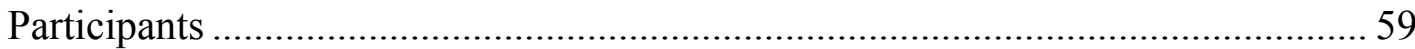

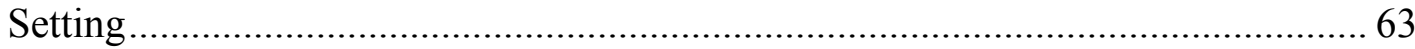

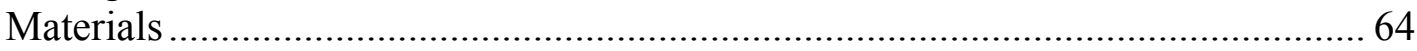

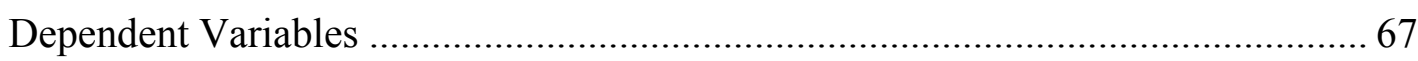

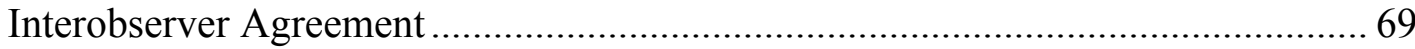

Treatment Fidelity …………………………………….............................. 70

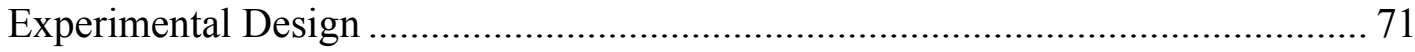

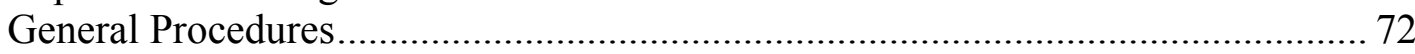

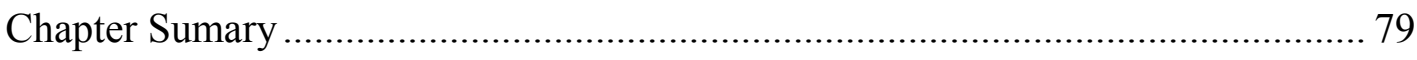

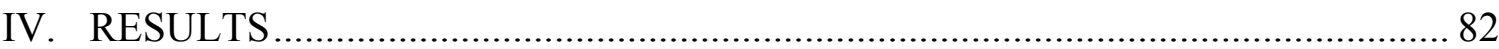

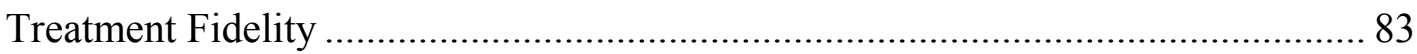

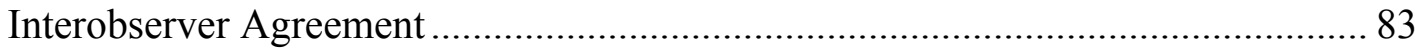

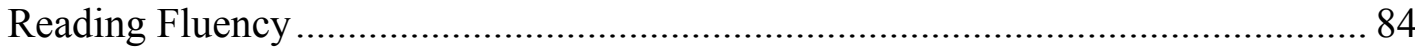

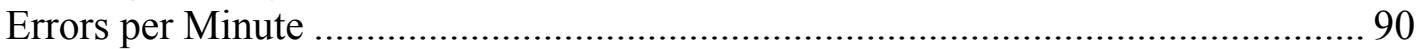

Correct Answers to Literal Comprehension Questions .............................................. 96

Repeated Readings Practice Trials Reading Fluency ............................................. 103

Repeated Readings Practice Trials Errors per Minute …………............................ 110

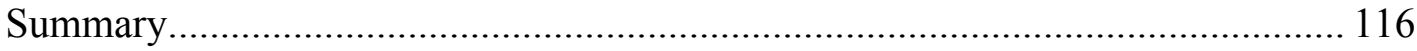




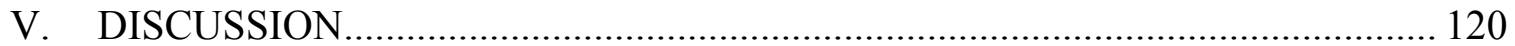

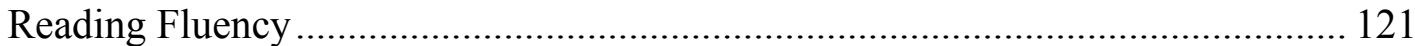

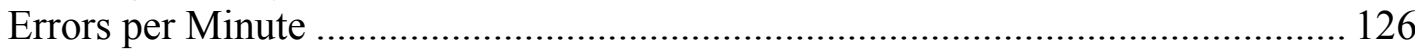

Correct Answers to Literal Comprehension Questions ............................................ 129

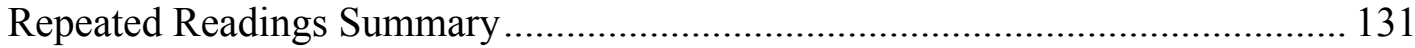

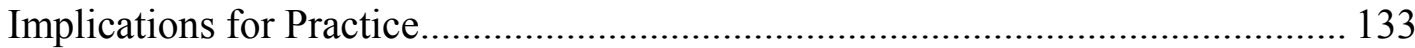

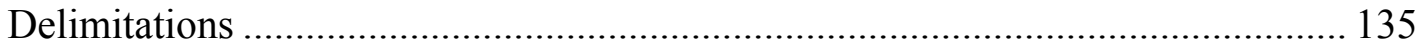

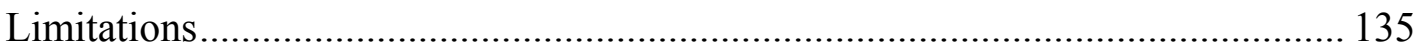

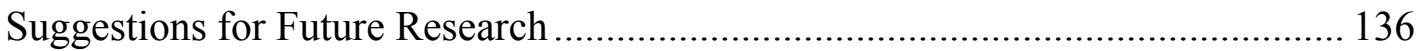

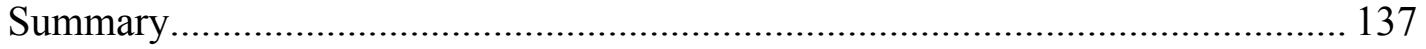

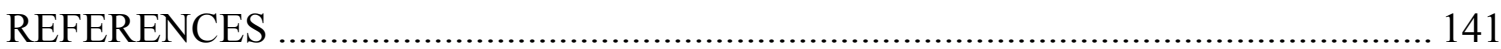

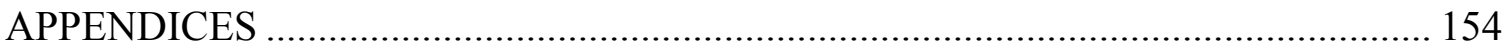

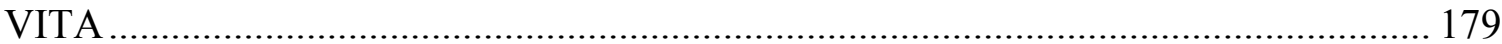




\section{LIST OF TABLES}

TABLE

PAGE

1. Demographic and Analytical Reading Inventory Data ......................................... 62

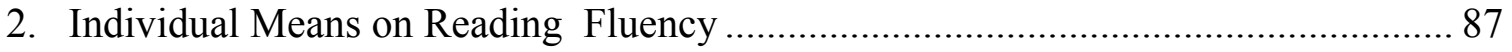

3. Individual Means on Reading Errors per Minute ................................................ 93

4. Individual Means on Literal Comprehension Questions Answered Correctly .......... 99

5. Individual Means on Repeated Readings Practice Trials-Fluency ......................... 106

6. Individual Means on Repeated Readings Practice Trials-Errors per Minute ........... 112 


\section{LIST OF FIGURES}

FIGURE

PAGE

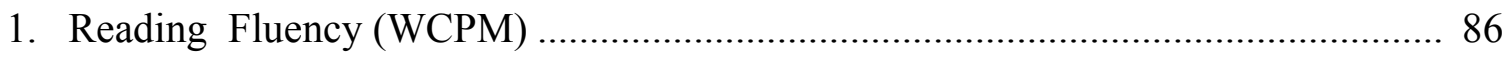

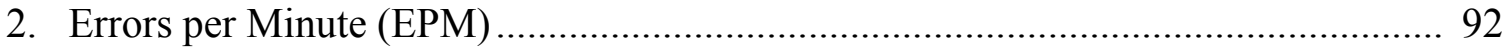

3. Correct Answers to Literal Comprehension Questions Answered Correctly ............. 98

4. Repeated Readings Practice Trials-Fluency …………….................................... 105

5. Repeated Readings Practice Trials-Errors per Minute............................................. 111 


\section{Chapter I}

\section{Introduction}

When one is able to read fluently there are benefits (Stromquist, 2008) including the ability to comprehend the text within a reasonable time limit (Rasinski, 2000) and to summarize, interpret, and accept or reject information on the printed page (Pressley, Gaskins, \& Fingeret, 2006). Also, fluent readers are more likely to read for pleasure, thereby increasing the amount of time spent reading outside the classroom (Stromquist, 2008). They are better prepared to attend college and post-secondary programs and succeed at these levels (American College Testing Program, 2006), and once they leave school, those who read well are more likely able to meet the increased workplace demands for a literate workforce (Torgesen, 2002) and to stay employed (National Center for Education Statistics [NCES], 2004; Rasinki, 2000).

Despite efforts to assist struggling readers, there are many students who do not read well (Begeny \& Martens, 2006; Chard, Vaughn, \& Taylor, 2002; NCES, 2004). As an example, Begeny and Martens (2006) stated that nearly $40 \%$ of American fourth graders are still reading below their grade level. In the state of Florida, 31\% of Florida's third graders are reading below grade level (Florida Department of Education [FLDOE], 2008). With respect to the local school district of this study, $37 \%$ of third-grade students in the Miami-Dade County Public School (M-DCPS) district scored below grade level and were considered to be struggling readers based on the reading portion of the Florida Comprehensive Assessment Test (FCAT)(FLDOE, 2008).

There are negative consequences associated with not being able to read well, both academically and socially. Typically, students who do not read with proficiency have 
difficulty in assignment completion (Hitchcock, Prater, \& Dowrick, 2004). Academically, these students have access to less information than their peers, as they cannot read as quickly or efficiently (Hitchcock et al., 2004). Ineffective readers tend to exhibit disruptive or withdrawn behaviors that do not allow them to engage in learning activities (Hitchcock et al., 2004). Other negative social outcomes of not being able to read well include low participation in extracurricular school activities and a higher probability of dropping out of school (Lazarus \& Callahan, 2000). After they leave school, ineffective readers may have limited employment opportunities, a greater likelihood of living in poverty, and a higher rate of incarceration (Elbaum, Vaughn, Hughes, \& Moody, 2000; Hitchcock et al., 2004).

Amongst others, students with emotional and/or behavioral disorders (EBD) present considerable learning challenges in reading and other subjects, along with their social and/or behavioral problems (Lane, Barton-Arwood, Nelson, \& Wehby, 2008). Students with EBD are those who display behaviors such as physical and verbal aggression and deficits in performance and acquisition of social skills (Walker, Ramsey, \& Gresham, 2004). EBD, also referred to as severe emotional disturbance/disabilities (SED), is defined in the Individual with Disabilities Education Act (IDEA) (2004) as: A condition exhibiting one or more of the following characteristics over a long period of time and to a marked degree, which adversely affects educational performance: An inability to learn which cannot be explained by intellectual, sensory, or health factors and an inability to build or maintain satisfactory interpersonal relationships with peers and teachers. (Council for Exceptional Children, 2009, pp. 42478-42479). 
Students with EBD are the most segregated and underserved group of students with disabilities (Sutherland \& Singh, 2004) and have some of the lowest academic grades of any category of students with disabilities (Sutherland \& Singh, 2004). In examining their general academic functioning, students with EBD consistently performed in the 25 th percentile including underachievement in reading, reading comprehension, vocabulary, and written language (Anderson, Kutash, \& Duchnowski, 2001; Nelson, Brenner, Lane, \& Smith, 2004). By the time these students leave elementary school, their learning gains are lower than students with other disabilities (Anderson et al., 2001). Their academic outcomes are typically lower than those of students without disabilities (Reid, Gonzalez, Nordness, Trout, \& Epstein, 2004), and their deficits do not improve over time (Anderson et al., 2001). Further, students with EBD have higher dropout rates and lower graduation rates than any other student group (Kauffman, 2001). Even though many of these students have academic challenges, their academic needs are often overlooked in order to deal with and control their behavioral issues (Gunter, Jack, Shores, Carrell, \& Flowers, 1993; Webby, Lane, \& Falk, 2003). Consequently, their successful education is among the most important and challenging tasks facing special education today (Landrum, Tankersly, \& Kauffman, 2003).

With respect to reading specifically, students with EBD display a number of reading challenges (Levy \& Chard, 2001a) including typically reading one to two years below grade level compared to their typical learning peers (Kauffman, 2001) which contributes to an achievement gap between students with EBD and their typical learning counterparts (Levy \& Chard, 2001a). Additionally, students with EBD are more likely to have problems in reading comprehension and fluency than their typical learning peers 
(Reid et al., 2004). When students with EBD do not read well, it stands as an indicator for future failures including dropping out of school, poor college enrollment, and even incarceration (Scott \& Shearer-Lingo, 2002).

According to Coleman and Vaughn (2000), teachers reported that students with EBD had difficulty with reading because of fear of failure, lack of trust, and emotional variability, and because they have difficulty separating their academic deficiencies from their emotional and/or behavioral problems. Teachers have reported that fear of failure was so entrenched in students with EBD that these students often refused to participate in reading or to complete reading-related activities unless they were assured that they would succeed at the task (Atkinson, Wilhite, Frey, \& Williams, 2002). Students with EBD are especially at risk for reading difficulties when they also have other disabilities such as learning disabilities or attention deficit disorder (Rittner \& Dozier, 2000). As reported by Blumberg et al., 2003, more than half of the students (51.7\%) who are labeled with an EBD, also have a learning disability making it necessary to differentiate their reading instruction in order to meet their academic needs. This reading instruction might include using flexible, small group instruction with a peer tutoring component and consistent, explicit, reading instruction (Vaughn, Levy, Coleman, \& Bos, 2002).

Given the strong correlation between reading failure and school failure (Scott \& Shearer-Lingo, 2002), finding effective reading intervention strategies is critical for students who are labeled with an EBD (Ishii-Jordan, 2000). However, there remains limited research on the effectiveness of reading instruction for these students (Rivera, AlOtaiba, \& Koorland, 2006). 
In 2000, The National Reading Panel (NRP) reviewed research on effective reading practices for students with and without disabilities. It was determined that instruction in reading should be explicit and methodical and should include (among other things) elements of fluency and comprehension. Based on the NRP's recommendations for students with EBD, there are specific reading interventions to consider when working with these students (Barton-Arwood, Wehby, \& Falk, 2005) such as peer tutoring (AlOtaiba \& Rivera, 2006; Locke \& Fuchs, 1995), and specific teacher-led, direct instruction which allows for numerous interactions between the teacher and student in a highlystructured and scripted program (Coleman \& Vaughn, 2000). Also, Direct Instruction, a program that provides an instructional script to deliver lessons consistently (Becker \& Carnine, 1980) has yielded positive gains in reading fluency for students with EBD (Strong, Wehby, Falk, \& Lane, 2004). The NRP (2000) also agreed that if the student is to build fluency, then reading practice must occur. The clear-cut evidence for building fluency and comprehension has favored guided repeated oral reading techniques (AlOtaiba \& Rivera, 2006).

Another reading strategy found to be effective in improving reading fluency and comprehension is repeated readings (e.g., Landa \& Barbetta, 2010; Nelson, Alber, \& Gordy, 2004). Repeated readings is a strategy that targets reading fluency by having the readers repeatedly read a short passage of usually no more than 200 words until their fluency improves (Samuels, 1979; Stahl \& Heubach, 2005; Therrien \& Kubina, 2006). The theory behind repeated readings is that once students are fluent in reading a passage, then more attention can be focused on their level of comprehension (Samuels, 1979). 
Repeated readings has been found to be successful with elementary and secondary students (e.g., Begeny, Daly, \& Valleley, 2006; Freeland, Skinner, Jackson, McDaniel, \& Smith, 2000). It has also been an effective strategy for students reading below grade level (Stoddard, Valcante, Sindelar, O'Shea, \& Algozzine, 1993; Tam et al., 2006), and for students at or above grade level (Bryant et al., 2000). In reviewing the research of students with disabilities, repeated readings has been found to be effective with students with visual impairments (Pattillo, Heller, \& Smith, 2004) and students with learning disabilities (Barley et al., 2002). A recent study indicated that repeated readings had a positive effect on the reading abilities of English language learners (ELL) with specific learning disabilities (Landa \& Barbetta, 2010). Yet, with all the studies examining the different populations of students, the research remains limited on repeated readings and students with EBD.

To date, only five repeated readings studies have been found by this researcher that were conducted with students with EBD (i.e., Alber-Morgan, Ramp, Anderson, \& Martin, 2007; Scott \& Shearer-Lingo, 2002; Staubitz, Cartledge, Yurick, \& Lo, 2005; Strong et al., 2004; Valleley \& Shriver, 2003). Three of the studies investigated the effects of repeated readings with students with EBD in middle school (i.e., Alber-Morgan et al. 2007; Scott \& Shearer-Lingo, 2002; Strong et al., 2004) while one study was with secondary students with EBD (Valleley \& Shriver, 2003), and one other with elementaryage students with EBD (Staubitz et al., 2005).

The results of the four studies conducted with middle and high school students with EBD (i.e., Alber-Morgan et al. 2007; Scott \& Shearer-Lingo, 2002; Strong et al., 2004; Valleley \& Shriver, 2003) demonstrated that most of the students made an 
improvement in reading fluency as a result of repeated readings. Additionally, repeated readings led to improved comprehension for most of the participants. The one study found conducted with elementary students with EBD (Staubitz et al., 2005) examined the effects of a repeated reading intervention on the fluency and comprehension of six, fourth- and fifth-grade students. Words per minute increased for all students from baseline as a result of the repeated readings condition and students answered more comprehension questions correctly than in baseline.

Apart from the fact that all five studies used repeated readings and students with EBD, there exist variations in the studies. For example, Strong et al. (2004) used two different direct instructional reading programs as part of the interventions, while Staubitz et al. (2005) used a peer-mediated component in their study. Alber-Morgan et al. (2007) used a prediction strategy as an additive to one of their repeated readings conditions. All of the studies differed by gender and ages of the students. The results of all of these studies demonstrated improvement in fluency using repeated readings, while all but one study demonstrated improvement in comprehension (i.e., Strong et al., 2004). Given the variations in these studies and the limited research on the effects of repeated readings with students with EBD, the present study was undertaken because there is a need for additional research in this area.

In addition, there remained other questions about the repeated readings approach to be answered. A pressing question is whether repeated readings is more effective than having students read an equal amount of non-repetitive text. Critiques of repeated readings research (Kuhn \& Stahl, 2003; Pressley, 2006) have proposed that the fluency developed during repeated reading may have little or nothing to do with repetition of 
passages but instead occured as a result of students reading more words and/or reading for longer periods of time during repeated readings than the comparison conditions (Kuhn $\&$ Stahl, 2003; Therrien, Ojwaya, Wickstom, \& Jones, 2008). These arguments may have been valid, given that research over the last several decades had consistently found significant positive correlations between the time students spend actively engaged in an academic task or active student responding (ASR) and learning (Jerome \& Barbetta, 2005; Malanga \& Sweeney, 2008; Miller, Hall, \& Heward, 1995).

Even with the consistent positive relation between ASR and student learning, only a limited number of studies had directly compared repeated reading to equal amounts of non-repetitive text by controlling the time spent reading or number of words read across the repeated reading and non-repeated reading conditions (e.g., Alber-Morgan, et al., 2007; Ardoin, McCall, \& Klubnik, 2007; Homan, Klesius, \& Hite, 1993; Mathes \& Fuchs, 1993; Nelson et al., 2004; Rashotte \& Torgesen, 1985; Von Bon, Boksebold, Font Freide, \& Van Den Hurk, 1991).

The studies that controlled (or equalized) the time-spent reading include AlberMorgan et al. (2007), Mathes and Fuchs (1993), and Nelson et al. (2004). Alber-Morgan et al. (2007) examined the effects of repeated readings combined with a systematic error correction and feedback on the reading fluency and comprehension of four middle school students with EBD. In that study, the repeated readings condition was added to the students' regular reading instruction program, which was the baseline condition. Time spent reading was controlled across both conditions. For three of four students, repeated readings resulted in an immediate increase in their reading rate and comprehension skills and a decrease in their errors per minute. 
Mathes and Fuchs (1993) examined the effects of sustained-reading and peermediated repeated readings during class wide peer tutoring, as measured by pre-and posttests. During the sustained reading condition one student read from the basal reader for 9 minutes to another student with error correction. During the repeated reading condition, the student read three different passages, three times, for 1 minute. In other words, the students read for a total of 9 minutes in each condition. Results of that study suggest that sustained reading may be better for developing fluency than typical reading instruction. However, there were no significant gains for either condition in comprehension. The repeated reading condition did not show significant gains for either fluency or comprehension.

In a similar study to the one of Alber-Morgan et al. (2007), Nelson et al. (2004) examined the effects of systematic error correction and systematic error correction with repeated readings on the reading accuracy and fluency of four, second-grade students with learning disabilities. In the error correction condition participants received feedback for each reading error during oral reading. During the error correction plus repeated readings, they read three 1-minute timings of the passage followed by error correction. Reading for 6 minutes in each time controlled condition. When repeated readings were used with error corrections, there were increases in words read correctly for all students and a decrease in errors.

The limited number of studies (mostly dated) controlled the number of words read across and repeated readings and non-repeated readings includes Ardoin et al. (2007), Homan et al. (1993), Rashotte and Torgesen (1985), Therrien, et al. (2008) and Van Bon et al. (1991). In this study, the condition in which the participants read equal amounts of 
non-repetitive text equal in number of words to the three readings in the repeated readings conditions is referred to as equivalent non-repetitive readings.

Rashotte and Torgesen (1985) examined repeated readings and equivalent amounts of non-repeated reading on the fluency and comprehension of 12 students with learning disabilities. In all conditions, the students read four passages for 15 minutes with error correction provided. In the second condition (as in the previous condition) the students also repeatedly read seven stories, but this time the stories shared a high degree of word overlap. In the third condition (equivalent non-repeated reading), the students read four stories each day, none of which were repeated. Results indicated that the fluency increased when there were greater numbers of overlapping words during the repeated readings conditions. Yet, if the stories shared few words, neither repeated readings nor equivalent amounts of non-repeated readings led to significant gains.

Von Bon et al. (1991) investigated the effects of reading while listening (RwL) through repeated readings and RwL of different texts (similar to equivalent non-repeated readings with 36 students with learning disabilities. In RwL of different texts, the students read and listened to a different text. During the repeated readings condition, the students repeatedly read the same text for each training session. Results of the study suggest that the repeated readings condition did not differ from those in the equivalent non-repeated readings condition or error detection in comparison to reading while listening to text.

Homan et al. (1993) examined the effects of repeated reading and assisted nonrepetitive strategies(equivalent non-repeated readings) on reading rate, error rate and comprehension of sixth-grade general education students. In the equivalent non-repetitive 
readings, the students either used echo reading, unison reading, or cloze reading. During the repeated readings condition, the students read repeatedly from the same reader used in the equivalent non-repetitive strategies condition. Comparing pre-and post-test scores, authors found that an increase in comprehension occurred in both conditions, but neither condition surpassed the other in terms of greater comprehension gains. Additionally, there were no significant gains in reducing word errors.

Therrien, et al. (2008) examined the effects of a repeated readings and a sequential readings (similar to equivalent non-repeated) readings on the fluency and errors of eight general education students in the second grade who were struggling readers. During the repeated readings condition, the participants read the first passage four times. During the sequential readings condition, the participants read the first four sequential readings passages. After a week, the participants were given a generalized session that either consisted of a second repeated reading passage or the last (fifth) sequential reading passage. Results indicated that all students had greater fluency gains in repeated readings than in sequential readings for all students. Additionally, there were no differences in fluency gains during the generalized sessions.

Ardoin et al. (2007) examined the effects of a high word overlap (similar to equivalent non-repeated readings) condition and a repeated readings condition on the fluency to generalized passages for six third-grade students. In both conditions, students were timed while reading the third (of six) passage (generalization passage), and then error correction was provided on the first passage. During the high overlap condition, the students read the first and second passages twice, while in the repeated readings condition, the students read the first passage four times. Results indicated that both 
interventions increased the fluency of three students on the generalization passages but the data for the remaining three students was inconclusive. Five out of the six students benefited from the readings being modeled for them.

In reviewing these four studies (i.e., Ardoin et al., 2007; Homan et al., 1993; Rashotte \& Torgesen, 1985; Van Bon et al., 1991) that compared repeated readings and a type of equivalent non-repeated readings some factors should be considered. Ardoin et al. (2007) included additional components such as earning tokens during reading sessions, syllable segmenting, and blending drills as part of their repeated and sequential readings conditions. Therefore, any differences due to repeated and equivalent non-repeated readings might have been affected by these other elements used in the conditions. In addition, all of the studies differed by ages and abilities of the students. There were mixed results for all studies in terms of gains in fluency and comprehension.

Given these variations, the mixed results and the limited research on the effects of repeated readings and equivalent non-repeated readings there is a need for additonal reaseach in this area. Additionally given the differences in the conditions compared, there is a need for additional research in the area of comparing repeated reading to equal amounts of words read for students with EBD.

Among the few studies found that have directly compared repeated reading to strategies that include the same amount of active engaged reading or time controlled during conditions (Mathes \& Fuchs, 1993; Nelson et al., 2004; Rashotte \& Torgesen, 1985; Van Bon et al., 1991), only one of the studies was conducted with students with special needs (Nelson et al., 2004) and none of these studies were conducted with students with EBD. More research was needed in the area of repeated readings and 
equivalent non-repeated readings especially with students with EBD. Therefore, this study added to the current literature by comparing the effects of equivalent non-repeated and repeated readings on the fluency and comprehension skills of students with EBD.

\section{Purpose of the Study}

The number of students identified with EBD increased more than $18 \%$ between 1992 and 2001 to almost half a million (U.S. Department of Education, 2006). Given that between $2 \%$ and $20 \%$ of the school age population are likely to have a prevalence for EBD, meeting both their academic and social needs is a monumental concern (Lane et al., 2008), including the use of effective reading instruction (Lingo, Slaton, \& Jolivette, 2006).

The U.S. Department of Education (2006) states that although reading difficulties can be attributed to most students with disabilities, students with EBD not only exhibit low reading grades, but also have the lowest academic grades of any disability group (Sutherland \& Singh, 2004). Additionally, if students with EBD do not progress in reading it can lead to other problems (Bos, Coleman, \& Vaughn, 2002) such as high drop out rates, poor college enrollment rates, and incarceration (Scott \& Shearer-Lingo, 2002).

One method that has been shown to be effective for improving the reading fluency and comprehension of typical learners (Bryant et al., 2000), and students with disabilities (Freeland et al., 2000), including those who are ELL (Landa \& Barbetta, 2010) is repeated readings. Unfortunately, there is limited research on the effectiveness of repeated readings for students with $\mathrm{EBD}$, as only three studies were found with middle school-age students (Alber-Morgan et al., 2007; Scott \& Shearer-Lingo, 2002; Strong et al., 2004); one study with secondary students (Valleley \& Shriver, 2003); and one study 
at the elementary level (Staubitz et al., 2005). While all the studies showed success with repeated readings and students with EBD, all of them differed somewhat in their approach which makes the comparisons challenging. As such, there are several gaps in this line of research. One major gap is that only one of the repeated reading studies conducted with students with EBD (Alber-Morgan et al., 2007) controlled (equalized) the time spent reading between the baseline and repeated readings conditions and none controlled for the number of words read.

Critiques of repeated reading have raised questions as to whether repeated reading is more effective than having students read the same number of equivalent non-repetitive passages. Kuhn and Stahl (2003) propose that the fluency acquired during repeated readings may be due to increased reading practice rather than repetitive reading. Further, Adams (1990) suggest that students should be exposed to a variety of texts as this may have positive results on students' vocabulary and background knowledge. If reading a diverse selection of literature may be helpful to students' oral fluency and comprehension, then repetition may be unnecessary. Others suggest that using equivalent non-repetitive interventions may be more appropriate because students will read multiple texts, which in turn increases their exposure to a variety of vocabulary words, content topics, and genres (Homan et al., 1993). Only a limited number of studies have (a) controlled (or equalized) the time-spent reading (Alber-Morgan et al., 2007; Mathes and Fuchs 1993; Nelson et al., 2004) or (b) directly compared repeated reading to equal amounts of non-repetitive text by controlling the words read across the repeated readings and equivalent non-repeated readings conditions (e.g., Ardoin et al., 2007; Homan et al., 1993; Rashotte \& Torgesen, 1985; Therrien et al., 2008; Van Bon et al., 1991). 
This study was guided by the increasing numbers of students with EBD in schools with reading challenges and the observed lack of research of effective reading interventions with this population. Further, this study was guided by the overall positive outcomes observed in repeated readings research on typical learners and students with other disabilities (e.g., Begeny et al., 2006; Freeland et al., 2000; Pattillo et al., 2004) along with the limited research with students with EBD. Also, this study was necessary due to the limited (and largely dated and/or unpublished) number of repeated readings studies that controlled the time that students spend reading (Alber-Morgan et al. 2007; Mathes and Fuchs 1993; and Nelson et al., 2004) and/or the number of words read in the equivalent non-repeated and repeated readings conditions (e.g., Ardoin et al., 2007; Homan et al., 1993; Rashotte \& Torgesen, 1985; Therrien et al., 2008; Van Bon et al., 1991).

In sum, the purpose of this study was to build upon the limited body of studies that examined repeated readings and students with EBD, and the even more limited number of studies that have compared repeated readings to conditions with an equal numbers of words read. No studies were found with students with EBD that compared repeated and non-repeated conditions that controlled for equal numbers of words read. Subsequently, the purpose of this study was to compare the effects of repeated readings and two non-repetitive reading conditions (one with an equivalent number of words) on the reading fluency, reading errors, and comprehension of students with EBD. Also, to further analyze the immediate effects of repeatedly reading a passage, this study was designed to compare any differences in reading fluency and errors made across each of the three practice trials during repeated readings sessions. 


\section{Statement of the Problem}

This study compared repeated readings and two non-repeated readings conditions on the reading fluency, reading errors and comprehension of separate day school students with EBD. Specifically, it examined, in alternating treatments design, the number of words read per minute, number of errors per minute, and correct responses to literal comprehension questions while being exposed to three experimental conditions: (a) Repeated readings in which participants repeatedly read a passage of about 100-150 words three times, (b) Non-repeated readings in which participants sequentially read an original passage of about 100-150 words once, and (c) Equivalent non-repeated readings in which participants read a passage of about 300-450 words, equivalent to the number of words in the repeated readings condition. In most repeated readings studies, the nonrepeated comparison condition had reading passages equivalent to only one reading (not three) in the repeated reading condition (comparable to equivalent non-repeated readings). Only one study reviewed was conducted with students with EBD that controls for equal time spent reading in all conditions (Alber-Morgan et al., 2007) and a limited number of dated studies (and none with students with EBD) compared repeated readings to equivalent non-repeated readings (e.g., Ardoin et al., 2007; Homan et al., 1993; Rashotte \& Torgesen, 1985; Van Bon et al., 1991) and none were with students with EBD. Further, no studies were found that compared equivalent and nonequivalent levels of non-repetitive reading with repeated readings, as was done with this study.

This study built on the existing study by Staubitz et al. (2005) and other studies using repeated readings and students with disabilities in several ways. First, it targeted elementary school-age students with EBD for the repeated readings intervention, adding 
to the limited research on repeated readings with that age and disability group. Second, this study addressed the issue of fluency gains as a result of repeated readings compared to reading equivalent and nonequivalent numbers of non-repeated readings. Previous studies compared repeated readings to a condition in which the number of words read was not equivalent to the repeated readings condition.

No studies were found with students with EBD that compares the results of repeated readings to two non-repeated readings conditions: non-repeated reading in which the number of words read is fewer than those read in repeated readings (which is typically done) and equivalent non-repeated readings in which the same number of words is read in the equivalent non-repeated and repeated readings conditions. That is, in most of the reviewed repeated readings studies, the participants read one short passage of approximately 100-150 words during baseline and read a short passage of the same length multiple times during repeated readings, thereby reading approximately 450-600 words during repeated readings. In this study, an additional condition was added (equivalent non-repeated readings) that included the sequential reading of 450-600 words. Subsequently, the same number of words was read in the equivalent non-repeated readings condition as the repeated readings condition. The addition of the equivalent nonrepeated readings condition contributed to determining whether repeated readings was effective because students repeatedly read the same passage or because the repeated readings of the same passage resulted in more active student responses or words read.

\section{Research Questions}

This study compared the effects of nonequivalent and equivalent sequential and repeated readings on the number of words read aloud per minute, number of errors read 
aloud per minute, and answers to literal comprehension questions answered aloud by students with EBD who are struggling readers in a self contained urban separate day school as follows. More specifically, the research questions are:

1. Will repeated readings, non-repeated readings, or equivalent non-repeated readings result in more words read correctly per minute (WCPM) by students with EBD who are struggling readers in a self contained urban separate day school?

2. Will repeated readings, non-repeated readings, or equivalent non-repeated readings result in fewer reading errors per minute (EPM) by students with EBD who are struggling readers in a self contained urban separate day school?

3. Will repeated readings, non-repeated readings, or equivalent non-repeated readings result in a higher number of literal comprehension questions answered aloud correctly by students with EBD who are struggling readers in a self contained urban separate day school?

4. Will there be any differences in WCPM in the three successive practice trials in repeated readings sessions by students with EBD who are struggling readers in a self contained urban separate day school?

5. Will there be any differences in reading errors per minute (EPM) in the three successive practice trials in repeated readings sessions by students with EBD who are struggling readers in a self contained urban separate day school?

\section{Operational Definitions}

In the following section, the terms as used in this study are defined. Other terms, which are not frequently used but require definitions, are explained as they are introduced. 


\section{Addition Error}

An addition error is a word said aloud by the student that is not printed in the passage.

\section{Alternating Treatments Design}

Alternating treatments design is a single subject research design model that is used in order to compare the effects of two or more treatments. Two treatments were alternated in succession and their changes are compared (Cooper, Heron, \& Heward, 2007).

\section{Agreement}

Agreement occurs when the researcher and blind scorer independently mark the same words and literal comprehension questions as correct or incorrect during independent ratings.

\section{Disagreement}

Disagreement occurs when the blind scorer and researcher do not score the same word or literal comprehension question as correct during independent ratings.

\section{Emotional and Behavioral Disorders (EBD)}

EBD, also referred to severe emotional disturbance/disabilities (SED) is defined in the Individual with Disabilities Education Act (IDEA) (2004) as:

A condition exhibiting one or more of the following characteristics over a long period of time and to a marked degree, which adversely affects educational performance: An inability to learn which cannot be explained by intellectual, 
sensory, or health factors and an inability to build or maintain satisfactory interpersonal relationships with peers and teachers. (Council for Exceptional Children, 2009, pp.

42478-42479)

\section{Enhanced Phase}

The sessions in this study that included reading passages that were increased in

difficulty by 6 months for two participants and by the number of words in the passages by $50 \%$ for two participants. In all figures, the data points to the right of the dashed line are in the enhanced phase.

\section{Equivalent Non-Repeated Readings}

A reading intervention that involves sequential or non-repetitive reading of connected text that is equivalent in the number of words to the three readings of the passages in the repeated readings conditions.

\section{Error Correction}

In this study, when the participant made an error, the researcher correctly said the word aloud, followed by the participant repeating the word. Correction refers to the researcher correctly saying the whole word that was read aloud incorrectly by the participant (Barbetta, Heward, \& Bradley, 1993b). The reader is subsequently asked to repeat the word aloud immediately following the error.

\section{Fluency}

The accuracy, speed and expression (prososy) while reading. It is also the number of words read correctly aloud per minute of reading (Nelson et al., 2004). 


\section{Fluency Assessment}

Assessment where participants read a passage from the beginning for 1 minute. WCPM were then calculated.

\section{Group Mean}

The average of the total number of group sessions completed by all four participants divided by the number of sessions.

\section{Hesitations}

Hesitations are a type of error that refers to a delay of more than 3 seconds from the end of one word read aloud to the beginning of the next word. The researcher counts silently and states the correct word to the student after 3 seconds so that the students continues to read.

\section{Interobserver Agreement (IOA)}

Interobserver agreement is a method for determining reliability in the collection of data on a target behavior. It involves an independent observer observing the same behavioral episode in order to compare the results. Interobserver agreement (IOA) data are taken in all treatment conditions. IOA is calculated by dividing the number of agreements by the number of agreements plus disagreements and then multiplying this total by 100 . There was a minimum mean IOA of $90 \%$ calculated for each participant of this study. Since there were no IOA observations that fell below $90 \%$, the researcher and the observer were not trained again. A word-by-word examination of the data sheets was counted to settle any disagreement. 


\section{Literal Comprehension Question}

A question that asks the participant to recall something explicitly stated in the text.

\section{Literal Comprehension Question Assessment}

In this study, the researcher asked five literal comprehension questions one at a time in each condition of the study. The student had 5 seconds to answer each question aloud. Student responses were compared to the answer key provided by the basal reader for that reading passage. Responses matching the answer key that are made within 5 seconds were scored as correct. No response, those not matching the answer key, and/or those made after 5 seconds of silence were scored as incorrect. The total number of correct responses was recorded and graphed. The literal comprehension questions were asked after the session's readings and before the fluency assessment.

\section{Mispronunciations}

Mispronunciations are a type of error defined as a printed word that is said aloud incorrectly. For example if the text says "She brought her flute to the parade," but the participant read aloud, "She brought her float to the parade," this was classed as a mispronunciation (Dictionary.com, 2008).

\section{Non-Repeated Readings}

A reading intervention that involves sequential or non-repetitive reading of connected text. In this study, the non-repeated readings passages were the same number of words as one reading in the repeated readings passage. However, during repeated readings the passage was read three times. 


\section{Number of Errors per Minute (EPM)}

This is defined as the total number of errors read aloud during one minute of reading. Errors include omissions, additions, mispronunciations, substitutions, and hesitations of more than 3 seconds from one word read to the next (Tam et al., 2006).

\section{Omissions}

Omissions are a type of error defined as a printed word in the passage that is not read aloud by the student.

\section{Repeated Readings}

Repeated readings refers to a method used primarily to build reading fluency. It consists of reading a short passage of about 200 words repeatedly aloud until a satisfactory or predetermined level of fluency is reached (Samuels, 1979). Error correction is a component of the first reading of the passages during the repeated readings condition.

\section{Repeated Readings Practice Trial}

One of the three successive times a passage was read during each session of the repeated readings condition.

\section{Reversals}

Reversals are a type of error defined as stating a word "backwards." For example, if the text said "was" and the participant read "saw," or the text says "dogs" and the participant reads "bogs," this error was defined as a reversal. 


\section{Standard Phase}

A phase of the study in which the difficulty and number of words in the reading passages were as those established prior to beginning the study. In all figures, the data points to the left of the dashed line are in the standard phase.

\section{Substitutions}

Substitutions are a type of error defined as stating a word aloud that is different than the printed word. For example, if the text says "We went to the market" and the participant reads "We went to the movies," the participant made a substitution.

\section{Typical Learners}

A term used to refer to students that do not have an Individual Education Plan and/or are not receiving special education services.

\section{Words Correct per Minute (WCPM)}

The words read correctly per minute (which are also referred to as fluency in this study) are defined as the number of words read aloud correctly per minute of reading (self-corrections accepted). A word is counted correct if the student independently pronounces it correctly aloud without prompting within 3 seconds (Nelson et al., 2004).

\section{Chapter Summary}

Students who are able to read well can easily access information both in and beyond school. On the other hand, students who do not read well find assignments challenging and are at risk of facing negative consequences both in and outside of school. One group of students who presents considerable academic challenges in the classroom, along with their behavioral problems, is the group with emotional and/or behavioral disorders (EBD) (Lane et al., 2008). Students with EBD are those who display behaviors 
such as physical and verbal aggression and deficits in performance and acquisition of social skills (Walker et al., 2004).These students are the most segregated and underserved group of students with disabilities (Sutherland \& Singh, 2004) and have some of the lowest academic grades of any category of students with disabilities (Sutherland \& Singh, 2004). Their academic outcomes are typically lower than those of students without disabilities (Reid et al., 2004) and their deficits do not improve over time (Anderson et al., 2001).

In terms of reading achievement, typically students with EBD perform 1 to 2 years below grade level with differences in their achievement compared to their typical learning peers (Kauffman, 2001). This difficulty in reading contributes to the widening of the achievement gap between students with EBD and their typical learning counterparts (Levy \& Chard, 2001a). Additionally, students with EBD are more likely to have reading problems than their typical learning peers (Epstein et al., 1989).

Given the strong correlation between reading failure and school failure and overall success (Scott \& Shearer-Lingo, 2002), finding effective approaches to reading instruction is imperative for students with EBD (Ishii-Jordan, 2000). The NRP (2000) reviewed research on effective reading practices for students with and without disabilities. It was determined that instruction in reading should be explicit and methodical and should include (among other objectives) fluency and comprehension objectives.

Repeated readings is an intervention that targets reading fluency by having the reader repeatedly read a short passage of usually no more than 100-150 words until reaching fluency (Samuels, 1979; Stahl \& Heubach, 2005). The research on repeated 
readings indicates that once students are fluent in reading a passage, then more attention can be focused on their comprehension (Samuels, 1979). This researcher found only four repeated readings studies that were conducted with students with EBD (i.e., AlberMorgan et al., 2007; Staubitz et al., 2005; Strong et al., 2004; Valleley \& Shriver, 2003); and, of those studies, only one (Staubitz et al., 2005) was with elementary students with EBD.

Only a limited number of reviewed studies have controlled (or equalized) across repeated and non-repeated readings conditions the time-spent reading (e.g., AlberMorgan et al., 2007; Mathes \& Fuchs, 1993; Nelson et al., 2004) or number of words read words (e.g., Ardoin et al., 2007; Homan et al., 1993; Rashotte \& Torgesen, 1985; Van Bon et al., 1991). This researcher found no previous studies with students who are EBD that compared the results of repeated readings to two non-repetitive readings conditions: non-repeated readings in which the number of words read was equal to the number of words read during only one of three practice trials during each repeated readings session (which is typically done in repeated readings research) and equivalent non-repeated readings in which the number of words read was equivalent to the total number of words read during the three practice trials readings in the repeated readings condition.

This study used an alternating treatments design to compare the effects of repeated readings, non-repeated readings and equivalent non-repeated on the number of WCPM (reading fluency), the number of EPM, and the number of correct answers to literal comprehension questions answered aloud. In addition, data were collected during each of the repeated readings sessions on any differences in reading fluency and errors 
per minute during each of the three successive repeated readings practice trials per session. 


\section{Chapter II}

\section{Literature Review}

Reading is a necessary skill that allows one to access knowledge. Students are instructed on the reading process (including fluency and comprehension) early in their academic careers and throughout their education. Nevertheless, there are some students who find reading a difficult task (Rasinki, 2000). Specifically, one group of students with reading challenges are those with emotional and/or behavioral disorders (EBD)(Levy \& Chard, 2001a). This study compared repeated readings and two forms of non-repeated readings and on the reading fluency, errors, and comprehension of students with EBD. In addition, an analysis was conducted of the differences in reading fluency and errors in each of the three practice trials during the repeated readings condition.

This chapter provides a review of the literature related to this proposed research. A general discussion of the characteristics of students who do and do not read well is presented initially. Then, the academic characteristics of students with EBD, is presented. This is followed by a discussion of active student responding and its effect on learning. Then, by a discussion of the reading performances of students with EBD and researched effective reading strategies with this group of students. Next, a thorough presentation of the research on repeated readings will be offered including its impact with students with EBD. Finally, research that compares the effects of equivalent non-repeated reading and repeated readings is presented.

\section{Characteristics of Students Who Do and Do Not Read Well}

Students who read well, read with comprehension and fluency (Rasinski, 2000). Good readers are able to use prior knowledge to derive meaning from the text (Valencia 
\& Pearson, 1986) and are able to summarize, interpret, and accept or reject the information on the printed page (Pressley et al., 2006). These readers usually feel positive about their reading abilities and are self-motivated enough to want to read more (Rasinski, 2000). They are better prepared to attend college and post secondary programs immediately after graduation and succeed at these levels (American College Testing Program, 2006), and they are more likely to be able to meet the increased workplace demands for a literate workforce (Torgenson, 2002).

Additionally, there are certain social benefits associated with reading fluently. These benefits include reading for pleasure, which increases the amount of time spent reading outside the classroom (NCES, 2005b; Rasinki, 2000). Good readers are expected to attain social and economic success beyond their school years (Snow, Burns, \& Griffin, 1998) because of their ability to read well.

Unfortunately, there are many students who do not read well (Begeny \& Martens, 2006; Chard et al., 2002; NCES, 2004). As an example, Begeny and Martens (2006) stated that nearly $40 \%$ of American fourth graders are still reading below their grade level. These students find it difficult to read fluently with comprehension. Consequently, these students are associated with academic failure (Hitchcock et al., 2004).

There are fallouts typically associated with not being able to read well, both for academic and social purposes. Typically, students who do not read well have difficulty in assignment completion (Hitchcock et al., 2004). Academically, these students have access to less information than their peers, as they cannot read as quickly or efficiently (Hitchcock et al., 2004). Further, poor readers tend to exhibit disruptive or withdrawn behaviors that distract them from learning activities (Hitchcock et al., 2004). Other 
negative social outcomes of not being able to read well include low participation in extracurricular school activities and a higher probability of dropping out of school (Lazarus \& Callahan, 2000). Also, poor readers may have limited employment opportunities, a greater likelihood of living in poverty, and a higher rate of incarceration (Elbaum et al., 2000; Hitchcock et al., 2004).

\section{Students with Emotional and/or Behavioral Disorders (EBD) and Academics}

Students with EBD are those who display inappropriate classroom behaviors such as physical and verbal aggression and deficits in performance and acquisition of social skills (Walker et al., 2004). These students (also referred to as students with severe emotional disturbance/disabilities; SED) often demonstrate off-task behaviors that can be

challenging to their teachers and other staff members (Kauffman, 2001). The behaviors of students with EBD are often so disruptive that they arouse negative feelings in others, often alienating their classmates and adults while eliminating their own learning opportunities (Kauffman, 2001). Students with EBD often are unable to maneuver successfully between teacher expectations for school and the demands made of them socially (Cullinan \& Saborine, 2004) which makes school a daunting task for these students (Lane et al., 2008).

Students with EBD are overwhelmingly male, behaviorally disruptive, noncompliant, verbally abusive, and physically aggressive (Reid et. al., 2004). A disproportionate percentage of these students are minorities with African American and Hispanic groups constituting $27.3 \%$ and $8.9 \%$ of the EBD population in the U.S., respectively (U. S. Department of Education, 2001). 
Many students with EBD face academic challenges along with behavioral challenges. These students have some of the lowest grades of any students in any disability category (Sutherland \& Singh, 2004). In a meta-analysis of students with EBD across all settings (i.e., general education, self-contained, and specialized school placement), students with EBD were found to exhibit considerable academic delays (Reid et al., 2004). Lane, Wehby, Little, and Cooley (2005a \& b) followed that analysis by comparing the academic profiles of students with EBD in self-contained settings with that of those students with EBD in self-contained schools. They found that students in self contained schools demonstrated broader academic deficits than those students in selfcontained classrooms. Even more disconcerting is that there was limited progress made in the areas of reading and math made in either setting.

Rates of prevalence vary for students with EBD who have a comorbidity of academic and behavioral difficulties from $25 \%$ to $97 \%$ (Reid et al., 2004). Having both academic and behavior deficits can make it difficult for practitioners to assist with effective instruction (Kauffman, 2005). In looking at the general academic functioning of students with EBD, these students consistently perform in the 25 th percentile including underachievement in reading, reading comprehension, vocabulary, and written language (Anderson et al., 2001; Nelson et al., 2004). Other studies advise that students with EBD are performing 1 to 2 years below their typical learning peers without disabilities (Kauffman, 2001; Reid et al., 2004; Trout, Nordness, Pierce, \& Epstein, 2003). Typical areas for underachievement by students with EBD include reading, reading comprehension, vocabulary, written language, and math (Lane, Wehby, \& Cooley, 2006; Nelson, Babyak, Gonzalez, \& Benner, 2003; Nelson et al., 2004). 
This deficiency in academics could be a result of factors such as the increasing attention to behavior issues in the classroom rather than academics (Gunter et al., 1993; Webby et al., 2003). Researchers have suggested that the problem behaviors with these students continue as a result of teachers increasingly lowering their demands for academic task completion (Carr, Taylor, \& Robinson, 1991). Levy and Chard (2001a) highlighted the problem by stating, "So much attention has been devoted to managing disruptive behaviors and dealing with emotional crises that the questions of what students should be taught and how they should be taught are often not afforded careful or even sufficient consideration" (p. 439). In other words, students with EBD earn lower grades, are less likely to pass classes, and experience higher rates of school drop out than typical students and students with other high incidence disabilities (Wagner \& Cameto, 2004).

Even with an increased attention to the academic needs of students with EBD, their academic achievement does not appear to be improving (Levy \& Chard, 2001a). Some studies indicate that those students who have a comorbidity of academic deficiencies and EBD do not show improvement over time (Anderson et al., 2001; Nelson et al., 2004). Unfortunately, these inadequate outcomes do not improve when these students leave school. Students with EBD go on to have pessimistic employment results, difficulties with substance abuse, and have a high demand for mental health services (Bullis \& Yovanoff, 2006; Walker et al., 2004). Given that between 2\% and 20\% of the school age population are likely to have prevalence for EBD, meeting their academic needs should be of monumental concern (Lane et al., 2008). 


\section{Students with Emotional and/or Behavioral Disorders and Reading}

Students with EBD provide a number of challenges (Levy \& Chard, 2001a). The U.S. Department of Education (2006) states that although reading difficulties can be attributed to most students with disabilities, students with EBD not only exhibit low reading grades, but also earn one of the lowest academic grades of any disability group (Sutherland \& Singh, 2004). Additionally, if students with EBD do not progress in reading, it can lead to other problems (Bos et al., 2002). As an example, early reading failure for students with EBD is a strong indicator for failure later in life including high drop out rates, poor college enrollment and incarceration (Scott \& Shearer-Lingo, 2002).

There is a small percentage of students with EBD who read fluently enough to comprehend the grade-level text they are reading or even work on grade level material (Trout et al., 2003). Greenbaum et al. (1996) studied students with EBD over a 7-year period. Over this time span, the researchers noted that the percentage of students reading below grade level increased from 54\% to $85 \%$. Nelson et al. (2004) documented that $83 \%$ of their sample of students with EBD scored below the normative group on a standardized measure of reading skills.

Since students with EBD are likely to face difficulty in academics, especially in reading (Staubitz et al., 2005), and the achievement gap seems to be growing between them and their typical learning peers over time (Gibb \& Wilder, 2003), effective reading interventions should be identified and implemented. Landrum et al. (2003) suggest that students who are part of academic intervention studies (reading included) display some of the same behavioral and educational concerns that students with EBD display. 
As stated earlier, in 1997, Congress initiated a series of events that led to the formation of the National Reading Panel (NRP) (Kostewicz \& Kubina, 2008). The sole purpose of the NRP (2000) was to "assess the status of research-based knowledge, including the effectiveness of reading approaches to teaching students to read" (p. 1-1 NRP). The NRP completed a review and made the following recommendations: students can benefit the most from fluency instruction given directly and from practicing fluency with guided repeated readings (NRP, 2000; Staubitz et al., 2005).

Based on the NRP's recommendations, there are certain reading strategies that have proven effective in working with students with EBD in regards to systematic and explicit instruction for all students (Barton-Arwood et al., 2005). The first category of these reading interventions is peer-mediated interventions, such as peer tutoring. Peer tutoring requires students to put into practice and deliver teacher-selected instructions to other students (Barton-Arwood et al., 2005). Peer-mediated instruction has been shown to improve reading achievement (Al Otaiba \& Rivera, 2006; Locke \& Fuchs, 1995; Mathes \& Fuchs, 1993). There are some studies involving the effectiveness of peer tutoring and students with EBD. Locke and Fuchs (1995) implemented a single subject withdrawal design to investigate the effects of peer-mediated reading instruction on the on-task behavior and social interaction of students with behavior disorders. They found improvements in on-task behavior and positive peer-to-peer comments relating to the inception of peer-mediated instruction although academic data was not collected. Wehby, Lane,and Falk (2003) supplemented Peer-Assisted Learning Strategy (PALS) with a modified version of a direct instruction program, Open Court Reading Program, for five 
students with EBD in an elementary setting. As a result of this reading intervention, three students progressed in their reading of nonsense words while all students showed growth in blending.

Another general area of reading interventions for consideration for students with EBD is teacher-mediated interventions such as Direct Instruction. Direct Instruction is a scripted teacher instruction technique, which incorporates numerous opportunities for the student to respond. This allows for copious exchanges between student and teacher (Barton-Arwood et al., 2005; Becker \& Carnine, 1980). There are several studies involving the effectiveness of direct instruction and students with EBD. Yell (1992) implemented a direct instruction reading intervention and reported increases in sight word identification and on-task behavior for students with EBD in grades four through six. Strong et al. (2004) implemented a single subject, multiple baseline design across subjects to measure two different teacher-directed reading programs: Corrective Reading, a reading program based on direct instruction and Great Leaps Reading, a high interest reading series for students ranging in levels from primer to seventh grade. Their results show increased reading fluency for students with EBD in middle school. Barton-Arwood et al. (2005) led a single subject, multiple baseline design across subjects in which an accelerated direct instruction reading program was implemented along with PALS (Fuchs et al., 2001) to six, third-grade students with EBD. Their results included improvements in basic reading skills with some transfer to oral reading fluency.

Dawson, Venn, and Gunter (2000) examined three different instructional approaches in teaching reading to four elementary students with EBD receiving reading instruction in a resource room. The purpose of this study was to determine the effects of 
modeling on reading performance. The authors examined computer models, teacher models, or no model. Results indicated that teacher model demonstrated more words read correctly than the other models. Skinner, Belifore, Mace, Williams-Wilson, and Johns (1997) examined the rate and accuracy with the presentation of either fast or slow taped words as part of read-alongs for three elementary students with EBD in a residential school. Results showed gains in accuracy and rate were maintained in both conditions.

\section{Reading Fluency}

After scrutinizing and reviewing over 115,000 research articles on reading, the NRP completed a review in which it made the following recommendations: students can benefit the most from fluency instruction given directly and from practicing fluency with guided repeated readings (NRP, 2000; Staubitz et al., 2003). The NRP also noted that using various strategies for building comprehension increases the exchange of knowledge (NRP, 2000; Staubitz et al., 2003).

Fluency is the ability to read a text text with accuracy, speed, and expression (Bursuck \& Damer, 2007; Manset-Williamson \& Nelson, 2005) and is often measured by counting the number of words read correctly per minute. Fluency has also been called the bridge between word recognition and comprehension (Carnine, Silbert, Kame'enui, \& Tarver, 2004; Rasinski \& Padak, 2004) and has been shown to predict comprehension (Fuchs, Fuchs, \& Hosp, 2001). For a reader to be able to read, a multi-step process is necessary including at least two activities: word identification or decoding and comprehension (Chard, Ketterlin-Geller, Baker, Doabler, \& Apichatabutra, 2009). To understand the author's message in a text, the reader must make inferences, understand details in a text, compare and contrast, and so forth. In order for a reader to understand 
what is being read, he/she cannot focus attention on both word identification and comprehension. Subsequently, a reader who is not fluent must alternate attention between these two practices. If the reader's attention is used for decoding words, then there is little, if any, capacity for comprehending the text (Chard, et al., 2009). As a result, being able to decode automatically — a critical component of fluency — is necessary for high levels of reading achievement (Ehri, 1995). When looking at reading fluency, if a word is read often enough, this practice results in an increased likelihood that the word will be encountered later, and speed will increase (Chard et al., 2009). Clear-cut evidence for building fluency and comprehension favors repeated oral reading techniques (Al-Otaiba \& Rivera, 2006).

\section{Repeated Readings}

Research has demonstrated one reading intervention that has been shown to be

effective in improving reading fluency and comprehension - that intervention is repeated readings (e.g., Landa \& Barbetta, 2010; Nelson et al., 2004; Tam et al., 2006; Weinstein \& Cooke, 1992). Samuels (1979) defined repeated readings as the process whereby a student reads a short passage many times during a reading session until a satisfactory reading rate is attained. He also stated that the practice involved in repeated reading makes the decoding in reading automatic, which leads to better reader comprehension. Fuchs and Fuchs (1992) define repeated reading as having a student read a short passage two or three times in succession prior to assessment.

Repeated readings targets reading fluency by having the reader repeatedly read a short passage of usually no more than 200 words until their fluency improves (Samuels, 
1979; Stahl \& Heubach, 2005; Therrien \& Kubina, 2006). The theory behind repeated readings is that once a student is fluent in reading a passage, then more attention can be focused on their comprehension (Samuels, 1979).

There is a substantial amount of research on repeated readings with learning difficulties (Bryant et al., 2000; Freeland et al., 2000; Pattillo et al., 2004). For example, Bryant et al. (2000) examined a multi-component reading intervention including repeated readings on the word identification, fluency, and comprehension of sixth grade students with reading difficulties. Students improved across all three areas through the use of these interventions. Freeland et al. (2000) examined the effects of a repeated readings intervention with a control condition on the silent reading comprehension levels of three students with learning disabilities. Results showed that repeated readings increased comprehension levels for these students. Pattillo et al. (2004) used a repeated readings strategy and optical character recognition computer software to examine fluency levels of students with visual impairments. Results indicate that all students increased their fluency.

There is research also on repeated readings with typical learning students (Le Vasseur, Macaruso,\& Shankweiler, 2007; Vadasay \& Sanders, 2008). Le Vasseur et al. (2007) compared three repeated reading interventions: standard text, cued text, and word lists of typical learning second graders. Results show that repeated readings with text demonstrated higher gains in fluency than repeated readings with word lists. Vadasay and Sanders (2008) examined the effects of a repeated reading intervention with word-level scaffolding instruction on student gains for second and third grade students. The authors 
found that there was an increase in word reading and fluency with the use of repeated readings.

There is a limited amount of research regarding the effectiveness of repeated readings with second language students (i.e., Linan-Thompson, Vaughn, Hickman-Davis, \& Kouzekanani, 2003; Tam et al., 2006). Linan-Thompson et al. (2003) examined the effect of a multi-component intervention including repeated readings on the oral reading fluency of second-grade ELL students using pre- and post-tests. The authors found that repeated readings assisted the students with making gains in oral reading fluency. Tam et al. (2006) used a multiple baseline across subjects design to examine the effects of a repeated readings intervention on the fluency and comprehension gains of five elementary-age ELL students. Results state that repeated readings contributed to fluency and comprehension gains.

There are some studies that examine repeated readings with students who have specific learning disabilities (e.g., Begeny et al., 2006; Nelson et al., 2004; Therrien et al., 2006; Weinstein \& Cooke, 1992). However, only two studies were found that included participants who were identified as second language learners or ELLs with specific learning disabilities (Landa \& Barbetta, 2010; Tam et al., 2006). Landa and Barbetta (2010) used a multiple baseline probe design to evaluate the effects of repeated readings on the reading fluency and comprehension of four ELLs with SLD. Results indicated that repeated readings improved the reading abilities of these students and that gains were generalized to untaught passages. Tam et al. (2006) studied five participants (two of whom were identified as ELLs with SLD). That study found reading improvements following the implementation of a repeated readings intervention that used error 
correction. However, the researchers noted that the findings of their study were preliminary, as there were only five participants in the study and the needs of ELLs vary from learner to learner (Tam et al., 2006).

\section{Students with Emotional and/or Behavioral Disorders and Repeated Readings}

While there has been a substantial amount of research on repeated readings with students of varying ages and abilities (e.g., Bryant et al., 2000; Freeland et al., 2000; Pattillo et al., 2004; Stoddard et al., 1993), there exists only limited research regarding its effectiveness with students with EBD. To date, only five studies have been found investigating the effects of repeated readings and students with EBD (i.e., Alber-Morgan et al., 2007; Scott \& Shearer-Lingo, 2002; Staubitz et al., 2005; Strong et al., 2004; Valleley \& Shriver, 2003). Of these studies, only three studies (Alber-Morgan et al., 2007; Scott \& Shearer-Lingo, 2002; Strong et al., 2004;) dealt with repeated readings for middle school students with EBD. Following is a review of the five studies examining the effects of repeated readings on students with EBD. First, the research with secondary students with EBD will be presented. This will be followed by a review of the elementary study, and finally, the three middle school studies.

Valleley and Shriver (2003) explored the impact of repeated readings on the fluency and comprehension of secondary students with EBD. During baseline, the participants read three passages each at a fourth-grade level and answered multiplechoice questions after reading one of the passages. In the repeated readings intervention, the students would read a passage repeatedly until they exhibited three consecutive improvements in their fluency as defined as an increase of at least one more word read. The students read the passages a minimum of four times. If the participants did not 
improve after 10 readings, they would move to the next passage. The researcher did provide error correction. The participants would also answer 10 multiple-choice questions after reading the third passage in its entirety. The other readings consisted of 1minute readings. Results show that all of the participants except for one increased their fluency rates with repeated readings, although comprehension did not improve. The authors attribute the lack of comprehension improvement to the short length of time of the repeated readings condition of the study (10 hours only).

Staubitz et al. (2005) examined the effects of a repeated readings intervention on the oral reading fluency of 10 fourth- and fifth-grade students who were at risk for or were EBD. A multiple baseline design across subjects was employed to examine the effects of a repeated readings intervention in terms of gains in reading fluency, comprehension, and generalization of unpracticed passages. During baseline, students were given 10 minutes to silently read a passage. Students were then asked to read aloud to the researcher for one minute but were unaware they were being timed. After the reading, the students were asked five comprehension questions in the form of a cloze passage. Researchers also trained students in peer-mediated repeated readings once the accuracy and words per minute were stable for the students. Repeated readings interventions began with students who demonstrated the greatest need in reading. Scott and Shearer-Lingo (2002) conducted a single subject, multiple baseline across subjects to implement two different teacher-directed reading programs. This study examined the effects of a repeated readings instructional strategy on the reading and ontask behavior of three, seventh-grade students with EBD who were placed in a selfcontained middle school classroom. Baseline occurred when each student received a 
weekly oral reading fluency probe and on-task behavior measure. After baseline was established, a teacher directed program was implemented according to the program's directions. Once per week, the students were probed using the same passage used during baseline. During the second phase, the researcher presented the students with repeated readings, which included instruction and timed readings as stated in the program's directions. Oral reading fluency measures were kept on a daily basis because fluency measures are part of the Great Leaps program. As the criteria were met for fluency, new sheets and passages were made. Results of the study indicate that there was moderate growth in oral reading fluency during the implementation of the Corrective Readings intervention. For four out of the six participants, the additive effect of repeated readings led to an increase in oral reading rates. These same four participants demonstrated greater proficiency in comprehension questions during the repeated readings intervention. The authors attribute the lack of gain for the other two students to a "ceiling effect" since they were reading at higher level than the other four participants (Scott \& Shearer-Lingo, 2002).

In a study by Strong et al. (2004), research was conducted using a single subject, multiple baseline design across subjects to evaluate the impact of a repeated readings intervention on various measures of fluency of six male students in middle school (seventh and eighth grade). During baseline, weekly reading probes were administered to measure the students' fluency growth while reading in text. During the intervention phase, a direct instruction measure, Corrective Readings, was used that provided instructional scripts for the teacher to use. 
After a 7-week time period, a second phase was added to investigate the added effects of a repeated readings intervention to the Corrective Readings intervention with a multiple baseline across participants. Students were sent to the library in pairs after the Corrective Readings intervention to chorally read an unfamiliar passage. One student read a passage aloud while the other student silently followed the passage. Error correction was given if a student paused on a word for longer than three seconds. After the passage was read twice, the students alternated. After each student read the passage aloud four times, the student was given a new passage of the same difficulty level. This passage was timed and the number of words read correctly was graphed. Results demonstrated that (for four out of the six participants) during the repeated readings condition, the addition of the repeated reading component resulted in an increase in oral reading fluency. These same four students answered more comprehension questions during the repeated readings intervention, an average of 0.50 to 1.00 more questions answered correctly out of 5 than in baseline (Strong et Al., 2004).

Alber-Morgan et al. (2007) examined the effects of repeated readings combined with a systematic error correction and performance feedback on the reading fluency and comprehension of four middle school students with EBD. Similar to Strong et al. (2004) the repeated readings condition was added to the students' regular reading instruction program (Corrective Readings). During baseline, the student read a 5-7 minute passage where fluency and errors were recorded for the first minute of the passage. After the passage was read, the student was given an 8-question comprehension test. The repeated readings condition contained a systematic error correction procedure used by Nelson et al. (2004).During the first repeated readings intervention, the students repeated the steps 
in baseline but were given error correction throughout the reading. After the initial reading, the students were given opportunities to improve their reading fluency by reading the passage two more times for one minute each time. A comprehension test was given as in baseline. During the second repeated readings condition a prediction strategy was employed to add to the baseline and previous repeated readings condition. Subsequently, during all conditions, the participants read the first minute of the passage three times. Results show that WCPM in baseline ranged from 38.8 to 91.6 and improved to 95.6 to 133.7 in repeated reading and 117 to 154 in repeated readings plus prediction. In comprehension baseline ranged from 1.8 to 3.2. During repeated reading the number of correct answers increased from 3.2 to 3.8 . In the repeated readings plus prediction, it ranged from 3.4 to 3.5 .

During the repeated readings intervention, students read passages of 180-200 words with partners for 10 minutes. As one read, the other student followed along with their finger and corrected errors using a scripted procedure. Students continued reading for the 10-minute period. After the peer-mediated reading, the students read aloud to the researcher for one minute but this time they were made aware that they were being timed. The students had a maximum of three opportunities in each session to improve their score. The students charted the number of words read during their best performance after every session in their folders. Once the student met the fluency criteria, they answered five comprehension questions. If the questions were answered correctly, they were allowed to move on to the next grade-level passage provided they had met the fluency criteria. Three generalization procedures were measured (overtly timed, covertly timed, and timed and charted) during the intervention. Results show that the mean for words per 
minute increased from 71 in the sustained silent reading condition to 133 in the repeated readings. All students read faster in generalization than in baseline as demonstrated by their group mean gain 71 (baseline) to 81 (generalization). The comprehension scores increased from 2.85 in baseline to 4.90 in repeated readings out of a possible 5 (Staubitz et al., 2005).

As a whole, the use of repeated readings with students who are EBD has been beneficial, even though the research is limited. Scott and Shearer-Lingo (2002) researched repeated readings and middle school students and found that although there was a limited increase in fluency, those increases were a result of the repeated readings opportunities. Additionally, on-task behavior showed an increase from baseline through both interventions. Strong et al. (2004) investigated the effects of repeated readings and middle school students with EBD, and the results demonstrated that the addition of repeated readings to the direct instruction reading program showed an increase in oral reading fluency. Finally, the Staubitz et al. (2005) study with elementary students who were at risk for or who were EBD demonstrated that all students improved both their reading fluency (i.e., speed \& accuracy) and comprehension when they participated in repeated readings. Their results also support the use of a peer-mediated approach as an option when working with students with EBD. Given the limited research on the effects of repeated readings with students with EBD and the differences in the conditions compared, there is a need for additional research in this area.

Critiques of repeated readings research (Kuhn \& Stahl, 2003; Pressley, 2006; Therrien, Ojwaya, Wickstom, \& Jones, 2008) propose that the fluency developed during repeated readings may have little or nothing to do with repetition of passages, but instead 
occurs as a result of students reading more words and/or reading for longer periods of time during repeated readings than the comparison conditions. Kuhn and Stahl (2003) propose that fluency acquired during repeated readings is due to increased reading practice rather than repetition.

\section{Active Student Responding and Opportunities to Respond}

Apart from the need for additional repeated readings research for students with EBD, there remain other questions to be answered. At the forefront is whether repeated readings is more effective than having students read an equal amount of non-repetitive text. These arguments may be valid given that research over the last several decades has consistently found significant positive correlations between the time students spend actively engaged in an academic task or active student responding (ASR) and learning (Sutherland, Alder,\& Gunter, 2003; Jerome \& Barbetta, 2005; Malanga \& Sweeney, 2008;Miller, Hall, \& Heward, 1995; Skinner, Belifore, Mace, Williams-Wilson, \& Johns, 1997). For example, with respect to reading specifically, Taylor et al. (2003) examined 792 students (grades 1-5) in 88 classrooms in nine high-poverty schools. These researchers found significant positive correlations between active learning environments (such as teachers asking higher level questions to students, high levels of coaching, involving students in active reading) and growth in reading comprehension whereas the correlation was negative in passive learning environments.

An active student response is an observable, measurable student response to an instructional antecedent such as reading aloud, writing an answer to a comprehension question (Barbetta, Heron, \& Heward, 1993a; Jerome \& Barbetta, 2005). Effective academic instruction in the form of opportunities to respond (OTR) for the students is an 
indicator for increasing students' academic achievement and improving their classroom behavior (Sutherland et al, 2003). OTR has also resulted in improved academic performance in reading (Skinner et al., 1997). If the students are able to respond frequently, this allows the teacher to adjust their lessons based on student feedback. This in turn will increase the quality of the lesson and increase the attentiveness of students (Sutherland et al, 2003).

An active student response should meet the following guidelines: (a) be relatively low in cost (e.g., in terms of teacher time and dollars); (b) be enjoyable for both teachers and students; (c) be simple enough to implement; (d) be adaptable to a variety of content areas; and (e) produce better learning outcomes than they replace (Narayan, Heward, Gardner, Courson, \& Omness, 1990). Some commonly used strategies for ASR include response cards, guided notes, and choral responding (Malanga \& Sweeney, 2008).

Using ASR methods is important because students learn more when they actively participate in class (Huby, 2001). Higher achievement scores are documented when teacher-directed instructional activities include high levels of active student responding compared with a more traditional question and answer format (Malanga \& Sweeney, 2008; Miller et al., 1995).

Even with the consistent positive relation between time on task and student learning, only a limited number of studies have directly compared repeated readings to equal amounts of time-spent reading (e.g., Alber-Morgan et al, 2007; Mathes \& Fuchs,1993; Nelson et al., 2004). Alber-Morgan et al. (2007) employed a multiple baseline design across subjects to examine the effects of repeated readings combined with a systematic error correction and feedback on the reading fluency and comprehension of 
four (3 males; 1 female) middle school students with EBD. For three of four students, repeated readings resulted in an immediate increase in their reading rate and comprehension skills and a decrease in their errors per minute.

Mathes and Fuchs (1993) employed a pre-test/post-test design to examine the effects of peer-mediated repeated readings and sustained-reading methods during classwide peer tutoring, on 67 fourth- through sixth-grade students with learning disabilities. During the sustained reading condition, one student read from the basal reader for 9 minutes to another student. While one student read, the other student monitored errors and awarded 2 points to the reader for a sentence read correctly. After 9 minutes, the students alternated roles. During the repeated readings condition, the student read three different passages, three times, for one minute, for a total of 9 minutes, following other baseline procedures. Additionally, there was a control condition in which students received reading instruction as they typically did from their teachers. Results of this study suggest that the sustained-reading condition performed better than the control condition on fluency, but not comprehension. Repeated readings did not perform better than sustained readings condition or the control condition on fluency and comprehension.

Nelson et al. (2004) used a multiple baseline design across subjects to examine the effects of systematic error correction and systematic error correction with repeated readings on the reading accuracy and fluency of four, second-grade students ( 3 males; 1 female) with learning disabilities. During baseline, the students read to the teacher for 5 minutes and were given error correction. After 5 minutes, the students were asked to reread the passage for 1 minute and the number of words read correctly and errors were documented. Similar to baseline, during the error correction condition, the students read 
the selection for 5 minutes to the teacher, were given error correction, and were asked to reread the passage for one minute. The number of words read correctly and errors were documented. During error correction plus repeated readings, the same procedures were followed as in baseline, but error correction took place within the first 3 minutes instead of the 5 minutes in the baseline and the error correction phases. The students then read three, 1-minute timings followed by documentation of the number of words read correctly and errors. Finally, during error correction plus repeated readings with previously read materials, the students followed the same steps as in the error correction plus repeated readings with the exception that the passages read were the ones from the baseline condition. Results indicate that all four students read fewer errors per minute (1.64 to 3.38) during the error correction condition. With the addition of repeated readings to error correction, the mean number of words per minute ranged from 66.00 to 77.40. Students also progressed from a pre-primer level passage to a first-grade passage.

\section{Repeated Readings and Equivalent Non-Repeated Readings by Number of Words in Passages}

There are a limited number of studies (mostly dated) that controlled the number of words read across equivalent non-repeated and repeated readings. These studies include Ardoin et al. (2007), Homan et al. (1993), Rashotte and Torgesen (1985), Therrien et al., 2008, and Van Bon et al. (1991).

Ardoin et al. (2007) examined the effects of a high word overlap and a repeated reading condition on the fluency to generalized passages for six, third-grade students. Both of the conditions were implemented using six sets of passages in which three of the passages showed a high degree of word overlap. In both conditions, students were timed 
while reading the third passage (generalization passage) and then error correction was provided on the first passage of the set. During the high word overlap readings, the students read the first and second passages twice, while in the repeated readings condition, the students read the first passage four times. Students were then timed while they read generalization passages as part of their evaluation for the conditions. Results show that the students' fluency increased by as much as 32 words read correctly during the repeated readings condition. The authors state that this was due to the opportunity to use repeated readings. In examining the results for the high word overlap readings condition, the students benefited from error correction as in the repeated readings condition. All students benefited from the high word overlap condition as demonstrated by one student's increase in fluency by almost 41 words read correctly per minute.

Homan et al. (1993) used a pre-test/post-test design to examine the effects of repeated readings and assisted non-repetitive oral reading strategies in which passages were not repeatedly read (e.g., cloze reading, unison reading, echo reading) on reading rate, error rate and comprehension of 26, sixth-grade general education students. Students were administered a pre-test based on six passages prior to the interventions. In the assistive non-repetitive readings, the students either used echo reading (students read what the teacher read with no repetition), unison reading (students and teacher read together), or cloze reading (teacher read the selection, stopping momentarily to let the students read certain words aloud). The students read from a basal reader for 20 minutes while alternating the non-repetitive strategies on a daily basis. The passages were read just once in the assistive non-repetitive condition. During the repeated readings condition, the students were paired up and read from the same basal reader used in the non- 
repetitive strategies condition. Each student repeatedly read a passage four times. Both conditions were implemented for a period of 7 weeks. During the eighth week, the students were administered a post-test similar to the pre-test. The authors found that during repeated readings, students reduced their errors in word recognition from pre- to post-tests (9.49 to 8.62). With respect to comprehension, during repeated readings, the mean score increased from 46.47 to 54.79 and increased in comprehension from 50.72 to 61.67 from pre- to post-test. During equivalent non-repeated reading, the mean score for errors in word recognition reduced from 10.15 to 8.38 .

Rashotte and Torgesen (1985) examined repeated readings and equivalent amounts of non-repeated readings (similar to equivalent non-repeated) readings on fluency and comprehension of 12 elementary school students with learning disabilities using a pre-test and posttest design. In all conditions, the students read four passages for 15 minutes with error correction provided. There were four comprehension questions asked at the end of the reading and one after each subsequent reading. In the first condition (repeated readings), the student read seven stories, four times a day, totaling 28 stories read. There was no overlap of words in this condition. In the second condition (repeated readings with a high degree of shared words), the students also repeatedly read seven stories but this time the stories shared a high degree of word overlap (three times as many as the first condition), but were not the same stories. In the third condition sequential (similar to equivalent non-repeated) readings, the students read four stories each day, none of which were repeated. This means that over a period of seven days (in the third condition) the students read the same amount of stories as in condition one and 
two. Results indicate that the fluency increased when there were greater amounts of word overlap during the repeated readings conditions.

Therrien, et al (2008) examined the effects of a repeated readings and a sequential readings condition (similar to equivalent non-repeated) on the fluency and word mastery of eight, general education students in the second grade who were struggling readers. During the repeated readings condition, the participants read the first passage four times. During the sequential readings condition, they read the first four sequential readings passage. After a week, the participants were given either a second repeated reading passage or the last (fifth) sequential reading passage as a generalization session. Results indicated that repeated readings produced a mean increase of 41.38 from the first reading to 71.25 WCPM during the fourth reading. During the sequential reading condition, participants improved their WCPM from 34.75 to 49.00. A generalization probe given on a new passage demonstrated a 2.25 WCPM growth from the first repeated reading. The generalization probe administered for sequential readings represented a mean score of 40.63 WCPM. This was lower than the within-sessions increase for sequential readings passages but it did represent a 5.88 increase over the first sequential readings passage. In sum, repeated readings produced a greater increase in WCPM as compared to sequential readings during the sessions but there was no difference between conditions for the generalized sessions Additionally, there were no significant differences in generalized word mastery gains between the two conditions.

In another study to compare equivalent non-repeated readings and repeated readings, Van Bon et al. (1991) used a pre-test and pos-test design to investigate the effects of text spoken in reading while listening $(\mathrm{RwL})$ through repeated readings and 
RwL of different texts (similar to equivalent non-repeated readings )with 36 students with learning disabilities. During the training sessions (which comprised seven, 2-week periods) the students independently read a passage while listening to a cassette recording of that passage. The first four sessions of a period were training sessions while the fifth session was a testing session. Each session took about 10 minutes. In the standard condition of RwL of different texts (similar to equivalent non-repeated readings), the students read and listened to a different text (which contained short stories) with the duration of the recorded passages varying from 6 to 8 minutes. During the repeated reading condition, the students repeatedly read the same text for each training session of a period. The text consisted of the standard condition's passage from the fourth session. During the error detection condition, the texts were the same as the standard condition. Students were assessed using a pre- and posttest. Results of the study suggest that the repeated readings condition did not differ from those in the RwL of different texts (similar to equivalent non-repeated readings) condition or error detection in regards to RwL to text. Error correction did improve over the sessions.

In addition to the published research, there are a limited number of unpublished studies that control the number of words read across sequential (similar to equivalent non-repeated and repeated readings (Ojwaya, 2008; Vincent, 2009). Ojwaya (2008) examined the acquisition and retention of previously known words that eight, secondgrade children are exposed to in the same context multiple times (repeated readings) or when exposed to these words in multiple contexts sequential (similar to equivalent nonrepeated readings). During baseline, each student was given a pre-test consisting of 50 sight words from a third- and fourth-grade list. From the total error words the student 
committed, 20 unknown words were randomly assigned to either the repeated readings condition or the sequential readings condition (10 words for each condition) where passages were created for these unknown words. During the first session, repeated readings or sequential readings were assigned to the students. In repeated reading, the students read a story four times and were provided error correction. For the sequential readings condition, the student read four different passages and received error correction. In both conditions, the researcher timed the first reading of the first minute of the readings. During the second session, the students were assessed for WCPM and correct number of sight words using a passage indicative of the condition. The final session (generalization) consisted of administering a test passage consisting of the test words the students practiced in session two. Repeated readings resulted in a 2.25 fluency improvement in WCPM and 5.0 words mastered, while sequential (similar to equivalent non-repeated) readings resulted in a fluency gain of 5.88 WCPM and 4.5 words mastered. Although both interventions were found to be effective interventions, there were no significant differences in reading fluency between repeated readings and sequential (similar to equivalent non-repeated) readings on generalization measures. Vincent (2009) compared the effects of repeated readings and sequential (similar to equivalent non-repeated) readings on the fluency and word acquisition using an alternating treatments design of nine, third-grade students. During the repeated readings condition, the students read an original passage four times, received error correction, and the researcher marked the spot where the child read to after one minute. During sequential readings, the student read the original passage and three generalization passages with the same error correction, and the adult marking the spot where they read 
to after one minute. During the control condition the child read the original passage. Results indicate that repeated readings led to greater gains in word acquisition. The mean for all students in word acquisition was 12.5 in the repeated reading condition compared to eight words in the sequential condition.

\section{Chapter Summary}

When one is able to read, there are certain benefits associated with this process (Stromquist, 2008). Good readers are able to summarize, interpret, and accept or reject the information on the printed page (Pressley et al, 2006). Unfortunately, there are many students who do not read well, and there are negative outcomes for not reading well (Begeny \& Martens, 2006). Ineffective readers tend to exhibit disruptive or withdrawn behaviors that distract them from learning activities and a greater likelihood of living in poverty (Hitchcock et al., 2004).

Students with EBD are those who display inappropriate classroom behaviors such as physical and verbal aggression (or are characterized as withdrawn) and deficits in performance and acquisition of social skills (Walker et al., 2004). Many students with EBD exhibit extensive deficiencies, which include underachieving in reading, reading comprehension, vocabulary, written language, and math (Lane et al., 2006; Nelson, et al., 2003; Nelson et al., 2004). Additionally, these students often are unable to successfully maneuver between teacher expectations and demands made of them socially (Cullinan \& Saborine, 2004), which makes school a challenging environment (Lane et al., 2008). Unfortunately, difficulty in the school setting along with inadequate social outcomes often cause these students' deficiencies to remain when they leave school. Students with 
EBD go on to have pessimistic employment results, difficulties with substance abuse, and have a high demand for mental health services (Bullis \& Yovanoff, 2006; Walker et al., 2004).

With respect to reading, students with EBD display a number of challenges (Levy \& Chard, 2001a). In reading achievement, students with EBD perform 1 to 2 years below grade level with differences in their achievement compared to their typical learning peers (Kauffman, 2001). Furthermore, when students with EBD do not learn to read well, it stands as an indicator for future failures including dropping out of school, poor college enrollment, and even incarceration (Scott \& Shearer-Lingo, 2002). Finding effective reading intervention strategies is necessary for students who are EBD (Ishii-Jordan, 2000) because there is a strong correlation between reading failure and school failure (Scott \& Shearer-Lingo, 2002). Students with EBD are especially at risk for reading difficulties when they have other disabilities such as learning disabilities or attention deficit disorder (Rittner \& Dozier, 2000). The NEP (2000) reviewed research on effective reading practices for students with and without disabilities and determined that instruction in reading should be explicit, methodical, and should include (among other things) fluency and comprehension. The NEP (2000) agrees that if students are to build fluency, then reading practice must occur. The clear-cut evidence for building fluency and comprehension favored guided, repeated, oral reading techniques (Al-Otaiba \& Rivera, 2006).

Repeated readings involves the reader repeatedly reading a short passage of usually no more than 200 words until fluency is achieved (Samuels, 1979; Stahl \& Heubach, 2005; Therrien \& Kubina, 2006). This strategy grew out of the Automaticity 
Theory of LaBerge and Samuels (1974) who state that a fluent reader could decode text without giving too much attention to the process of reading, therefore leaving attention free to comprehend the text (Samuels, 1979). According to this theory, beginning readers need to focus on letters and sounds, but as they become more fluent readers they can focus their attention on phrases, sentences, and meaning. Samuels (1979) stated that the practice provided in repeated readings makes the decoding necessary for reading automatically, which leads to better comprehension.

The literature on repeated readings and students with EBD is limited but has shown promise. All five studies reviewed showed an increase in the students' reading fluency (Alber-Morgan et al., 2007; Scott \& Shearer-Lingo, 2002; Strong et al., 2004; Staubitz, et al., 2005; Valleley \& Shriver, 2003). Two studies used a teacher-directed method (Scott \& Shearer-Lingo, 2003; Strong et al., 2004) successfully as part of their conditions. Staubitz et al.(2005) incorporated peer-mediation successfully to assist with better comprehension gains. While all the studies employed similar or diverse methods, the results showed that repeated readings was an effective reading fluency strategy with students with EBD.

While all the repeated readings studies demonstrated success with repeated readings and students with EBD, all of them differed somewhat in their approach, making the comparisons challenging. As such, there are several gaps in this line of research. One major gap is that only one of the repeated reading studies with students with EBD (i.e., Alber-Morgan et al., 2007) had equivalent time spent reading during baseline and repeated readings intervention conditions, and no studies had equivalency in the number of words read across conditions. 
Kuhn and Stahl (2003) propose that the fluency acquired during repeated readings is due to increased reading practice rather than repetitive reading. Others suggest that using sequential (similar to equivalent non-repeated) readings may be more appropriate because students will read multiple texts which in turn increases their exposure to a variety of vocabulary words, content topics and genres (Homan et al., 1993).

Only a limited number of studies have controlled (or equalized) the time-spent reading (i.e., Alber-Morgan et al., 2007; Mathes \& Fuchs, 1993;Nelson, et al., 2004) or directly compared repeated readings to equal amounts of non-repetitive text reading (e.g., Ardoin et al., 2007; Homan et al., 1993; Ojwaya, 2008; Rashotte \& Torgesen, 1985; Vincent, 2009; Von Bon et al., 1991). This study was designed to fill this gap in the research by comparing the effects of repeated and two non-repeated readings conditions on reading fluency, reading errors, and comprehension of students who are EBD. Specifically, it examined the number of words read per minute and the number of errors per minute while being exposed to three experimental conditions: (a) Repeated readings in which participants repeatedly read a passage of about 100-150 words, three times, (b) Non-repeated readings in which participants sequentially read an original passage of about 100-150 words once, and (c) Equivalent non-repeated readings in which participants sequentially read a passage of about $300-450$ words, equivalent to the number of words in the repeated readings condition. Also, to further investigate the effectiveness of repeated readings, reading fluency and error data were collected for each of the three successive reading passages during each repeated readings session. 


\section{Chapter III}

\section{Method}

This study compared the effects of repeated readings and two non-repeated readings conditions on the reading fluency, reading errors, and reading comprehension of sixth grade students who have emotional/behavioral disorders (EBD) and are struggling readers. In addition, it examined the effects of each of the three repeated readings practice trials per sessions on reading fluency and reading errors. Specifically, this study used an alternating treatments design to compare the effects of three conditions: Repeated readings in which participants repeatedly read a passage of about 100-150 words, three times, (b) Non-repeated readings in which participants sequentially read an original passage of about 100-150 words once, and (c) Equivalent non-repeated readings in which participants sequentially read a passage of about $300-450$ words, equivalent to the number of words in the repeated readings condition.

Included in this chapter are descriptions of the study's participants, setting, and materials used. Also, all dependent variables and the experimental design are identified and explained. This chapter concludes with a detailed section on the general procedures and a chapter summary.

\section{Participants}

Participants were four students with EBD who are struggling readers in the sixth grade and were nominated by their teacher for participation in this study. The nominating teacher was a special education reading and language arts teacher who has known the participants for at least 3 years and is certified in reading and exceptional student 
education. The teacher's nominations were based on experiences with the participants and the participants' performances in reading tasks in her classes.

Since teachers are an invaluable source of information regarding their students (Abidin \& Robinson, 2002), and single subject researchers generally view them as an ideal source for identifying those in most need of intervention (Cooper et al., 2007; Tam et al., 2006), the teacher was employed in the selection procedures for the participants. In order for each participant to take part in the study, there was a written parental permission (see Appendix A) form and a participant assent form that were signed (see Appendix B). Also, to be considered for this study, participants had to have been identified by the school district as having EBD. In the Miami-Dade County Public School System (MDCPS), the first step in identifying students as EBD is through a teacher, parent, and/or specialist recommendation. Afterwards, the evaluation procedures set up by the district allow for evaluative materials such as valid tests to be implemented and interpreted by qualified district personnel according to the assessment's instructions. For a student to meet the eligibility criteria for EBD, the following must be documented: (a) the student, after receiving supportive educational assistance and counseling services available to all students, still exhibits an emotional and/or behavioral disorder; (b) the emotional and/or behavioral disorder exists over an extended period of time and in more than one situation; (c) the emotional and/or behavioral disorder interferes with the student's own learning, reading, math, or writing skills, social-personal development, or behavioral processes and control; and (d) when intellectual, sensory or physical deficits exist, they are addressed by other appropriate interventions or special programs (MDCPS, 2007). 
For a participant to have been selected for this study, he/she had to have been identified as a struggling reader. As in Landa and Barbetta (2010) and others (Pressley et al., 2006; Tam et al., 2006), in this study the struggling readers were defined as reading at least 1 year below grade level in reading (Nelson et al., 2004). This rating was based on grade level assessments given at the beginning and midpoint of the school year by the reading and language arts teacher. Additionally, the Analytical Reading Inventory (ARI)(Woods \& Moe, 2007) was given as an informal assessment by the researcher prior to commencement of the study. The ARI determined the participants' instructional reading level and was also used to confirm that the participants' reading levels were at least 1 year below his present grade level.

A detailed description of each of the participants follows. Even though the researcher taught all the participants, at the time of the study the researcher was no longer teaching them. Also see Table 1 (page 61) for the demographic information of each participant. Pseudonyms were used for the participant names to safeguard confidentiality.

\section{Participant 1}

Gabriel (pseudonym) is a 12-year-old Hispanic boy, who was retained in the third grade because he had not passed the Florida Comprehensive Assessment Test (FCAT) in reading. He met special education eligibility because of an emotional and/or behavioral disability along with a learning disability and an Individualized Education Plan (IEP) was developed. His ARI results indicated that his instructional reading level was second grade. Gabriel accessed the curriculum in a self-contained class at a separate day school for students with EBD. His class consisted of 10 sixth graders, all of whom had current IEPs. Two certified teachers taught the class. 
Table 1

Demographic and Analytical Reading Inventory Data

\begin{tabular}{|c|c|c|c|c|c|c|}
\hline Participant & Gender & Age & Grade & Ethnicity & Disability & $\begin{array}{c}\text { ARI } \\
\text { Instructional } \\
\text { Reading } \\
\text { Level*** } \\
\end{array}$ \\
\hline Gabriel* & M & 12 & 6 & Hispanic & EBD/SLD & 2 \\
\hline Kevin* & M & 11 & 6 & $\begin{array}{l}\text { African- } \\
\text { American }\end{array}$ & EBD/SLD & 2 \\
\hline Fred & M & 12 & 6 & Hispanic & EBD/SLD & 5 \\
\hline Ulysses & M & 12 & 6 & $\begin{array}{l}\text { White } \\
\text { Non- } \\
\text { Hispanic }\end{array}$ & EBD/SLD & 5 \\
\hline
\end{tabular}

Note. All participants' names are pseudonyms.

*Indicates a participant who is repeating the grade because of failure to pass the Florida Comprehensive Assessment Test (FCAT).

\section{Participant 2}

Kevin (pseudonym) is a 12-year-old African American boy, who was retained in the third grade because he had not passed the FCAT in reading. He met criteria for an emotional and/or behavioral disability and a learning disability and an IEP was developed. His ARI results indicated that his instructional reading level was second grade. Kevin accessed the curriculum in a self-contained class at a separate day school for students with EBD. His class consisted of 11 sixth graders, all of whom had current IEPs for EBD. Two certified teachers taught the class.

\section{Participant 3}

Fred (pseudonym) is a 12-year-old Hispanic boy. He met criteria for an emotional and/or behavioral disability and a learning disability and an IEP was developed. His ARI results indicated that his instructional reading level was fifth grade. Fred accessed the curriculum in a self-contained class at a separate day schoolor students with EBD. His 
class consisted of 12 sixth graders, all of whom had current IEPs for EBD. Two certified teachers taught the class.

\section{Participant 4}

Ulysses (pseudonym) is a 12-year-old, White, Non-Hispanic boy. He met criteria for an emotional and/or behavioral disability and a learning disability and an IEP was developed. His ARI results indicated that his instructional reading level was at the fifth grade. Ulysses accessed the curriculum in a self-contained class at a separate day school or students with EBD. His class consisted of 10 sixth graders, all of whom had current IEPs for EBD. Two certified teachers taught the class.

\section{Setting}

This study took place at an urban, separate day school for students with EBD in the Miami-Dade County Public School District (MDCPS). The school ranges from kindergarten through 12th grade with a diverse population including African American (31\%), Hispanic (46\%), and White (22\%) students. 100\% of the school's 195 students were identified as EBD (MDCPS, 2007). The researcher, who is a special education teacher at the school site, conducted all of the study's individualized sessions in a room with desks and/or tables that permitted the researcher and the participant to sit next to each other. There was no one else in the room during the study sessions.

In order to participate in this study, the participants were escorted individually to the study site for approximately 15 to 20 minutes each session day. The study sessions took place in the morning during elective classes. Each participant took part in one session daily ( 5 days a week) at approximately the same time each day. The study lasted 10 weeks. 


\section{Materials}

The following is a description of the materials that were used in the study:

\section{Parental Consent Form}

A consent form for their child's participation in the proposed research study in both English and Spanish was provided to the parents (see Appendix A). This form was included in a condensed study description and expectations for parental and student commitments of the study and other pertinent information. Relevant researcher and university contact information was provided on the form.

\section{Participant Assent Form}

To participate in the study, a student must have signed an assent research study form that included pertinent information regarding the purpose, length of study, and expectations of the proposed study (see Appendix B). The form was written free of any terminology and used developmentally appropriate language and reading level for the potential participant. The researcher and university contact information was supplied on the form.

\section{Treatment Fidelity Checklist Form}

A treatment fidelity checklist including the procedures for each segment in the study was used during each session by the researcher (see Appendix C). An independent rater verified that the researcher was implementing proper procedure by independently filling out a treatment fidelity checklist form for a random selection of $25 \%$ of the sessions. 


\section{Interobserver Agreement (IOA) Forms}

For $25 \%$ of the study's sessions, IOA forms were completed (see Appendix D). The IOA form (Landa \& Barbetta, 2010) was used to compare the data collected in the same session by the researcher and a non-participant observer once the session was completed.

\section{Data Collection Forms}

In this study, the data collection forms were used to document participant performance (see Appendix E) by the researcher and an independent observer who listened to a recording of the session. Each form contained a reading passage of approximately 100 to 450 (95-455) words that were typed in 14-point size and leftaligned. These data collection forms were printed on $8.5^{\prime \prime} \times 11^{\prime \prime}$ plain white copy paper and had 1-inch margins on each side. Below the passages, there were two spaces in which the raters wrote the total number of correct WCPM and EPM. Additionally, this form had a grid to document the types of errors made during reading including: additions, hesitations, mispronunciations, omissions, and substitutions. The forms had five questions related to the reading passage printed on them with a "yes" or "no" next to each question to record the correct and incorrect answers.

\section{Informal Reading Inventory}

The Analytical Reading Inventory (ARI) (Woods \& Moe, 2007) was the informal reading inventory used to determine the overall instructional reading level of each participant. The responses were coded for word recognition and categorized as independent (99-100\% accuracy), instructional (91-98\% accuracy), or frustration (90\%

or below). The scores in comprehension were coded as independent (90-100\% accuracy), 
instructional (75-89\% accuracy), or frustration (74\% or below). The ARI has been shown to have content validity in reading comprehension in areas including passage genre, passage length and pictures/graphic supplements (Applegate, Quinn, \& Applegate, 2002). Additionally, alternate-form reliability levels were acceptable based on similar content that occurs across all three narrative forms (Woods \& Moe, 2007).

\section{Fry Readability Graph}

The Fry Readability Graph (Fry, Fountoukidis, \& Polk, 1985), which utilizes the mean number of sentences (y-axis) and syllables (x-axis) per 100 words, was used to verify the grade reading level of the study's passages. To determine the reading level of the content, the mean was plotted and the intersection of the mean number of sentences and the mean number of syllables were displayed.

\section{Reading Passages}

Approximately, 35 to 40,100 - to 450 -word passages were selected for each participant at his instructional reading level. The passages contained both narrative and expository texts. To eliminate picture cues, the passages were retyped (Alber-Morgan et al., 2007) using double spacing and 1-inch margins in a 14-point, Times New Roman font on $8.5^{\prime \prime} \mathrm{x} 11^{\prime \prime}$ plain white copy paper and left-aligned. Once the participants' individual instructional reading levels were ascertained using the ARI, the reading passages were developed appropriately for those levels. The instructional level of the reading passages was determined by the ARI. The reading level of the passages was verified both by the Fry’s Readability Graph (1985) and the code provided by the publisher. 


\section{Flashcards of Challenging Words}

Flashcards were developed that contained five words considered challenging for each reading selection. These words were also printed in a 14-point, Times New Roman font on $3 "$ x 5" plain white flashcards used in vocabulary instruction. The definitions of these challenging words were printed on the back of the flashcards and taken directly from the reading program's glossary (See Appendix F).

\section{Literal Comprehension Questions}

Five literal comprehension questions were developed for each reading passage. These questions were retyped using double spacing and 1-inch margins in a 14-point, Times New Roman font on 8.5" x 11" plain white copy paper (See Appendix G).

\section{Digital Recording Device}

In order to create a permanent product of each session, a digital recorder with a built in timer was used for this study. The digital recorder had a cable that allowed audio files to be archived in the researcher's computer, which permitted the researcher, the nonparticipant personnel to score the reading assessments.

\section{Dependent Variables}

To allow for precise measurement of the dependent variables, each session was recorded and transferred to a digital file. The dependent variables were as follows: (a) reading fluency as measured by the number of correct words read aloud per minute, (b) number of errors read aloud per minute of reading, and (c) number of literal comprehension questions answered correctly aloud. The following definitions of terms are similar to those used by Landa and Barbetta (2010). 


\section{Reading Fluency as Measured by Words Correct per Minute (WCPM)}

Reading fluency was the number of words read correctly aloud per minute of reading. This was done for the standard as well as the enhanced passages. Participant self-corrections were accepted as correct.

\section{Errors per Minute (EPM)}

This refers to the total number of errors read aloud during a 1-minute recording (Barbetta \& Landa, 2010; Tam et al., 2006). Data on the following error types were collected:

Omissions. Defined as a printed word in the passage that was not read aloud by the participant.

Additions. Defined as a word that was read aloud by the participant but was not printed in the passage.

Mispronunciations. Defined as a printed word that was read aloud incorrectly. For example if the text said "She brought her flute to the parade," but the participant read aloud, "She brought her float to the parade," this was classed as a mispronunciation (Dictionary.com, 2008).

Substitutions. Defined as a word that was read aloud differently than the printed word. For example, if the text said, "We went to the market" and the participant read, "We went to the movies."

Hesitations. Defined as a delay in reading aloud of more than 3 seconds from the end of one word read aloud to the beginning of the next word. The researcher, counting silently, timed the seconds. Once 3 seconds had passed, the researcher read the word correctly so that the participant could continue to read. 


\section{Answers to Literal Comprehension Questions}

After completing the passage readings, five literal comprehension questions were asked by the researcher. The researcher asked the school's reading coach to look at $25 \%$ of the intervention's literal comprehension questions (across the three conditions) to determine if the questions were literal comprehension questions. This included making sure there was only one correct answer to the each literal comprehension question and that the correct answers matched a prepared answer key. The participants were not asked to infer, give opinions, predict or draw conclusions about stories as part of the literal comprehension questions (Tam et al., 2006). The questions were found directly in the passage. The participant had 5 seconds to answer each question. Participant responses were compared with the answer key provided by the basal reader for that reading passage. Correct responses were those that matched the answer key and were stated aloud within 5 seconds after the end of the question. Responses that did not match the answer key or those begun more than 5 seconds after the end of the question were scored as incorrect. The total number of correct responses were recorded and graphed.

\section{Interobserver Agreement}

An independent rater was trained to listen to the recordings and record the performance of the participants on each dependent variable. The independent rater was a special education reading teacher employed at the school where the research was conducted.

The researcher trained the independent rater in one, face-to-face session with a summary handout, which defined how to score the audio sessions (see Appendix E). After the training, there were opportunities for the rater and the researcher to practice by 
scoring a previously scored independent recording. The researcher and the rater then compared their scores with each other. This practice continued until both the researcher and the rater agreed on at least $90 \%$ of the samples. When the rater and the researcher agreed on $90 \%$ of their sample scores, then the training was considered completed.

During that time, an independent reader was trained to score $25 \%$ of the sessions. Interobserver agreement (IOA) data were taken in all treatment conditions. IOA was calculated by dividing the number of agreements by the number of agreements plus disagreements and then multiplying this total by 100 . There was a minimum mean IOA of $90 \%$ calculated for each participant in the study. If an IOA observation fell below $90 \%$, the researcher and the observer will be trained again but this did not occur. Therefore, a word-by-word examination of the data sheets was not merited.

\section{Treatment Fidelity}

Treatment fidelity is the degree to which the treatment, or intervention, is being carried out according to the methods section of the study in question (Cooper et al., 2007). The ability to monitor treatment fidelity leaves evidence of the researcher's consistency. This also determines any problems in the implementation of the procedures before they can become routine for the participants. For each session, a treatment fidelity measure was used. Also, this measure was conducted by using a checklist in order to document the daily occurrence and nonoccurrence of the planned procedures.

There was a 1-hour training for treatment fidelity. To help measure the fidelity of the design, the same individual who was trained for the IOA also provided the training for treatment fidelity. This session consisted of a treatment fidelity checklist (see Appendix C), and where the individual was asked to listen to an audio recording of the 
researcher explaining the steps of the process to a participant. The rater and the researcher then compared their checklists for that session to measure that the researcher was self-assessing the written procedure correctly. This procedure was repeated until there was agreement between the researcher and the rater for every step in the checklist. At that time, the observer was considered trained for the study.

After the training, the observer independently listened to $25 \%$ of the randomly selected sessions and scored the nonoccurrence and occurrence of the procedures. The total percentage of nonoccurrence and occurrence of procedures was recorded. Data were collected during all three intervention conditions for this study and the treatment fidelity forms that were completed by the researcher and the independent rater were analyzed for the percentage of fidelity to the procedure. Finally, this percentage is reported in the discussion section of this study.

\section{Experimental Design}

An alternating treatments design (Cooper, Heron, \& Heward, 2007) was used to compare the effects of a repeated readings and two non-repeated readings conditions on the dependent variables by students with EBD. This experimental design is characterized by the rapid alternation of two or more distinct treatments (i.e., independent variables) and observing their effects on the target behavior (i.e., dependent variable). In this study, the rapid alternation was presented by alternating the three conditions across sessions. Even though these conditions were presented randomly, the conditions were counterbalanced by ensuring that no condition was presented more than twice per week. In contrast to other experimental designs in which intervention is made after steady-state responding, the different interventions in an alternating treatments design are 
manipulated independently of the level of responding. The differences in responding between or among conditions in an alternating treatments design are attributed to the effects of the condition (Cooper et al., 2007).

Prediction, verification, and replication are found in an alternating treatments design. However, each part is not identified with a separate phase of the design. Each successive data point for a specific treatment play all three parts: it provides (a) a basis for the prediction of future levels of responding under that treatment, (b) potential verification of the previous prediction of performance under that treatment, and (c) the opportunity for replication of previous effects formed by that treatment (Cooper et al., 2007).

A consistent sequence of verification and replication is evidence that experimental control has been achieved and strengthens the functional relation between the treatments and levels of responding. The presence of experimental control in an alternating treatments design is determined by visually inspecting the difference between the data paths, which represent the different treatments (Cooper et al., 2007).

\section{General Procedures}

The following describes the procedures for this study. The pre-study section describes the procedures that were completed prior to the beginning of the study including the selection of the participants, obtaining parental consent, obtaining participant assent, an informal assessment of reading and comprehension skills, and independent observer selection and training. This is followed by a description of how the reading materials were prepared prior to the tutoring sessions. The general study procedures section includes the procedures used in the intervention conditions. 


\section{Pre-Study Procedures}

The following procedures were implemented prior to the beginning of the study. These procedures were used for the selection of participants, consent and assent forms, reading materials, and assessment of potential participants.

Selection of participants. In order to select the participants for this study, the researcher received permission from the principal at the research site. When permission was granted, the researcher scheduled a meeting with the special education reading teacher who worked with the participants the previous school year. At this meeting, the researcher delineated the criterion necessary for participant nominations and asked the teacher to nominate students with EBD who were at least 1 year below grade level. The teacher was instructed that these nominations must be based on her experiences with the participants and their performance in reading tasks in their classes the previous school year. The researcher then scheduled a second session with the teacher to collect approximately seven names of prospective participants.

Parental consent. A consent form in English and Spanish was created and sent home with the teacher-nominated potential participants who also met the verified researcher criteria. The parents were given 5 days to read, sign, and return the consent form or contact the researcher with questions they may have had about the proposed study. Any parent who declined was removed from the list of potential participants. but this was not needed. Instead, all the parents responded in a timely manner. Additionally, although tentative plans were made to do so, no follow-up calls were made to answer any questions about the study, as no parents made the request. 
Participant assent. Any participants, whose parents gave permission for them to participate in this study, were given a form similar to the parental consent form during a one-on-one meeting with the researcher. This form was written in language that was developmentally appropriate for the potential participant. The participant assent form discussed the study and the roles of the researcher and participants. The researcher then answered any questions that the participant had about the proposed study at this time. The potential participants were asked to sign the participant assent form affirming their participation in the study. The participants were given a copy of the signed form.

Informal assessment of reading and comprehension skills. Approximately 1 week before beginning the proposed study, the ARI (Woods \&Moe, 2007) was administered to the participants. The participants read aloud grade-level passages and answered questions while the researcher recorded the errors. The oral reading responses of the participants were coded and classified as independent (99-100\% accuracy), instructional (91-98\% accuracy), or frustration (90\% or below). The comprehension scores were coded as independent (90-100\% accuracy), instructional ( $75-89 \%$ accuracy), or frustration $(74 \%$ or below). In order to determine the overall instructional reading scores, the oral reading scores and the comprehension scores were taken into consideration.

Independent observer selection and training. A special education teacher was recruited from the school site and served as an independent observer. The researcher attended a staff meeting and gave a brief presentation summarizing the duties of the observer. This observer was the same person used as the independent rater and assisted the researcher with the treatment fidelity 
Reading material preparation. Since there had been no exposure to these texts by the participants, the reading passages were chosen from a reading program at the school. The researcher chose 40 passages for each student according to his independent reading level as indicated by his ARI score. Since there were three conditions for this study, there were an equal number of passages for each of the conditions. The materials' reading levels were verified both by the publisher's provided key, as well as by the readability graph developed by Fry et al. (1985).

Using double spacing, the researcher retyped the reading program's passages in a 14-point, Times New Roman font. The passages were approximately 100-450 words (with a minimum of 95 words and a maximum of 455 words) and were printed on 8.5" x 11" plain white copy paper with 1-inch margins on all four sides and a left alignment. The passages for study were randomly assigned to each condition.

\section{Study Procedures}

In all three alternating treatments design conditions there were three distinct components: vocabulary instruction, reading under one of three conditions (i.e., repeated readings, non-repeated readings, equivalent non-repeated readings), and end-of-session assessments, with the vocabulary instruction and assessment procedures identical throughout. All sessions and their components were digitally recorded for later data analysis.

Through ongoing analysis of the data towards the end of the study, the decision was made to test the effects of the three reading conditions under an enhanced phase for the limited number of remaining sessions. During the enhanced phase the reading levels for all four participants was an increase of 6 months, and for the two participants (Fred 
and Ulysses) who functioned at a higher reading level, the number of words in the reading passages was increased by $50 \%$. The phase of data collection prior to these enhancements is referred to as "standard," whereas data collected after is referred to as "enhanced" (Note: standard and enhanced data are separated by a dashed line on all figures.)

Each of the participants was escorted independently to the research room and the following three components were conducted during each of the standard and enhanced phases.

Room preparation. The room where the sessions took place was prepared prior to each participant's arrival. A blank file folder with the passage for the day was waiting at the desk where the participant sat. The researcher had a blank file with the treatment fidelity form, the passage of the day, the flashcards of the five challenging words, and the corresponding questions.

Vocabulary instruction. The researcher began each session by introducing the passage of the day through vocabulary instruction. The researcher used flashcards to ascertain the participant's knowledge of five challenging words for the upcoming reading. These words were selected from the reading program's challenge word list. The researcher taught unknown words from the reading program to the student. The researcher asked the participant to read the word aloud. If the participant could not read the word, the researcher said the word aloud and asked the participant to repeat it back to him and use the word in a sentence. The researcher praised the participant and moved on to the next word if he said the word correctly. But, if the participant did not use the word in a sentence, the researcher would read the definition from the back of the card and ask 
the participant to use the word in a sentence aloud. If the participant still could not do this, the researcher used the word in a sentence that demonstrated its meaning. This lasted approximately 3-5 minutes depending on the number of words the student knew. After vocabulary instruction, the participants moved into one of three alternating treatments design conditions: repeated readings, non-repeated readings, or equivalent non-repeated readings.

Repeated Readings Condition. The repeated readings condition began with the participant reading a 100-150 word passage (100 word passages in the standard phase and 150 in the enhanced phase). During the initial reading or practice trial, a whole word error correction strategy was employed (Barbetta et al., 1993a). Whole word correction occurs when a participant makes a reading error; the researcher immediately reads the word correctly. After whole word correction, the participant repeated the word aloud as well as the entire sentence aloud. Once the passage was read aloud in its entirety, the words in which the participant made an error were reread aloud by the participant again in isolation. In addition, each session contained repeated readings (two additional readings or practice trials) of the $100-150$ word passages for a total of three readings or practice trials. The two additional readings or practice trials occurred following the initial reading of the passage and did not contain the error correction procedures. During the first minute of each of the three practice trials, reading fluency and errors data were kept for later analysis. After repeated readings, the participants moved into end-of-session assessments.

Non-Repeated Readings Condition. In the non-repeated readings condition, the participant was asked to read aloud one time only a 100-150 word passage (100 word 
passages in the standard phase and 150 in the enhanced phase) with the researcher employing the whole-word error correction procedures, identical to those used in the repeated readings condition.

Equivalent Non-Repeated Readings Condition. The equivalent non-repeated readings condition used procedures identical to the non-repeated readings condition with one difference: this session contained a 300-450 word passage (300 word passages in the standard phase and 450 in the enhanced phase) to equal the number of words read in the repeated readings condition.

\section{End of Session and Repeated Readings Practice Trial Assessments. Two}

digitally-recorded assessments were given at the end of each of the repeated, nonrepeated equivalent non-repeated and readings session components. First, an oral comprehension assessment was given which consisted of five literal comprehension questions. The researcher asked the questions aloud, one question at a time. The participant was given 5 seconds to answer each question. If the participant responded correctly, he or she received a short positive statement (such as "yes" or "correct") from the researcher. If the participant responded incorrectly, he or she was told the answer was incorrect with a brief statement followed by the correct answer (such as "no, the girl went to school, not to sleep"). The last question was followed by statements such as the ones listed above and then a statement of appreciation (such as "thank you"). After the literal comprehension question assessment, a 1-minute fluency reading assessment was administered in which the participant was asked to read the passage from the beginning for 1 minute. Oral reading fluency was measured by counting the number of words read aloud correctly during the 1-minute assessment, and errors per minute were measured by 
counting the number of reading errors made during that one minute.

In addition to the end of session assessments, data were collected and analyzed from the repeated readings practice trials to determine the effects of each of the three successive repeated readings practice trials per session on the oral reading fluency and errors per minute. The practice trial fluency and error data were determined by analyzing the first minute of reading during each of the practice trials using the same definitions as the end-of-session assessments.

\section{Chapter Summary}

An alternating treatments design was used to compare the effects of repeated readings, non-repeated and equivalent non-repeated readings on oral reading fluency, oral reading errors, and oral responses to literal comprehension questions of sixth-grade students with EBD who are struggling readers (1 year below grade level). Additionally, data were collected to examine the effects of each of the three successive repeated readings practice trials per session on the oral reading fluency and errors of the participants.

The participants for this proposed study were four, sixth-grade students with EBD who were struggling readers enrolled in an urban, separate day school for students who are EBD. These participants were nominated by their reading and language arts teacher to participate in this study.

The dependent variables for this proposed study were reading fluency, measured by the number of correct words read aloud per minute, the number of errors read aloud per minute, and the number of correct answers to literal comprehension questions. The reading fluency and error data were collected in 1-minute timed assessments at the end of 
each session's reading. Also, reading fluency and error data were collected during the first minute of each of the three practice trials during the repeated readings sessions. The comprehension data were collected in the form of five literal comprehension questions asked by the researcher at the end of the session's reading but before the fluency assessment. Also, IOA and treatment fidelity data were collected and reported for this study.

Pre-study procedures began with obtaining written permission from the principal and meeting the teachers at the educational center. The reading and language arts teacher recommended approximately seven potential participants. From these recommendations, the researcher selected the students who met the criteria of being EBD and struggling with reading. These students received forms, followed by telephone calls to obtain parent permission. The first four participants who returned their parental forms signed were chosen for the study. After parental permission was verified, the potential participants and the researcher read and discussed the participant assent form. Following this, an informal reading assessment was conducted on each participant. The independent observer was selected and trained. The reading materials were also prepared, organized, and randomly assigned to one of the three conditions prior to the start of the study.

The researcher conducted the study in a quiet classroom. Sessions were conducted one-on-one during 10-20 minute scheduled sessions. In all three conditions, the sessions began with the participants receiving vocabulary instruction. This was followed by the repeated readings, non-repeated readings, or equivalent non-repeated readings conditions. During the repeated readings condition, participants read aloud a passage of approximately 100 words in length in the standard phase and 150 words in the enhanced 
phase while receiving corrective feedback. Following this, the participants repeatedly read aloud the same passage two additional times (or practice trials) without error correction feedback. During the non-repeated readings condition, participants read aloud only once a passage of approximately 100 words in length in the standard phase and 150 words in the enhanced phase while receiving corrective feedback. While in the equivalent non-repeated readings condition, participants read aloud only once a passage of approximately 300 words in length in the standard phase and 450 words in the enhanced phase while receiving corrective feedback. In this phase, the number of words in each passage was equivalent to the total number of words read across the three practice trials of the repeated readings condition.

Immediately after the repeated, non-repeated or equivalent non-repeated readings, two end-of-session assessments were given. First, an oral comprehension assessment was given which consisted of five literal comprehension questions. The researcher asked these questions aloud and the participant responded orally. After the literal comprehension question assessment, a 1-minute fluency reading assessment was administered in which the participant was asked to read the passage from the beginning for 1 minute. Oral reading fluency was measured by counting the number of words read aloud correctly during the 1-minute assessment, and errors per minute was measured by correctly counting the number of reading errors. In addition to the end of session assessments, data were collected and analyzed from the repeated readings practice trials to determine the effects of each of the three successive repeated readings practice trials per session on the participants' oral reading fluency and errors per minute. All data were graphed for visually analysis. 


\section{Chapter IV}

\section{Results}

This chapter describes the findings of a study which used an alternating treatments design to examine the effects of repeated readings and two non-repeated readings conditions on the reading performances of sixth-grade students with emotional/behavioral disorders (EBD) who were struggling readers. The reading performances measured were the number of correct words read aloud per minute (WCPM), reading errors read aloud per minute (EPM), and literal comprehension questions answered correctly across three conditions: repeated readings, non-repeated readings and equivalent non-repeated readings. Each condition had two phases: standard and enhanced. The reading passages during the standard sessions were at the difficulty level and number of words per passage originally established in the study. During the enhanced sessions, the reading passage difficulty level was raised by 6 months for all participants and contained 50\% more words for two participants (Fred and Ulysses).

During repeated readings, participants read a short passage of approximately $100-150$ words, three times in a row with error correction in the initial reading (totaling 300 words in the standard phase and 450 in the enhanced phase). During non-repeated readings, a short passage of approximately 100 words in the standard phase and 150 words in the enhanced phase was read once with error correction. Finally, when participants were in the equivalent non-repeated readings condition, they read a passage of approximately 300-450 words in the standard and enhanced phases, respectively (equivalent to the number of words in the repeated readings condition). In addition, 
measures of WCPM and EPM were taken during each of the three repeated readings practice trials per session.

Presented first are the treatment fidelity and interobserver agreement (IOA) data. This is followed by the results of each participant's and the group's performances and on the dependent variables. In all figures, the data points to the left of the dashed lines represent performances during standard phase sessions and those to the right of the dashed lines represent data collected during enhanced phase sessions. Finally, this chapter concludes with a summary of the results.

\section{Treatment Fidelity}

The researcher and one trained independent observer collected treatment fidelity data to help confirm that procedures were followed as specified. The researcher collected data in every session (100\%) for all participants and all the conditions. These data indicated that procedures were being followed an average of $99.67 \%$ of the time (range 93.75-100) throughout all of the sessions. Additionally, an independent observer collected treatment fidelity data on 40 of 159 or $25 \%$ of the sessions for all participants across all conditions. The independent observer's data indicated that the procedures were being followed an average of $98.52 \%$ of the time (range $93.50-100)$.

\section{Interobserver Agreement}

For this study, one trained observer collected data for $25 \%$ of all sessions across all dependent variables. The mean IOA for reading fluency was 98.59\% (range 93.56100), for number of EPM was $95.67 \%$ (range 72.78-100), and the mean IOA for literal comprehension questions answered correctly was 94.65\% (range 90-100). 
Also, the observer collected reading fluency and errors per minute IOA for the three practice trials during $25 \%$ of the repeated reading sessions. For practice trial one, the mean IOA for reading fluency was $98.76 \%$ (range 95.62-100) and for errors per minute was $97.56 \%$ (range 94.57-100). Similarly, the mean fluency IOA for practice trials two and three for reading fluency was 95.86\% (range 93-100) and 97.25\% (range 94.55-100), and for errors per minute was 99.78\% (range 93.56-100) and 98.34\% (range 94.67-100) respectively.

\section{Reading Fluency}

This study was conducted, in part, to examine the effects of repeated readings and two non-repeated conditions on the oral reading fluency of sixth-grade students with EBD who also have reading challenges. Oral reading fluency was measured by counting the number of words read aloud correctly per minute during a 1-minute reading assessment at the end of each session. Each participant's reading fluency data per session are presented visually in Figure 1, and in Table 2, individual and group mean and range performances are presented.

\section{Gabriel}

Figure 1 and Table 2 display Gabriel's reading fluency performances during repeated, non-repeated, and equivalent non-repeated readings during the standard and enhanced phase. During standard sessions, Gabriel's mean repeated readings fluency performance, as measured in WCPM was 96.70 (range 89-104). His mean performance during non-repeated readings was 82.40 (range 73 -85) and during equivalent nonrepeated readings was 62.30 (range 51-69). 
During the standard phase, Gabriel's mean fluency performance was highest during repeated readings, with a mean performance of 14.30 WCPM over non-repeated readings and 35.50 over equivalent non-repeated readings. His second highest mean fluency performance was during non-repeated readings with a mean of 21.20 more words read correctly per minute than during equivalent non-repeated reading which was the condition in which his overall performance in reading fluency was lowest during the standard phase.

During the enhanced phase when the difficulty of the reading passages was raised 6 months, Gabriel's mean repeated readings fluency performance was 109.66 WCPM (range 107-112). His mean performance during non-repeated readings was 87.00 (range 86-88) and during equivalent non-repeated readings was 70.67 (range 69-73). During the enhanced phase, Gabriel's mean fluency performance was highest during repeated readings, with a mean performance of 22.66 WCPM over non-repeated readings and 38.99 over equivalent non-repeated readings.

His second highest mean fluency performance was during the non-repeated reading condition. This condition had a mean of 16.33 more words read correctly per minute than during equivalent non-repeated reading which was the condition in which his overall performance in reading fluency was lowest during the enhanced sessions.

\section{Kevin}

Figure 1 and Table 2 display Kevin's reading fluency performances during repeated, non-repeated, and equivalent non-repeated readings during the standard and 

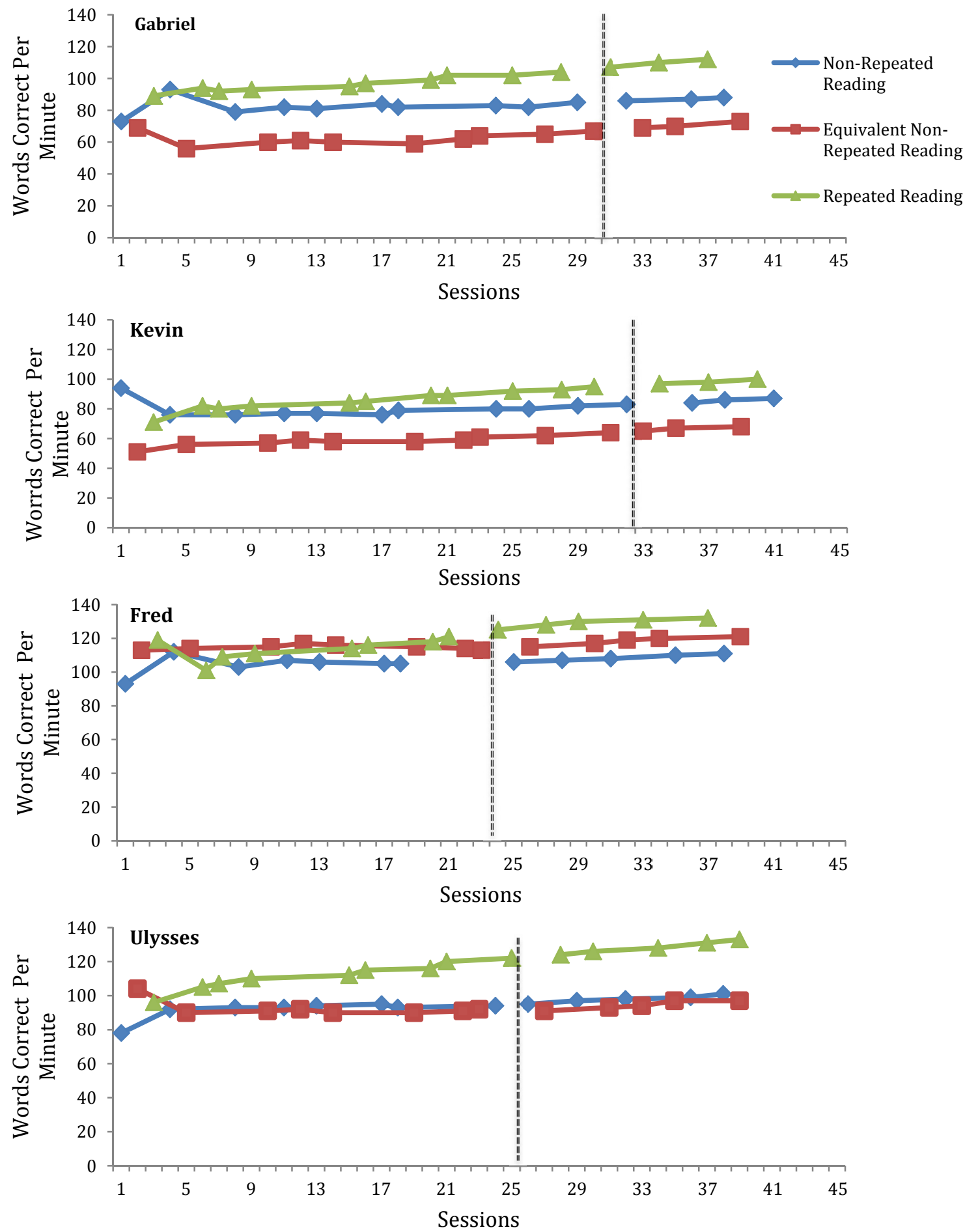

Figure 1. Reading Fluency (WCPM). Reading fluency as measured by the number of words read correctly per minute during a 1-minute fluency assessment at the end of each session. 
Table 2

Individual Means on Reading Fluency

\begin{tabular}{|c|c|c|c|c|c|c|}
\hline \multirow[b]{2}{*}{ Participant } & \multicolumn{2}{|c|}{ Repeated Reading } & \multicolumn{2}{|c|}{ Non-Repeated Reading } & \multicolumn{2}{|c|}{$\begin{array}{c}\text { Equivalent } \\
\text { Non-Repeated Readings }\end{array}$} \\
\hline & Standard & Enhanced & Standard & Enhanced & Standard & Enhanced \\
\hline \multirow[t]{2}{*}{ Gabriel } & 96.70 & 109.66 & 82.40 & 87.00 & 62.30 & 70.67 \\
\hline & $(89-104)$ & $(107-112)$ & $(73-85)$ & $(86-88)$ & $(51-69)$ & $(69-73)$ \\
\hline \multirow[t]{2}{*}{ Kevin } & 85.64 & 98.33 & 80.00 & 85.67 & 58.50 & 66.67 \\
\hline & $(71-95)$ & $(97-100)$ & $(76-84)$ & $(84-87)$ & $(51-64)$ & $(65-68)$ \\
\hline \multirow[t]{2}{*}{ Fred } & 113.63 & 129.20 & 104.43 & 108.40 & 114.63 & 118.40 \\
\hline & $(101-121)$ & $(125-132)$ & $(93-112)$ & $(106-111)$ & $(113-117)$ & $(115-121)$ \\
\hline \multirow[t]{2}{*}{ Ulysses } & 111.44 & 128.40 & 91.50 & 98.00 & 92.50 & 94.40 \\
\hline & $(96-122)$ & $(124-133)$ & $(78-95)$ & $(95-101)$ & $(90-104)$ & $(91-97)$ \\
\hline \multirow[t]{2}{*}{ Group } & 100.55 & 119.50 & 87.97 & 96.88 & 79.58 & 92.25 \\
\hline & $(71-122)$ & $(97-133)$ & $(87-97)$ & (84-111) & $(51-117)$ & $(65-121)$ \\
\hline
\end{tabular}

Note. The top numbers indicate individual mean number of words read correctly per minute. The bottom numbers represent the range of scores. The standard sessions are those in which the reading passages were at the difficulty level and/or number of words originally established in the study. During the enhanced sessions, for all participants the reading passage difficulty was increased by 6 months. In addition, for Fred and Ulysses, the passages contained 50\% more words. Group mean was calculated by adding the total number of group sessions completed by all four participants and dividing that total by the number of individual sessions.

enhanced phase. During the standard phase, Kevin's mean repeated readings fluency performance, as measured in WCPM, was 85.64(range 71-95). His mean performance during non-repeated readings was 80.00 (range 76-84) and during equivalent nonrepeated readings was 58.50 (range 51-64). During the standard phase, Kevin's mean fluency performance was highest during repeated readings, with a mean performance of 5.64 WCPM over non-repeated readings and 27.14 WCPM over equivalent non-repeated readings. His second highest mean fluency performance was during non-repeated 
readings with a mean of 21.50 more words read correctly per minute than during equivalent non-repeated reading which was the condition in which his overall performance in reading fluency was lowest during the standard phase.

During the enhanced phase when the difficulty of the reading passages was raised 6 months, Kevin's mean repeated readings fluency performance was 98.33 WCPM (range 97-100). His mean performance during non-repeated readings was 85.67 (range 84-87) and during equivalent non-repeated readings was 66.67 (range 65-68). During enhanced sessions, Kevin's mean fluency performance was highest during repeated readings, with a mean performance of $12.66 \mathrm{WCPM}$ over non-repeated readings and 31.66 WCPM over equivalent non-repeated readings. His second highest mean fluency performance was during non-repeated reading with a mean of 19.00 more words read correctly per minute than during equivalent non-repeated reading, which was the condition in which his overall performance in reading fluency was lowest during the enhanced phase.

\section{Fred}

Figure 1 and Table 2 display Fred's reading fluency performances during repeated, non-repeated, and equivalent non-repeated readings during the standard and enhanced phase. During standard sessions, Fred's mean repeated readings fluency performance, as measured in WCPM, was 113.63 (range 101-121). His mean performance during non-repeated readings was 104.42 (range 93-112) and during equivalent non-repeated readings was 114.63 (range 113-117). During the standard phase, Fred's mean fluency performance was highest during equivalent non-repeated readings, with a mean performance of only 1.00 WCPM over repeated readings and 10.21 
WCPM over non-repeated readings. His second highest mean fluency performance was during repeated readings with a mean of 9.21 more words read per minute than during non-repeated reading, which was the condition in which his overall performance in reading fluency was lowest during the standard phase.

During the enhanced phase when the difficulty of the reading passages was raised 6 months and reading passages contained 50\% more words, Fred's mean repeated readings fluency performance was 129.20 WCPM (range 125-132). His mean fluency performance during non-repeated readings was 108.40 (range 106-111) and during equivalent non-repeated readings was 118.40 (range 115-121). During enhanced sessions, Fred's mean fluency performance was highest during repeated readings, with a mean performance of $10.80 \mathrm{WCPM}$ over equivalent non-repeated readings and 20.80 WCPM over non-repeated readings. His second highest mean fluency performance was during equivalent non-repeated reading with a mean of 10.00 more words read correctly per minute than during non-repeated reading, which was the condition in which his overall performance in reading fluency was lowest during the enhanced phase.

\section{Ulysses}

Figure 1 and Table 2 displays Ulysses' reading fluency performances during repeated, non-repeated, and equivalent non-repeated readings during standard and enhanced sessions. During the standard phase, Ulysses' mean repeated readings fluency performance, as measured in WCPM, was 111.44 (range 96-122). His mean performance during non-repeated readings was 91.50 (range 78-95) and during equivalent nonrepeated readings was 92.50 (range 90-104). During the standard phase, Ulysses' mean fluency performance was highest during repeated readings, with a mean performance of 
18.94 WCPM over equivalent non-repeated readings and 19.94 WCPM over nonrepeated readings. His second highest mean fluency performance was during equivalent non-repeated readings with a mean of 1.00 more words read correctly per minute than during non-repeated reading, which was the condition in which his overall performance in reading fluency was lowest during the standard phase.

During the enhanced phase when the difficulty of the reading passages was raised 6 months and the reading passages contained 50\% more words Ulysses' mean repeated readings fluency performance was 128.40 (range 124-133). His mean performance during non-repeated readings was 98.00 (range 95-101) and during equivalent non-repeated readings was 94.40 (range 91-97). During the enhanced phase, Ulysses' mean fluency performance was highest during repeated readings, with a mean performance of 30.40 WCPM over non-repeated readings and 34.00 WCPM over equivalent non-repeated readings. His second highest mean fluency performance was during non-repeated reading with a mean of 3.60 more words read per minute than during equivalent non-repeated reading, which was the condition in which his overall performance in reading fluency was lowest during the enhanced phase.

\section{Errors Per Minute}

This study was conducted, in part, to examine the effects of repeated readings and two non-repeated conditions on the errors per minute (EPM)by sixth-grade students with emotional and behavioral disorders (EBD) who have reading challenges. Errors per minute were measured by counting the number of omission, addition, substitution, mispronunciation, and hesitation reading errors during a 1-minute reading assessment at 
the end of each session. Each participant's EPM data per session are presented visually in Figure 2 In Table 3 individual and group mean and range performances are presented.

\section{Gabriel}

Figure 2 and Table 3 display Gabriel's EPM performance in repeated, nonrepeated, and equivalent non-repeated readings during the standard and enhanced phase During the standard phase, Gabriel's mean EPM repeated readings performance was 3.60 (range 2-5). His mean EPM performance during non-repeated readings was 4.00 (range 3-6) and during equivalent non-repeated readings was 4.50 (range 3-5). During the standard phase, Gabriel's mean number of reading errors was least during repeated readings, with 0.40 fewer EPM made during non-repeated readings and 0.90 fewer than during equivalent non-repeated readings. The condition in which he made the second least mean number of EPM was non-repeated readings with a mean of 0.50 fewer EPM than during equivalent non-repeated readings, which was the condition in which he made the highest number of EPM during the standard phase.

During the enhanced phase when the difficulty of the reading passages was raised six months, Gabriel's mean EPM repeated readings performance was 3.33 (range 3-4). His mean EPM performance during non-repeated readings was 4.00 (range 4-4) and during equivalent non-repeated readings was 5.33 (range 5-6). During the enhanced phase, Gabriel's mean number of reading errors was least during repeated readings, with 0.67 fewer EPM made during non-repeated readings and 2.00 fewer than during equivalent non-repeated readings. The condition in which he made the second least mean number of EPM was non-sequential readings with a mean of 1.33 fewer EPM than during 

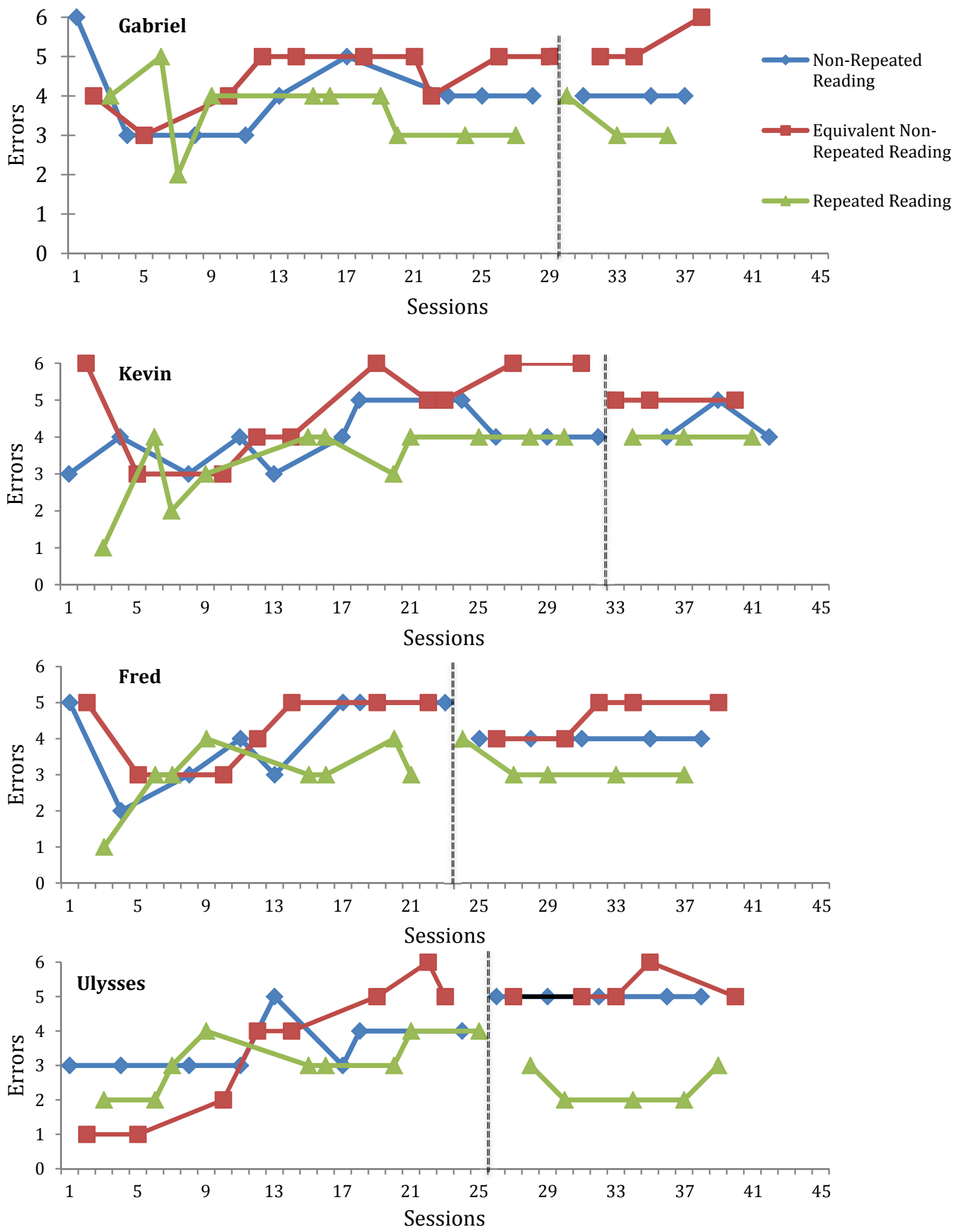

Figure 2. Errors per Minute (EPM). Reading fluency as measured by the number of words read correctly per minute during a 1-minute fluency assessment at the end of each session. 
Table 3

Individual Mean Errors Per Minute

\begin{tabular}{|c|c|c|c|c|c|c|}
\hline \multirow[b]{2}{*}{ Participant } & \multicolumn{2}{|c|}{ Repeated Reading } & \multicolumn{2}{|c|}{$\begin{array}{c}\text { Non-Repeated } \\
\text { Reading }\end{array}$} & \multicolumn{2}{|c|}{$\begin{array}{l}\text { Equivalent Non- } \\
\text { Repeated Readings }\end{array}$} \\
\hline & Standard & Enhanced & Standard & Enhanced & Standard & Enhanced \\
\hline \multirow[t]{2}{*}{ Gabriel } & 3.60 & 3.33 & 4.00 & 4.00 & 4.50 & 5.33 \\
\hline & $(2-5)$ & $(3-4)$ & $(3-6)$ & $(4-4)$ & $(3-5)$ & $(5-6)$ \\
\hline \multirow[t]{2}{*}{ Kevin } & 3.36 & 3.00 & 3.91 & 4.33 & 4.81 & 5.00 \\
\hline & $(1-4)$ & $(3-4)$ & $(3-5)$ & $(4-5)$ & $(3-6)$ & $(5-5)$ \\
\hline \multirow[t]{2}{*}{ Fred } & 3.00 & 3.20 & 4.00 & 4.40 & 4.28 & 4.60 \\
\hline & $(1-4)$ & $(3-4)$ & $(2-5)$ & $(4-4)$ & $(3-5)$ & $(4-5)$ \\
\hline \multirow[t]{2}{*}{ Ulysses } & 3.11 & 2.40 & 3.50 & 4.00 & 3.50 & 5.20 \\
\hline & $(2-4)$ & $(2-3)$ & $(3-5)$ & $(5-5)$ & $(1-5)$ & $(5-6)$ \\
\hline \multirow[t]{2}{*}{ Group } & 3.28 & 3.13 & 3.86 & 4.37 & 4.31 & 5.00 \\
\hline & $(1-5)$ & $(2-4)$ & $(2-6)$ & $(5-5)$ & $(1-6)$ & $(4-6)$ \\
\hline
\end{tabular}

Note. The top numbers indicate individual mean number of words read correctly per minute. The bottom numbers represent the range of scores. The standard sessions are those, which the reading passages were at the difficulty level and number of words originally established in the study. During the enhanced sessions, for all participants the reading passage difficulty was increased by 6 months. In addition, for Fred and Ulysses, the passages contained 50\% more words. Group mean was calculated by adding the total number of group sessions completed by all four participants and dividing that total by the number of individual sessions.

equivalent non-repeated readings, which was the condition in which he made the highest number of EPM during the enhanced phase.

\section{Kevin}

Figure 2 and Table 3 display Kevin's EPM performance in repeated, nonrepeated, and equivalent non-repeated readings during the standard and enhanced phase. During standard sessions, Kevin's mean EPM repeated readings performance was 3.36 
(range 1-4). His mean EPM performance during non-repeated readings was 3.91 (range 3-5) and during equivalent non-repeated readings was 4.81 (range 3-6). During the standard phase, Kevin's mean number of reading errors was least during repeated readings, with 0.55 fewer EPM made during non-repeated readings and 1.45 fewer than during equivalent non-repeated readings. The condition in which he made the second least mean number of EPM was non-repeated readings with a mean of 0.90 fewer EPM than during equivalent non-repeated readings, which was the condition in which he made the highest number of EPM during the standard phase.

During the enhanced phase, when the difficulty of the reading passages was raised six months, Kevin's mean EPM repeated readings performance was 3.00 (range 3-4). His mean EPM performance during non-repeated readings was 4.33 (range 4-5) and during equivalent non-repeated readings was 5.00 (range 5-5).

During the enhanced phase, Kevin's mean number of reading errors was least during repeated readings, with 1.33 fewer EPM made during non-repeated readings and 2.00 fewer made during equivalent non-repeated readings. The condition in which he made the second least mean number of EPM was non-repeated readings with a mean of 0.67 fewer EPM than during non-repeated readings, which was the condition in which he made the highest number of EPM during the enhanced phase.

\section{Fred}

Figure 2 and Table 3 display Fred's EPM performance in repeated, non-repeated, and equivalent non-repeated readings during the standard and enhanced phase. During standard sessions, Fred's mean EPM repeated readings performance was 3.00 (range 14). His mean EPM performance during non-repeated readings was 4.00 (range 2-5) and 
during equivalent non-repeated readings was 4.28 (range 3-5). During the standard phase, Fred's mean number of reading errors was least during repeated readings, with 1.00 fewer EPM made during non-repeated readings and 1.28 during equivalent nonrepeated readings. The condition in which he made the second least mean number of EPM was equivalent non-repeated readings with a mean of 0.28 fewer EPM than during non-repeated readings, which was the condition in which he made the highest number of EPM during the standard phase.

During the enhanced phase when the difficulty of the reading passages was raised six months and the number of words in the passages increased by 50\%, Fred's mean EPM repeated readings performance was 3.20 (range 3-4). His mean EPM performance during non-repeated readings was 4.40 (range 4-4) and during equivalent non-repeated readings was 4.60 (range 4-5). During the enhanced phase, Fred's mean number of reading errors was least during repeated readings, with 1.20 fewer EPM made during non-repeated readings and 1.40 during equivalent non-repeated readings. The condition in which he made the second least mean number of EPM was non-repeated readings with a mean of 0.20 fewer EPM than during equivalent non-repeated readings, which was the condition in which he made the highest number of EPM during the enhanced phase.

\section{Ulysses}

Figure 2 and Table 3 display Ulysses’ EPM performance in repeated, nonrepeated, and equivalent non-repeated readings during the standard and enhanced phase. During the standard phase, Ulysses' mean EPM repeated readings performance was 3.11 (range 2-4). His mean EPM performance during non-repeated readings was 3.50 (range 3-5) and during equivalent non-repeated readings was 3.50 (range 1-5). During the 
standard phase, Ulysses' mean number of reading errors was least during repeated readings, with 0.39 fewer EPM made during equivalent non-repeated readings and 0.39 during non-repeated readings. The condition in which he made the second least mean number of EPM was a tie between equivalent non-repeated readings and non-repeated readings with a mean of 0.50 fewer EPM during the standard phase.

During the enhanced phase when the difficulty of the reading passages was raised 6 months and the number of words in the passages increased by $50 \%$, Ulysses' mean EPM repeated readings performance was 2.40 (range 2-3). His mean EPM performance during non-repeated readings was 4.00 (range 5-5) and during equivalent non-repeated readings was 5.20 (range 5-6). During the enhanced phase, Ulysses' mean number of reading errors was least during repeated readings, with 1.60 fewer EPM made during non-repeated readings and2.80during equivalent non-repeated readings. The condition in which he made the second least mean number of EPM was non-repeated readings with a mean of 1.20 fewer EPM than during equivalent non-repeated readings, which was the condition in which he made the highest number of EPM during the standard phase.

\section{Correct Answers to Literal Comprehension Questions}

This study was conducted, in part, to examine the effects of two non-repeated conditions, and a repeated readings condition on the correct answers to reading comprehension questions by sixth-grade students with EBD who also had reading challenges. Reading comprehension was measured by counting the number of correct answers to five literal comprehension questions given after the end of each session. Each participant's reading comprehension data per session are presented visually in Figure 3, The data points to the left of the dashed line represent performances during the standard 
phase in which the reading passages were at the difficulty level and number of words originally established in the study. Data points to the right of the dashed line represent data collected during the enhanced phase where the reading passage difficulty level was raised by 6 months and/or reading passages contained 50\% more words. In Table 3 , individual and group mean and range performances are presented.

\section{Gabriel}

Figure 3 and Table 4 display Gabriel's literal comprehension question performance during repeated, non-repeated, and equivalent non-repeated readings during the standard and enhanced phase. During standard sessions, Gabriel's mean number of correct answers to literal comprehension questions during repeated readings was 4.20 (range 2-5). His mean performance during non-repeated readings was 2.20 (range $1-3$ ) and during equivalent non-repeated readings was 3.20 (range 2-5). During the standard phase, Gabriel's mean number of correct answers to literal comprehension questions was highest during repeated readings, with a mean performance of 2.00 over non-repeated readings and 1.00 over equivalent non-repeated readings. His second highest mean number of correct answers to literal comprehension questions was during equivalent nonrepeated readings with a mean of 1.00 more questions answered correctly than during non-repeated readings, which was the condition in which his overall performance in reading comprehension was lowest during the standard phase.

During the enhanced phase when the difficulty of the reading passages was raised 6 months, during repeated readings, Gabriel's mean number of correct answers to literal comprehension questions was 5.00 (range 5-5). His mean performance during nonrepeated readings was 3.00 (range 3-3) and during equivalent non-repeated readings was 

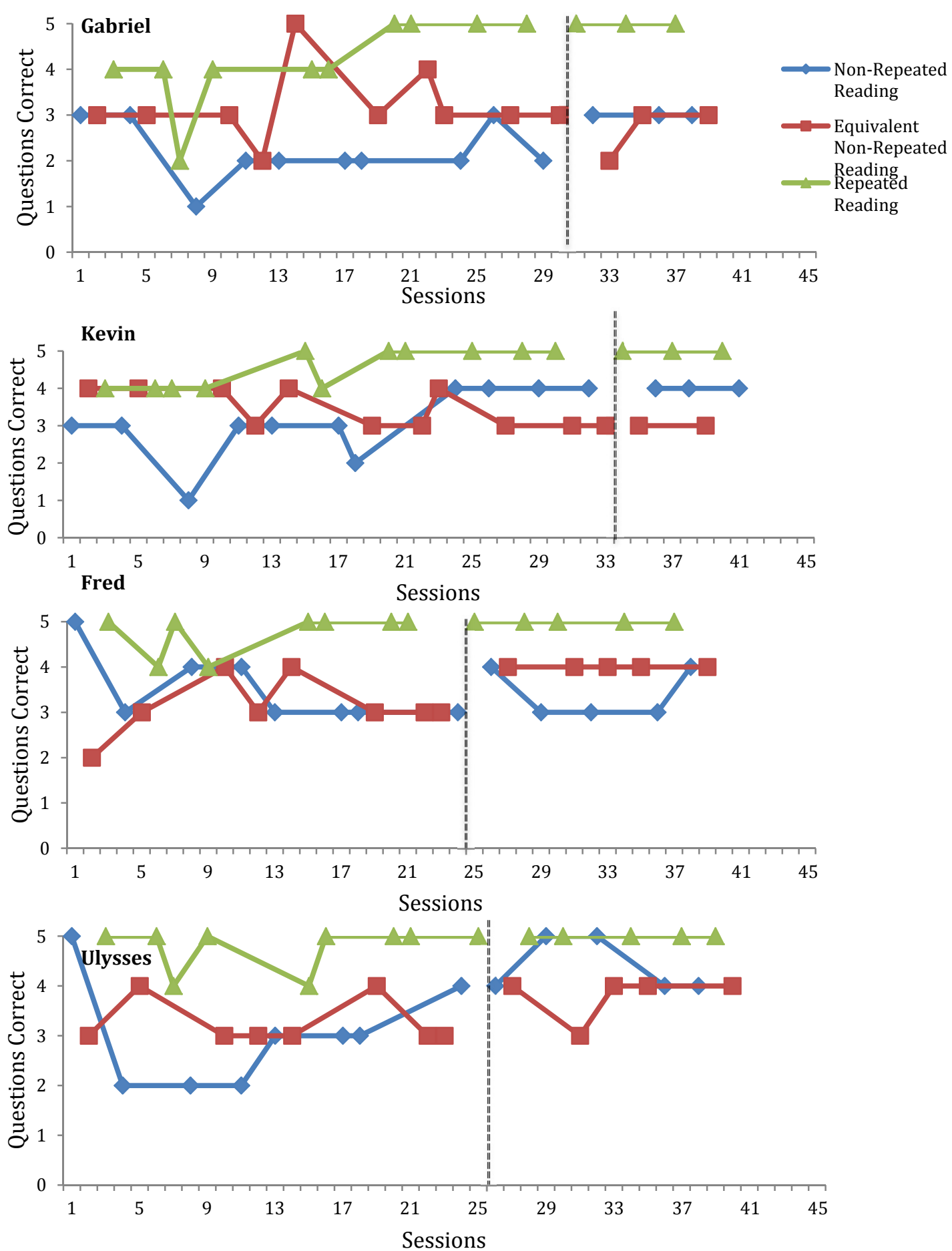

Figure 3. Correct Answers to Comprehension Questions

Literal Comprehension as measured by the number of literal comprehension questions answered correctly during the 5-question assessment at the end of each session. 
Table 4

Individual Mean of Literal Comprehension Questions Answered Correctly

\begin{tabular}{|c|c|c|c|c|c|c|}
\hline \multirow[b]{2}{*}{ Participant } & \multicolumn{2}{|c|}{ Repeated Reading } & \multicolumn{2}{|c|}{$\begin{array}{c}\text { Non-Repeated } \\
\text { Reading } \\
\end{array}$} & \multicolumn{2}{|c|}{$\begin{array}{c}\text { Equivalent Non- } \\
\text { Repeated Readings }\end{array}$} \\
\hline & Standard & Enhanced & Standard & Enhanced & Standard & Enhanced \\
\hline \multirow[t]{2}{*}{ Gabriel } & 4.20 & 5.00 & 2.20 & 3.00 & 3.20 & 2.66 \\
\hline & $(2-5)$ & $(5-5)$ & $(1-3)$ & $(3-3)$ & $(2-5)$ & $(2-3)$ \\
\hline \multirow[t]{2}{*}{ Kevin } & 4.55 & 5.00 & 3.09 & 3.00 & 3.50 & 3.00 \\
\hline & $(4-5)$ & $(5-5)$ & $(1-4)$ & $(4-4)$ & $(3-4)$ & $(3-3)$ \\
\hline \multirow[t]{2}{*}{ Fred } & 4.75 & 5.00 & 3.50 & 3.40 & 3.13 & 4.00 \\
\hline & $(4-5)$ & $(5-5)$ & $(3-5)$ & $(3-4)$ & $(2-4)$ & $(4-4)$ \\
\hline \multirow[t]{2}{*}{ Ulysses } & 4.78 & 5.00 & 3.00 & 4.40 & 3.25 & 3.80 \\
\hline & $(4-5)$ & $(5-5)$ & $(2-5)$ & $(4-5)$ & $(3-4)$ & $(3-4)$ \\
\hline \multirow[t]{2}{*}{ Group } & 4.55 & 5.00 & 2.92 & 3.75 & 3.28 & 3.50 \\
\hline & $(2-5)$ & $(5-5)$ & $(1-5)$ & $(3-5)$ & $(2-5)$ & $(2-4)$ \\
\hline
\end{tabular}

Note. The top numbers indicate individual mean number of words read correctly per minute. The bottom numbers represent the range of scores. The standard sessions are those, which the reading passages were at the difficulty level and number of words originally established in the study. During the enhanced sessions, for all participants the reading passage difficulty was increased by 6 months. In addition, for Fred and Ulysses, the passages contained 50\% more words. Group mean was calculated by adding the total number of group sessions completed by all four participants and dividing that total by the number of individual sessions.

2.66 (range 2-3). During the enhanced phase, Gabriel's mean literal comprehension performance was highest during repeated readings, with a mean performance of 2.00 correct answers over non-repeated readings and 2.34 over equivalent non-repeated readings. His second highest mean literal comprehension performance was during nonrepeated readings with a mean of 0.34 more correct answers than during equivalent nonrepeated condition, which was the condition in which his overall performance in literal comprehension performance was lowest during the enhanced phase. 


\section{Kevin}

Figure 3 and Table 4 display Kevin's literal comprehension question performance

during repeated, non-repeated, and equivalent non-repeated readings during standard and enhanced sessions. During the standard phase, Kevin's mean number of correct answers to literal comprehension questions during repeated readings was 4.55 (range 4-5). His mean performance during non-repeated readings was 3.09 (range 1-4) and during equivalent non-repeated readings was 3.50 (range 3-4). During the standard phase, Kevin's mean number of correct answers to literal comprehension questions was highest during repeated readings, with a mean performance of 1.46 over non-repeated readings and 1.05 over equivalent non-repeated readings. His second highest mean number of correct answers to literal comprehension questions was during equivalent non-repeated readings with a mean of 0.41 more questions answered correctly than during nonrepeated readings, which was the condition in which his overall performance in reading comprehension was lowest during the standard phase.

During the enhanced phase when the difficulty of the reading passages was raised 6 months, during repeated readings, Kevin's mean number of correct answers to literal comprehension questions was 5.00 (range 5-5). His mean performance during nonrepeated readings was 3.00 (range 4-4) and during equivalent non-repeated readings was 3.00 (range 3-3). During the enhanced phase, Kevin's mean literal comprehension performance was highest during repeated readings, with a mean performance of 2.00 correct answers over non-repeated readings and 2.00 over equivalent non-repeated readings. The condition in which he made the second least mean number off correct 
answers was a tie between equivalent non-repeated readings and non-repeated readings with a mean of 2.00 correct answers to literal comprehension questions during the enhanced phase.

\section{Fred}

Figure 3 and Table 4 display Fred's literal comprehension question performance during repeated, non-repeated, and equivalent non-repeated readings the during standard and enhanced phase. During standard sessions, Fred's mean number of correct answers to literal comprehension questions during repeated readings was 4.75 (range 4-5). His mean performance during non-repeated readings was 3.50 (range 3-5) and during equivalent non-repeated readings was 3.13 (range 2-4). During the standard phase, Fred's mean number of correct answers to literal comprehension questions was highest during repeated readings, with a mean performance of 1.25 over non-repeated readings and 1.62 over equivalent non-repeated readings. His second highest mean number of correct answers to literal comprehension questions was during non-repeated readings with a mean of 0.37 more questions answered correctly than during equivalent non-repeated readings, which was the condition in which his overall performance in reading comprehension was lowest during the standard phase.

During the enhanced phase when the difficulty of the reading passages was raised 6 months and the number of words in each passage increased by $50 \%$, during repeated readings, Fred's mean number of correct answers to literal comprehension questions was 5.00 (range 5-5). His mean performance during non-repeated readings was 3.40 (range 34) and during equivalent non-repeated readings was 4.00 (range 4-4). During the enhanced phase, Fred's mean literal comprehension performance was highest during 
repeated readings, with a mean performance of 1.00 correct answers over equivalent nonrepeated readings and 1.60 over non-repeated readings. His second highest mean literal comprehension performance was during equivalent non-repeated readings with a mean of

0.60 more correct answers than during non-repeated condition which was the condition in which his overall performance in literal comprehension performance was lowest during the enhanced phase.

\section{Ulysses}

Figure 3 and Table 4 display Ulysses' literal comprehension question performance during repeated, non-repeated, and equivalent non-repeated readings during the standard and enhanced phase. During the standard phase, Ulysses' mean number of correct answers to literal comprehension questions during repeated readings was 4.78 (range 4-5). His mean performance during non-repeated readings was 3.00 (range 2-5) and during equivalent non-repeated readings was 3.25 (range 3-4). During the standard phase, Ulysses' mean number of correct answers to literal comprehension questions was highest during repeated readings, with a mean performance of 1.78 over non-repeated readings and 1.53 over equivalent non-repeated readings. His second highest mean number of correct answers to literal comprehension questions was during equivalent nonrepeated readings with a mean of 0.25 more questions answered correctly than during non-repeated readings, which was the condition in which his overall performance in reading comprehension was lowest during the standard phase.

During the enhanced phase when the difficulty of the reading passages was raised six months and the number of words in passages increased by $50 \%$, during repeated readings, Fred's mean number of correct answers to literal comprehension questions was 
5.00 (range 5-5). His mean performance during non-repeated readings was 4.40 (range 4 5) and during equivalent non-repeated readings was 3.80 (range 3-4). During the enhanced phase, Ulysses' mean literal comprehension performance was highest during repeated readings, with a mean performance of 0.60 correct answers over non-repeated readings and 1.20 over equivalent non-repeated readings. His second highest mean literal comprehension performance was during non-repeated readings with a mean of 0.60 more correct answers than during equivalent non-repeated condition, which was the condition in which his overall performance in literal comprehension performance was lowest during the enhanced phase.

\section{Repeated Reading Practice Trials Reading Fluency}

This study was conducted, in part, to examine the effects of each of the three successive repeated readings practice trials per session on the oral reading fluency of sixth-grade students with EBD who had reading challenges. Oral reading fluency per repeated readings practice trial was measured by counting the WCPM of each of the three repeated readings practice trials during each session. Each participant's reading fluency data per repeated readings practice trials are presented visually in Figure 4. The data points to the left of the dashed line represent performances during the standard phase in which the reading passages were at the difficulty level and number of words originally established in the study. Data points to the right of the dashed line represent data collected during enhanced sessions where the reading passage difficulty level was raised by 6 months and/ reading passages contained 50\% more words for Fred and Ulysses. In

Table 5, individual and group mean and range performances are presented. 


\section{Gabriel}

Figure 4 and Table 5 display Gabriel's reading fluency performances during the

first, second, and third repeated readings practice trials per session (referred to as Practice Trials One, Two, and Three). During the standard phase, Gabriel's mean Practice Trial One repeated readings fluency performance, as measured in words correct per minute (WCPM), was 88.70(range 72-95). His mean Practice Trial Two repeated readings fluency performance was 91.70 (range 76 -99), and his mean Practice Trial Three was 94.80 (range 78-103). During the standard phase, Gabriel's mean fluency performance during repeated readings practice trials successively increased from the first through the third trials with a mean of 3.00 more WCPM from Practice Trial One to Practice Trial Two and 3.10 more words read correctly from Practice Trial Two to Practice Trial Three. From Practice Trial One to Practice Trial Three there was a mean increase of 6.10 more WCPM.

During the enhanced phase when the difficulty of the reading passages was raised 6 months, Gabriel's mean Practice Trial One repeated readings fluency performance was 102.33 WCPM (range 100-105). His mean Practice Trial Two repeated readings fluency performance was 106.67 WCPM (range 102-109), and his mean Practice Trial Three was 109.33 WCPM (range 106-112). During the enhanced phase when the difficulty of the reading passages was raised 6 months, Gabriel's mean fluency performance during 

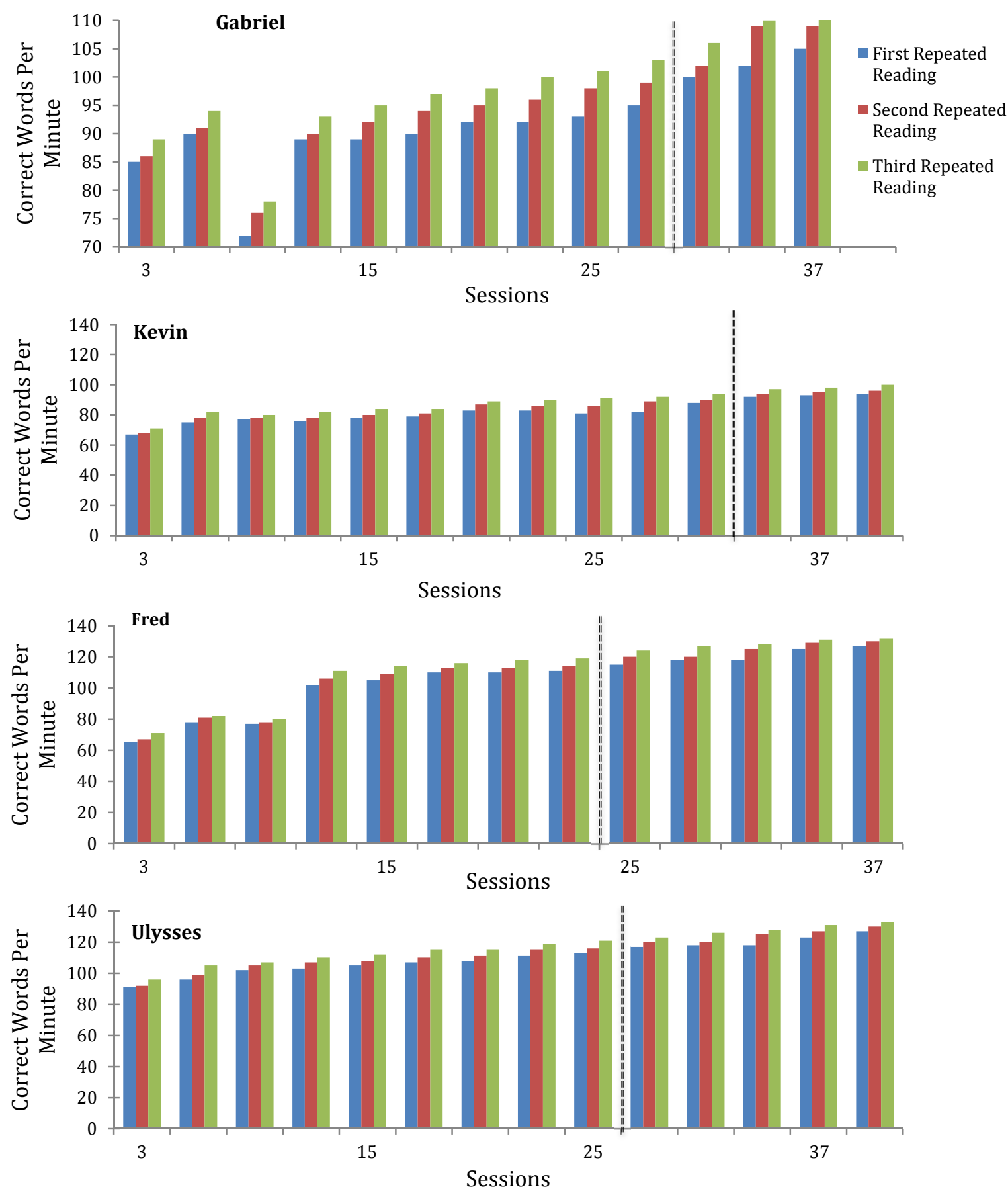

Figure 4. Repeated Reading Fluency is measured by the number of correct words per minute read at the end of each session of repeated reading. 


\section{Table 5}

Individual Mean of Repeated Readings Practice Trials-Fluency

\begin{tabular}{|c|c|c|c|c|c|c|}
\hline \multirow[b]{2}{*}{ Participants } & \multicolumn{3}{|c|}{ Reading Fluency-Standard } & \multicolumn{3}{|c|}{ Reading Fluency-Enhanced } \\
\hline & $\begin{array}{l}\text { Practice } \\
\text { One }\end{array}$ & $\begin{array}{l}\text { Practice } \\
\text { Two }\end{array}$ & $\begin{array}{l}\text { Practice } \\
\text { Three }\end{array}$ & $\begin{array}{l}\text { Practice } \\
\text { One }\end{array}$ & $\begin{array}{l}\text { Practice } \\
\text { Two }\end{array}$ & $\begin{array}{l}\text { Practice } \\
\text { Three }\end{array}$ \\
\hline \multirow[t]{2}{*}{ Gabriel } & 88.70 & 91.70 & 94.80 & 102.33 & 106.67 & 109.33 \\
\hline & $(72-95)$ & $(76-99)$ & $\begin{array}{l}(78- \\
103)\end{array}$ & $(100-105)$ & $102-109$ & $(106-112)$ \\
\hline \multirow[t]{2}{*}{ Kevin } & 79.00 & 81.91 & 85.36 & 93.00 & 95.00 & 98.33 \\
\hline & $(67-88)$ & $(68-90)$ & (71.94) & $(92-94)$ & $(94-96)$ & $(97-100)$ \\
\hline \multirow[t]{2}{*}{ Fred } & 94.75 & 97.62 & 101.38 & 120.60 & 124.80 & 128.40 \\
\hline & $(65-111)$ & $(67-114)$ & $\begin{array}{l}(71- \\
119)\end{array}$ & $(115-127)$ & $(120-130)$ & $(124-132)$ \\
\hline \multirow[t]{2}{*}{ Ulysses } & 104.00 & 107.00 & 111.11 & 120.60 & 124.40 & 128.20 \\
\hline & $(91-113)$ & $(92-116)$ & $\begin{array}{l}(96- \\
121)\end{array}$ & $(117-121)$ & $(120-130)$ & $(123-133)$ \\
\hline \multirow[t]{2}{*}{ Group } & 90.79 & 96.27 & 97.32 & 112.00 & 115.69 & 119.13 \\
\hline & $(65-113)$ & $(67-116)$ & $\begin{array}{l}(71- \\
121)\end{array}$ & $(92-127)$ & $(94-130)$ & $(97-133)$ \\
\hline
\end{tabular}

Note. The top numbers indicate individual mean number of words read correctly per minute. The bottom numbers represent the range of scores. The standard sessions are those, which the reading passages were at the difficulty level and number of words originally established in the study. During the enhanced sessions, for all participants the reading passage difficulty was increased by 6 months. In addition, for Fred and Ulysses, the passages contained 50\% more words. Group mean was calculated by adding the total number of group sessions completed by all four participants and dividing that total by the number of individual sessions.

repeated readings practice trials successively increased from the first through the third trials with a mean of 4.34 more WCPM from Practice Trial One to Practice Trial Two and 2.66 more words read correctly from Practice Trial Two to Practice Trial Three. From Practice Trial One to Practice Trial Three there was a mean increas of 7.00 more WCPM. 


\section{Kevin}

Figure 4 and Table 5 display Kevin's reading fluency performances during the

first, second, and third practice repeated readings practice trials per session (referred to as Practice Trials One, Two, and Three). During the standard phase, Kevin's mean Practice Trial One repeated readings fluency performance, as measured in WCPM, was 79.00 (range 67-88). His mean Practice Trial Two repeated readings fluency performance was 81.91 (range 68-90), and his mean Practice Trial Three was 85.36 (range 71-94). During the standard phase, Kevin's mean fluency performance during repeated readings practice trials successively increased from the first through the third trials with a mean of 2.91 more WCPM from Practice Trial One to Practice Trial Two and 3.45 more WCPM from Practice Trial Two to Practice Trial Three. From Practice Trial One to Practice Trial Three there was a mean increase of 6.36 more WCPM.

During the enhanced phase when the difficulty of the reading passages was raised 6 months, Kevin's mean Practice Trial One repeated readings fluency performance, as measured in correct words per minute (WCPM), was 93.00 (range 92-94). His mean Practice Trial Two repeated readings fluency performance was 95.00 (range 94-96), and his mean Practice Trial Three was 98.33 (range 97-100). During the enhanced phase, Kevin's mean fluency performance during repeated readings practice trials successively increased from the first through the third trials with a mean of 2.00 more WCPM from Practice Trial One to Practice Trial Two and 3.33 more WCPM from Practice Trial Two to Practice Trial Three. From Practice Trial One to Practice Trial Three there was a mean increase of 5.33 more WCPM. 


\section{Fred}

Figure 4 and Table 5 display Fred's reading fluency performances during the first, second, and third practice repeated readings practice trials per session (referred to as Practice Trials One, Two, and Three). During the standard phase, Fred's mean Practice Trial One repeated readings fluency performance, as measured in correct words per minute (WCPM), was 94.75(range 65-111). His mean Practice Trial Two repeated readings fluency performance was 97.62 (range 67-114), and his mean Practice Trial Three was 101.38 (range 71-119). During the standard phase, Fred's mean fluency performance during repeated readings practice trials successively increased from the first through the third trials with a mean of 2.87 more WCPM from Practice Trial One to Practice Trial Two and 3.76 more WCPM from Practice Trial Two to Practice Trial Three. From Practice Trial One to Practice Trial Three there was a mean increase of 6.63 more WCPM.

During the enhanced phase when the difficulty of the reading passages was raised 6 months and the number of words in the passages was increased by $50 \%$, Fred's mean Practice Trial One repeated readings fluency performance, as measured in correct words per minute (WCPM), was 120.60 (range 115-127). His mean Practice Trial Two repeated readings fluency performance was 124.80 (range 120-130), and his mean Practice Trial Three was 128.40 (range 124.32). During the enhanced phase, Fred's mean fluency performance during repeated readings practice trials successively increased from the first through the third trials with a mean of 4.20 more WCPM from Practice Trial One to 
Practice Trial Two and 3.60 more WCPM from Practice Trial Two to Practice Trial Three. From Practice Trial One to Practice Trial Three there was a mean increase of 7.80 more WCPM.

\section{Ulysses}

Figure 4 and Table 5 display Ulysses' reading fluency performances during the first, second, and third practice repeated readings practice trials per session (referred to as Practice Trials One, Two, and Three). During the standard phase, Ulysses' mean Practice Trial One repeated readings fluency performance, as measured in WCPM, was 104.00(range 91-113). His mean Practice Trial Two repeated readings fluency performance was 107.00 (range 92-116), and his mean Practice Trial Three was 111.11 (range 96-121). During the standard phase, Ulysses' mean fluency performance during repeated readings practice trials successively increased from the first through the third trials with a mean of 3.00 more WCPM from Practice Trial One to Practice Trial Two and 4.11 more WCPM from Practice Trial Two to Practice Trial Three. From Practice Trial One to Practice Trial Three there was a mean increase of 7.11 more WCPM.

During the enhanced phase when the difficulty of the reading passages was raised 6 months and the number of words in the passages increased by $50 \%$, Ulysses' mean Practice Trial One repeated readings fluency performance, as measured in WCPM, was 120.60 (range 117-121). His mean Practice Trial Two repeated readings fluency performance was 124.40 (range 120-130), and his mean Practice Trial Three was 128.20 (range 123-133). During the enhanced phase, Ulysses' mean fluency performance during repeated readings practice trials successively increased from the first through the third trials with a mean of 3.80 more WCPM from Practice Trial One to Practice Trial Two 
and 3.80 more WCPM from Practice Trial Two to Practice Trial Three. From Practice Trial One to Practice Trial Three there was a mean increase of 7.60 more WCPM.

\section{Repeated Reading Practice Trials Reading Errors per Minute}

This study was conducted, in part, to examine the effects of each of the three successive repeated readings practice trials per session on the reading errors made by sixth-grade students with EBD who also had reading challenges. Reading errors per minute was measured by counting the number of reading errors made correctly during the first minute $(\mathrm{EPM})$ of each of the three repeated readings practice trials during each session. Each participant's reading EPM data per repeated readings practice trials are presented visually in Figure 5. The data points to the left of the dashed line represent performances during the standard phase in which the reading passages were at the difficulty level and number of words originally established in the study. Data points to the right of the dashed line represent data collected during the enhanced phase where the reading passage difficulty level was raised by 6 months and for Fred and Ulysses reading passages contained 50\% more words. In Table 5, individual and group mean and range performances are presented.

\section{Gabriel}

Figure 5 and Table 6 display Gabriel's reading EPM performances during the

first, second, and third practice repeated readings practice trials per session (referred to as Practice Trials One, Two, and Three). During the standard phase, Gabriel's mean Practice Trial One repeated readings EPM performance was 7.10(range 4-8). His mean Practice 

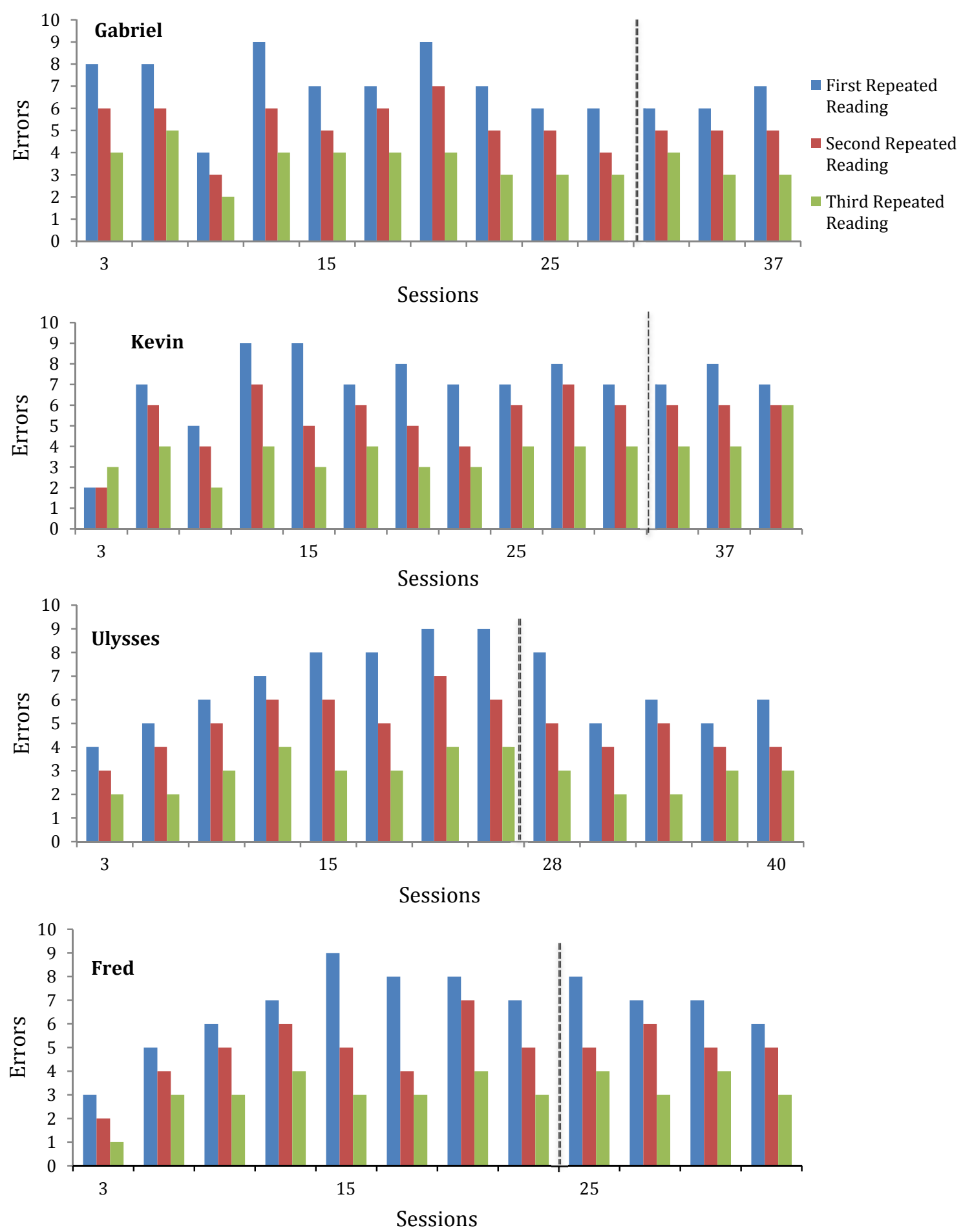

Figure 5. Repeated Readings Practice Trials-Errors per Minute. Repeated Reading Fluency is measured by the number of words correct per minute read at the end of each session of repeated reading. 


\section{Table 6}

Individual Mean of Repeated Readings Practice Sessions-Errors Per Minute

\begin{tabular}{ccccccc}
\hline & \multicolumn{3}{c}{ Errors-Standard } & \multicolumn{3}{c}{ Errors-Enhanced } \\
\cline { 2 - 7 } Participants & $\begin{array}{c}\text { Practice } \\
\text { One }\end{array}$ & $\begin{array}{c}\text { Practice } \\
\text { Two }\end{array}$ & $\begin{array}{c}\text { Practice } \\
\text { Three }\end{array}$ & $\begin{array}{c}\text { Practice } \\
\text { One }\end{array}$ & $\begin{array}{c}\text { Practice } \\
\text { Two }\end{array}$ & $\begin{array}{c}\text { Practice } \\
\text { Three }\end{array}$ \\
\hline Gabriel & 7.10 & 5.30 & 3.60 & 6.33 & 5.00 & 3.33 \\
Kevin & $(4-8)$ & $(3-7)$ & $(3-5)$ & $(6-7)$ & $(5-5)$ & $(3-4)$ \\
& 6.90 & 5.20 & 3.40 & 7.25 & 6.00 & 4.00 \\
Fred & $(2-9)$ & $(2-7)$ & $(2-4)$ & $(7-8)$ & $(6-6)$ & $(4-4)$ \\
& 6.57 & 4.71 & 3.00 & 7.25 & 5.25 & 3.50 \\
Ulysses & $(3-8)$ & $(2-7)$ & $(1-4)$ & $(7-8)$ & $(5-6)$ & $(3-4)$ \\
& 7.00 & 5.25 & 3.13 & 6.00 & 4.40 & 5.32 \\
& $(4-9)$ & $(3-7)$ & $(2-4)$ & $(5-8)$ & $(4-5)$ & $(2-3)$ \\
Group & 6.91 & 5.14 & 3.31 & 6.65 & 5.12 & 3.41 \\
& $(2-9)$ & $(2-7)$ & $(2-5)$ & $(6-8)$ & $(2-7)$ & $(2-4)$
\end{tabular}

Note. The top numbers indicate individual mean number of words read correctly per minute. The bottom numbers represent the range of scores. The standard sessions are those, which the reading passages were at the difficulty level and number of words originally established in the study. During the enhanced sessions, for all participants the reading passage difficulty was increased by 6 months. In addition, for Fred and Ulysses, the passages contained 50\% more words. Group mean was calculated by adding the total number of group sessions completed by all four participants and dividing that total by the number of individual sessions.

Trial Two repeated readings EPM performance was 5.30 (range 3-7), and his mean

Practice Trial Three was 3.60 (range 3-5). During the standard phase, Gabriel's mean EPM performance during repeated readings practice trials successively decreased from the first through the third trials with a mean of 1.80 fewer EPM from Practice Trial One 
to Practice Trial Two and 1.70 fewer EPM from Practice Trial Two to Practice Trial Three. From Practice Trial One to Practice Trial Three there was a mean decrease of 3.50 fewer EPM.

During the enhanced phase when the difficulty of the reading passages was raised 6 months, Gabriel's mean Practice Trial One repeated readings EPM performance was 6.33 (range 6-7). His mean Practice Trial Two repeated readings EPM performance was 5.00 (range 5-5), and his mean Practice Trial Three was 3.33 (range 3-4). During the enhanced phase, Gabriel's mean EPM performance during repeated readings practice trials successively decreased from the first through the third trials with a mean of 1.33 fewer EPM from Practice Trial One to Practice Trial Two and 2.33 fewer EPM from Practice Trial Two to Practice Trial Three. From Practice Trial One to Practice Trial Three there was a mean decrease of 3.00 fewer EPM.

\section{Kevin}

Figure 5 and Table 6 display Gabriel's reading EPM performances during the

first, second, and third practice repeated readings practice trials per session (referred to as Practice Trials One, Two, and Three). During the standard phase, Kevin's mean Practice Trial One repeated readings EPM performance was 6.90(range 2-9). His mean Practice Trial Two repeated readings fluency performance was 5.20 (range 2-7), and his mean Practice Trial Three was 3.40 (range 2-4). During the standard phase, Kevin's mean EPM performance during repeated readings practice trials successively decreased from the first through the third trials with a mean of 1.70 fewer EPM from Practice Trial One 
to Practice Trial Two and 1.80 fewer EPM from Practice Trial Two to Practice Trial Three. From Practice Trial One to Practice Trial Three there was a mean decrease of 3.50 fewer EPM.

During the enhanced phase when the difficulty of the reading passages was raised 6 months, Kevin's mean Practice Trial One repeated readings EPM performance was 7.25 (range 7-8). His mean Practice Trial Two repeated readings EPM performance was 6.00 (range 6-6), and his mean Practice Trial Three was 4.00 (range 4-4). During the enhanced phase, Kevin's mean EPM performance during repeated readings practice trials successively decreased from the first through the third trials with a mean of 1.25 fewer EPM from Practice Trial One to Practice Trial Two and 2.00 fewer EPM from Practice Trial Two to Practice Trial Three. From Practice Trial One to Practice Trial Three there was a mean decrease of 3.25 fewer EPM.

\section{Fred}

Figure 5 and Table 6 display Fred's reading EPM performances during the first, second, and third practice repeated readings practice trials per session (referred to as Practice Trials One, Two, and Three). During the standard phase, Fred's mean Practice Trial One repeated readings EPM performance was 6.57(range 3-8). His mean Practice Trial Two repeated readings fluency performance was 4.71 (range 2-7), and his mean Practice Trial Three was 3.00 (range 1-4). During the standard phase, Fred's mean EPM performance during repeated readings practice trials successively decreased from the first through the third trials with a mean of 1.86 fewer EPM from Practice Trial One to 
Practice Trial Two and 1.71 fewer EPM from Practice Trial Two to Practice Trial Three. From Practice Trial One to Practice Trial Three there was a mean decrease of 3.57 fewer EPM.

During the enhanced phase when the difficulty of the reading passages was raised 6 months and reading passages contained 50\% more words, Fred's mean Practice Trial One repeated readings EPM performance was 7.25 (range 7-8). His mean Practice Trial Two repeated readings EPM performance was 5.25 (range 5-6), and his mean Practice Trial Three was 3.50 (range 3-4). During the enhanced phase, Fred's mean EPM performance during repeated readings practice trials successively decreased from the first through the third trials with a mean of 2.00 fewer EPM from Practice Trial One to Practice Trial Two and 1.75 fewer EPM from Practice Trial Two to Practice Trial Three. From Practice Trial One to Practice Trial Three there was a mean decrease of 3.75 fewer EPM.

\section{Ulysses}

Figure 5 and Table 6 display Ulysses' reading EPM performances during the first, second, and third practice repeated readings practice trials per session (referred to as Practice Trials One, Two, and Three). During the standard phase, Ulysses' mean Practice Trial One repeated readings EPM performance was 7.00 (range 4-9). His mean Practice Trial Two repeated readings fluency performance was 5.25 (range 3-7), and his mean Practice Trial Three was 3.13 (range 2-4). During the standard phase, Ulysses' mean EPM performance during repeated readings practice trials successively decreased from the first through the third trials with a mean of 1.75 fewer EPM from Practice Trial One 
to Practice Trial Two and 2.12 fewer EPM from Practice Trial Two to Practice Trial

Three. From Practice Trial One to Practice Trial Three there was a mean decrease of 3.87 fewer EPM.

During the enhanced phase when the difficulty of the reading passages was raised 6 months and reading passages contained 50\% more words, Ulysses' mean Practice Trial One repeated readings EPM performance was 6.00 (range 5-8). His mean Practice Trial Two repeated readings EPM performance was 4.40 (range 4-5), and his mean Practice Trial Three was 5.32 (range 2-3). During the enhanced phase, Ulysses' mean EPM performance during repeated readings practice trials successively decreased from the first through the third trials with a mean of 1.60 fewer EPM from Practice Trial One to Practice Trial Two and 0.92 fewer EPM from Practice Trial Two to Practice Trial Three. From Practice Trial One to Practice Trial Three there was a mean decrease of 0.68 fewer EPM.

\section{Summary}

The study sought to examine repeated and two non-repeated readings conditions on sixth grade students with EBD. The results of this study demonstrate repeated readings resulted in a higher improvement in oral reading fluency and literal comprehension questions and fewer EPM as compared to non-repeated readings and equivalent nonrepeated readings. The data points to the left of the dashed line represent student performances during standard sessions in which the reading passages were at the difficulty level and number of words originally established in the study. Data points to the right of the dashed line represent data collected during enhanced sessions where the reading passage difficulty level was raised by 6 months for all participants and reading 
passages contained 50\% more words for two students (Fred and Ulysses). This study also examined the effects of each of the three successive repeated readings practice trials per session on the oral reading fluency and reading errors of the participants.

In examining reading fluency, the condition that showed the overall highest fluency gains during the standard phase (for 3 out of 4 participants individually) was repeated readings followed by non-repeated readings (for 3 out of 4 participants) and finally equivalent non-repeated readings (for 3 out of 4 participants). For the one participant (Fred) whose mean score was the highest with equivalent non-repeated readings, that mean score was only 1.00 more WCPM than with repeated readings. During the enhanced phases when the difficulty of the reading passages was raised 6 months for all and the number of words in passages increased by $50 \%$ for Fred and Ulysses, the condition that showed the highest mean reading fluency was repeated readings (for all participants), followed by non-repeated readings (for 3 out of 4 participants) and finally equivalent non-repeated readings (for 3 out of 4 participants). Fred was the only participant whose mean fluency score during the enhanced condition was higher in equivalent non-repeated readings than non-repeated readings.

The group mean for reading fluency for the standard phase of repeated readings, non-repeated readings, and equivalent non-repeated readings was $100.55,87.97$, and 79.58 respectively. The results from highest to lowest were the same during the enhanced phase, the group mean for reading fluency were 119.50, 96.88, and 92.25, respectively.

In examining EPM, the condition that showed the lowest errors per minute during the standard phase (for all participants individually) was repeated readings followed by 
non-repeated readings (for 3 out of 4 participants) and finally equivalent non-repeated readings (for 3 out of 4 participants). One participant (Ulysses) had the same mean EPM in the non-repeated and equivalent non-repeated conditions. During the enhanced phase when the difficulty of the reading passages was raised 6 months for all and the number of words in passages increased by $50 \%$ for Fred and Ulysses, the condition that showed the lowest EPM was again the repeated reading fluency (for all participants), followed by non-repeated readings (for all participants) and finally equivalent non-repeated readings (for all participants).

The group mean for EPM for the standard phase of repeated readings, nonrepeated readings, and equivalent non-repeated readings was 3.28, 3.86, and 4.31, respectively. The results from highest to lowest had the same ordinal rankings during the enhanced phase, the group mean for reading fluency were 3.13, 4.37, and 5.00, respectively.

In examining literal comprehension questions answered correctly, the condition that showed the most correct answers (for all participants individually) during the standard phase was repeated readings followed by equivalent non-repeated readings (for 3 out of 4 participants) and finally non-repeated readings (for 3 out of 4 participants). During the enhanced phase when the difficulty of the reading passages was raised 6 months for all and the number of words in passages increased by $50 \%$ for Fred and Ulysses, the condition that showed the most correct answers was again repeated readings (for all participants individually), followed by a tie between non-repeated readings (for 2 out of 4 participants) and equivalent non-repeated readings (for 2 out of 4 participants). 
The group mean for literal comprehension questions answered correctly for the standard phase of repeated readings, non-repeated readings, and equivalent non-repeated readings was $4.55,2.92$, and 3.28 , respectively. The results from highest to lowest were the same during the enhanced non-repeated readings condition, the group mean for reading fluency were $5.00,3.75$, and 3.50 , respectively.

In examining the repeated readings practiced trials for oral reading fluency, all participants improved their oral reading fluency from Practice Trial One through Practice Trial Three. During the standard phase, the group means for Practice Trials One, Two and Three for correct words per minute were 90.79, 96.27, and 97.32, respectively. During the enhanced condition when the difficulty of the reading passages was raised 6 months and the number of words in passages increased by $50 \%$ for Fred and Ulysses, the group mean for correct words per minute for Practice Trial One was 112.00. The group mean for Practice Trial Two was 115.69 and 119.13 for Practice Trial Three.

In examining the repeated readings practiced trials for errors per minute, all participants reduced their reading errors from Practice Trial One through Practice Trial Three. During the standard phase, the group mean for errors per minute for Practice Trials One, Two and Three were 6.91, 5.14 and 3.31 respectively. During the enhanced phase, when the difficulty of the reading passages was raised 6 months and the number of words in passages increased by 50\% for Fred and Ulysses, the group means for errors per minute for Practice Trials One, Two and Three were 6.66, 5.12, and 4.04, respectively. 


\section{Chapter V}

\section{Discussion}

This chapter presents a discussion of the results of a study that used an alternating treatments design to compare the effects of a repeated and two non-repeated readings conditions on the reading fluency, reading errors, and reading comprehension of sixth grade students who have emotional/behavioral disorders (EBD) and are struggling readers. In addition, assessed were the effects of the three successive repeated readings practice trials per session on reading fluency and errors.

Reading passage difficulty and the number of words per passage were established prior to commencing the study and were used throughout much of the study, which is referred to as the standard phase. Toward the end of the study, the enhanced phase, the reading levels for all four participants were increased by 6 months, and for the two participants (Fred and Ulysses) who functioned at a higher reading level (fifth grade), the number of words in the reading passages was increased by $50 \%$. The enhanced phase was added to assess the effects of the three conditions under more rigorous circumstances. Data for all dependent variables across both phases were collected and analyzed on a total of 169 intervention sessions which included a total of 54 repeated readings conditions, 53 non-repeated readings conditions, and 52 equivalent non-repeated readings conditions.

This chapter offers an overview of the study along with a summary of the results in relation to pertinent literature in repeated readings and equivalent non-repeated 
readings. Additionally, the study's delimitations, limitations, implications for practice, and suggestions for future research are discussed. Finally, a chapter summary is provided.

Although the final outcomes varied slightly for each of the participants, overwhelmingly the results revealed that the repeated readings condition had a more positive impact across all three dependent variables on the reading skills of students with EBD as compared to non-repeated and equivalent non-repeated readings. In addition, overall the participants' reading fluency increased and errors per minute decreased across the three successive repeated reading practice trials. A detailed analysis of the results for each dependent variable, along with how those results align to previous research is noted below.

\section{Reading Fluency}

In examining reading fluency, overall repeated readings resulted in the best outcome for three out of four participants individually across the standard phase and four out four for the enhanced phase of the study. When reviewing performances in the standard phase only, for three of four participants (Gabriel, Kevin, and Ulysses), experimental control was clearly established with the overlap of only one or two data points across the three conditions. For one student (Fred), there was not as clear a distinction between the effects of repeated readings and equivalent repeated readings during the standard phase with considerable overlap in these data paths. That is, for Fred repeated readings and equivalent non-repeated readings resulted in essentially the same outcome (non-repeated readings resulted in a mean 1.00 more WCPM). However, for Fred, both equivalent non-repeated readings and repeated readings resulted in a 
substantially higher mean score than non-repeated readings (approximately 10 WCPM more). With the exception of only one data point, Fred's fluency performance was consistently the poorest with non-repeated readings.

In comparing fluency performances during the non-repeated and equivalent nonrepeated readings only (not repeated readings) during the standard phase of fluency performances, two students (Gabriel and Kevin) who read at the second grade level, had a substantially better outcome in non-repeated than equivalent non-repeated readings. For one of the two students who read at the fifth grade level (Ulysses), the WCPM was similar between non-repeated and equivalent non-repeated readings, with a mean difference of only 1.00. Whereas, with the other fifth grade reader (Fred) equivalent nonrepeated readings resulted in a substantially higher mean WCPM (10.20 more words) than non-repeated readings. In sum, for two of four participants non-repeated readings clearly outperformed equivalent non-repeated readings during the standard phase, whereas, the results were essentially the same between non-repeated and equivalent repeated readings for one participant. Finally, for one participant, equivalent nonrepeated reading substantially outperformed non-repeated readings. In conclusion when comparing non-repeated and equivalent non-repeated readings during the standard phase, experimental control was not clearly established.

The analysis of reading fluency during the enhanced phase, on the other hand, resulted in clear experimental control being demonstrated for all four participants with no overlap in repeated, non-repeated, or equivalent non-repeated readings data paths. Fluency performances were the highest with repeated readings, followed by non-repeated and then equivalent non-repeated readings. It is particularly important to point out that for 
the one participant (Fred), whose fluency outcomes with repeated readings and equivalent non-repeated readings were similar during the standard phase, there was a substantially different outcome during the enhanced phase with nearly 11 more WCPM with repeated readings than equivalent non-repeated readings.

This study also collected reading fluency data during the three practice trials during the repeated readings sessions only. The group's mean for reading fluency during the standard phase for the repeated readings practice trials were 93.24, 96.27, and 99.94 WCPM respectively. Similarly, during the enhanced phase, the group means for reading fluency were $112.00,115.69$ and 119.13. When looking at individual participant performances during the standard phase, all participants increased their WCPM from Practice Trial One through Practice Trial Three. Ulysses made the greatest improvement (7.11 more words read) from Practice Trial One through Practice Trial Three. For Gabriel, Kevin, and Fred their gains were 6.10, 6.36, and 6.63, respectively. During the enhanced phase, Gabriel, Fred, and Ulysses made the most substantial improvement (7.00, 7.80, and 7.60) from Practice Trial One through Practice Trial Three, whereas Kevin's fluency improvement was less substantial than the other participants at 5.33. In sum, all participants increased their WCPM from Practice Trial One through Practice Trial Three. However, when interpreting these data, one must keep in mind that during Practice Trial One for each participant, the researcher provided error correction as needed which likely decreased their correct WCPM. No error correction was provided during Practice Trials Two and Three. As such, these results should be viewed with this consideration. 
The end-of session fluency results of this study lend support to the multiple studies for typically-learning students(e.g., Le Vasseur et al., 2007; Vadasay and Sanders, 2008), students with disabilities (e.g., Bryant et al., 2000; Pattillo et al., 2004), and those ESOL or ELL students with disabilities (e.g., Landa \& Barbetta, 2010; Tam et al., 2006) that demonstrated the positive effects of repeated readings on reading fluency. Additionally, the results of this study also support repeated readings studies for students with EBD who are struggling readers (e.g., Alber-Morgan, Ramp, Anderson, \& Martin, 2007; Staubitz, Cartledge, Yurick, \& Lo, 2005; Scott \& Shearer-Lingo, 2002; Strong et al., 2004; Valleley \& Shriver, 2003). In all of these studies, repeated readings resulted in an improvement in reading fluency. In the current study, repeated readings resulted in the best overall fluency outcome, especially in the enhanced phase.

This study extends the existing literature for repeated readings in fundamental ways. First, only five studies were located that examined fluency in repeated readings with students with EBD (Alber-Morgan et al., 2007; Scott \& Shearer-Lingo, 2002; Staubitz et al., 2005; Strong et al., 2004; Valleley \& Shriver, 2003). None of the reviewed repeated readings studies with students with EBD contained an equivalent non-repeated readings condition. This study also adds to the existing literature in that it contained an enhanced phase in which the reading levels for all participants were increased six months, and for two participants the number of words in the reading passages was also increased by $50 \%$. This allowed a comparison of repeated, non-repeated and equivalent nonrepeated readings under more rigorous conditions. Under these enhanced phases, the 
positive effects of repeated readings were more demonstrative. Finally, there is only one other study found prior to this one (Therrien et al., 2008) that collected and reported repeated readings practice trial fluency data for all participants.

Another unique feature of this study is that fluency data were collected on each of the three repeated readings practice trials, with consistent improvement through the trials being observed for all participants. No other studies were found that collected these data. Teachers have reported that fear of failure is so entrenched in students with EBD that these students often refused to participate in reading or to complete a reading-related activities unless they were assured that they would succeed at the task (Atkinson, Wilhite, Frey, \& Williams, 2002). In the present study with repeated readings, immediate improvements from the first to the third practice trial often were evident with the participants. The researcher noted anecdotally that participants frequently made statements such as "I like this better" or "It gets easier." Perhaps, the immediate and consistent improvement from one practice trial to the next may have reduced the participants' fear of failure during reading readings, thus contributing to its success.

The results of this study do not support the literature suggesting that the fluency developed during repeated readings may have little or nothing to do with repetition of passages but instead occurs as a result of students reading more words and/or reading for longer periods of time during repeated readings than the comparison conditions (e.g., Kuhn \& Stahl 2003; Pressley, 2006). When participants read an equivalent number of words during this study, repeated readings still resulted in a far superior outcome (with the exception of one participant during the standard phase only, when the outcomes were essentially identical). In examining the studies that compared equal amounts of non- 
repetitive text to repeated readings (e.g., Ardoin et al., 2007; Homan et al., 1993; Rashotte \& Torgesen, 1985; Therrien, et al., 2008;Van Bon et al., 1991), the studies showed mixed results in terms of fluency gains as a result of reading equivalent amounts of non-repetitive text as compared to repeated readings. Whereas, in this study, the repeated readings condition overall was the most effective across the three conditions for improving reading fluency. More specifically, this study refutes Rashotte and Torgesen (1985) and Homan et al, (1991) studies, which stated that given the same amount of practice between conditions, repeated readings was not a more effective means for increasing fluency.

In summary, the results of this study suggest that for students with EBD, repeated readings can be an effective approach in improving reading fluency. Although reading fluency is a staple of repeated readings research, there are limited studies that have looked at WCPM with students with EBD, and no studies were found that had compared repeated readings with equivalent non-repetitive readings with students with EBD. Therefore, the results of this study extend the limited research in this area. However, additional research is needed.

\section{Errors per Minute}

In examining the results of this study concerning participants' EPM, overall repeated readings resulted in the best outcome for all four participants individually across the standard and enhanced phases. When reviewing mean scores during the standard phase specifically, all four participants averaged fewer errors per minute during repeated readings than during non-repeated and equivalent non-repeated readings, albeit often not substantial. However, there was overlap in the data paths across the three conditions. For 
two of four participants, repeated readings resulted in an average of one fewer reading EPM than did equivalent non-repeated readings. For one participant (Fred), repeated readings also resulted in an average of one fewer reading EPM than did non-repeated readings. All other differences across the conditions were less than one EPM.

When comparing non-repeated and equivalent non-repeating readings only during the standard phase, for three of four participants, non-repeated readings resulted in fewer EPM, albeit the difference was slight. For the fourth participant, the EPM mean performance was identical in both non-repeated and equivalent non-repeated readings.

When reviewing mean scores during the enhanced phase specifically, all four participants averaged fewer EPM during repeated readings than during non-repeated and equivalent non-repeated readings. For all four participants, repeated readings resulted in an average greater than one fewer reading EPM than did equivalent non-repeated readings, whereas, three out of four participants had a mean greater than one EPM in repeated readings than non-repeated readings. When comparing non-repeated and equivalent non-repeated readings, all four participants did better (i.e., averaged fewer EPM) in non-repeated and equivalent non-repeated readings. In sum, across all three conditions, overall repeated readings resulted in the best outcome, followed by nonrepeated, and then equivalent non-repeated readings.

This study also collected EPM data during the three practice trials during the repeated readings sessions only. The group's mean for EPM during the standard phase for the repeated readings practice trials were 6.91, 5.14, and 3.31 EPM respectively. Similarly, during the enhanced phase, the group means for EPM were 6.65, 5.12, and 3.41. When looking at individual participant performances during the standard phase, all 
participants decreased their EPM from Practice Trial One through Practice Trial Three by 3.50 EPM or more. Similarly, during the enhanced phase, all four participants reduced their mean number of EPM from Practice Trial One through Practice Trial Three. Only one participant, Ulysses, had fewer errors in Practice Trial Two than Practice Trial Three, but he had fewer errors in Practice Trial Three than Practice Trial One. However, as when interpreting reading fluency practice trial data, it must be understood that during Practice Trial One for each participant, the researcher provided error correction as needed which may have affected the numbers of words read per minute and subsequently the opportunity to error. No error correction was provided during Practice Trial Two and Practice Trial Three. As such, these results should be viewed with this consideration. In examining the end-of-session EPM data, results of this study lend support to the studies for typical learning students (e.g., Le Vasseur et al., 2007), students with disabilities (e.g., Nelson et al., 2004), and those ELL students with disabilities (e.g., Landa \& Barbetta, 2010; Tam et al., 2006) that revealed the positive effects of repeated readings on reducing the number of EPM. This study adds to the limited research on the effects of repeated readings on EPM in studies with students with EBD. Prior to this research, only one such study was found that included EPM data with this population (Alber-Morgan et al., 2007).

This study extends the literature that examined the effects repeated readings to reading equal amounts of non-repetitive text (i.e., Ardoin et al., 2007, Homan et al.,1993; Rashotte \& Torgesen, 1985; Van Bon et al., 1991). None of these previous studies examined errors per minute. Additionally, this study adds to the literature in that in contained an enhanced phase in which there were increases in the reading levels and the 
number of words in the passages. Under this enhanced phase, similar to the reading fluency outcomes, the positive effects of repeated readings were more demonstrative. This preliminarily suggests that repeated readings may be more effective in reducing EPM when the reading passages are more challenging for students and have more words.

In summary, the results of this study suggest that for students with EBD, repeated readings should be considered for reducing the number of EPM. Although EPM is an important aspect of repeated readings research, only one study that examined EPM with students with EBD (Alber-Morgan et al., 2007), and no studies were found that had compared repeated readings with equivalent non-repetitive readings with for students with EBD. Subsequently, the results of this study extend the limited research in this area.

\section{Correct Answers to Literal Comprehension Questions}

With respect to correct answers to literal comprehension questions, overall, repeated readings resulted in the best outcome for all four participants individually across the standard and enhanced phases. When reviewing performances in the standard phase for all four participants, most often repeated readings resulted in the best comprehension scores. While repeated readings resulted in the best outcome, overall non-repeated reading resulted in the fewest correct answers for three out of four participants (Gabriel, Kevin, and Fred). Ulysses had a minimal difference between non-repeated and equivalent non-repeated readings, with equivalent non-repeated readings resulting in 0.25 higher mean score.

When reviewing performances in the enhanced phase, all four participants answered more literal comprehension questions correctly during repeated readings with a mean of 5.00 out of 5.00 for all participants. The differences in effects of non-repeated 
readings compared to equivalent non-repeated readings is not as clear during the enhanced phase with two participants performing better during non-repeated readings, one during equivalent non-repeated readings, and the final having identical mean scores on both conditions.

As with the other variables, the results of this study lend support to the multiple studies for typical learning students (e.g., Begeny, Daly, \& Valleley, 2006; Freeland, Skinner, Jackson, McDaniel, \& Smith, 2000), students with disabilities (e.g., Pattillo, Heller, \& Smith, 2004), and for students reading below grade level (Stoddard, Valcante, Sindelar, O’Shea, \& Algozzine, 1993; Tam et al., 2006) that demonstrated the positive effects of repeated readings on comprehension. As with reading fluency and errors per minute, this study extends the existing literature in repeated readings. Four studies were found that examined comprehension in repeated readings with students with EBD (AlberMorgan et al., 2007; Staubitz et al., 2005; Strong et al., 2004; Valleley \& Shriver, 2003) and all demonstrated improvement in comprehension as a result of repeated readings. This study also extends the literature that examined comprehension in repeated readings to reading equal amounts of non-repetitive text (i.e., Rashotte \& Torgesen 1985; Homan et al., 1993) in that only one study (Homan et al., 1993) showed improvement in comprehension as a result of repeated readings. Additionally, this study adds to the literature in that it contained an enhanced phase in which there were increases in the reading levels and the number of words in the passages for two participants. Under these enhanced phases, similar to the reading fluency and errors per minute outcomes, the 
positive effects of repeated readings were more pronounced. This suggests that repeated readings may be more effective for literal comprehension when the reading passages are more challenging for students and/or having read more words.

In summary, the results of this study suggest that for students with EBD, repeated readings is an effective literal comprehension approach. Although correct answers to literal comprehension questions is an important component of repeated readings research, limited studies that have investigated the effects of repeated readings on this skill with students with EBD, and no studies were found that compared repeated readings with equivalent non-repetitive readings with students with EBD. Therefore, the results of this study extend the limited research in this area.

\section{Repeated Readings Summary}

This study used an alternating treatments design to compare the effects of a repeated and two non-repeated readings conditions on the reading fluency, reading errors, and reading comprehension of sixth grade students who have emotional/behavioral disorders (EBD) and are struggling readers. Also investigated were the effects of the three successive repeated readings practice trials per session on their reading fluency and reading errors. Reading passage difficulty and length for all conditions were established prior to commencing the study and were used throughout the standard phase. During the enhanced phase, the reading levels for all four participants were increased 6 months, and for the two participants, who functioned at a higher reading level (fifth grade), the number of words in the reading passages was increased by $50 \%$. This allowed a comparison of repeated, non-repeated and equivalent non-repeated readings under more rigorous conditions. 
In examining reading fluency, overall repeated readings resulted in the best outcome for three out of four participants individually across the standard phase and four out four for the enhanced phase. While looking at all three conditions, overall repeated readings resulted in the best outcome, followed by non-repeated, and then equivalent non-repeated readings. All participants increased their WCPM from Practice Trial One through Practice Trial Three in both the standard and enhanced phase. However, when interpreting these data, one must keep in mind that during Practice Trial One for each participant, the researcher provided error correction as needed, which likely decreased their correct WCPM. No error correction was provided during Practice Trials Two and Three.

In looking at the results of this study related to participants'EPM, overall repeated readings resulted in the best outcome for all four participants individually across the standard and enhanced phases. Overall, repeated readings resulted in the best outcome, followed by non-repeated, and then equivalent non-repeated readings. When looking at individual participant performances during the standard phase, all participants decreased their EPM from Practice Trial One through Practice Trial Three by 3.50 EPM or more. Similarly, during the enhanced phase, all four participants reduced their mean number of EPM from Practice Trial One through Practice Trial Three.

In examining correct answers to literal comprehension questions, overall repeated readings resulted in the best outcome for all four participants individually across the standard and enhanced phases. During the standard phase, while repeated readings resulted in the best outcome, overall non-repeated reading resulted in the fewest correct answers for three out of four participants. In the enhanced phase, repeated readings 
resulted in the best outcome for all participants while the other two conditions varied in their results for the participants.

In closing, the results of this study support the findings of the limited number of studies with students with EBD that demonstrated the positive effects of repeated readings on reading fluency (e.g., Alber-Morgan, et al., 2007; Staubitz, et al., 2005; Scott \& Shearer-Lingo, 2002; Strong et al., 2004; Valleley \& Shriver, 2003), errors per minute (Alber-Morgan et al., 2007), and comprehension (Alber-Morgan et al., 2007; Staubitz et al., 2005; Strong et al., 2004; Valleley \& Shriver, 2003). Additionally, this current study extends the literature in that few studies were found that examined these three dependent variables in repeated readings with students with EBD (Alber-Morgan et al., 2007; Scott \& Shearer-Lingo, 2002; Staubitz et al., 2005; Strong et al., 2004; Valleley \& Shriver, 2003); none of which contained an equivalent non-repeated readings condition or an enhanced phase. This enhanced phase also adds to the existing literature in that it allowed for a comparison of repeated, non-repeated and equivalent non-repeated readings under more rigorous conditions. Under these enhanced phases, the positive effects of repeated readings were more demonstrative.

\section{Implications for Practice}

The results of this study leave notable implications for classroom practice. This study used a repeated readings condition, which resulted in the best outcome for improving reading fluency, decreasing errors per minute, and correctly answering literal comprehension questions. During the enhanced phase when circumstances were more rigorous, the positive effects of repeated readings (as compared to non-repeated and equivalent non-repeated readings) were even more demonstrative. 
Since research tells us that students who read well, read with fluency (Rasinski, 2000) and that there are certain social benefits associated with reading fluently (Snow et al., 1998), repeated readings should be considered an effective intervention for assisting students (typical learning and special needs) with their reading fluency. In particular, teachers may want to add repeated readings to their reading program when moving students to more challenging reading given the increased impact of this approach during the enhanced phase of this study.

Specifically, since students with EBD not only exhibit poor reading grades, but also earn one of the lowest academic grades of any disability group (Sutherland $\&$ Singh, 2004) repeated readings should be considered as a supplement for teachers to use with their reading programs for students with EBD. Teachers may want to use repeated readings as individualized instruction as students work with themselves, paraprofessionals or class volunteers. Another suggestion is that the teacher could have the entire class participate in repeated readings, breaking into dyads and peers repeatedly reading to each other and asking comprehension questions, as research has shown that repeated readings has been effective when used with peers (Barton-Arwood et al., 2005; Staubitz et al., 2005). Even though the effects of parents implementing a repeated readings program at home have not been sufficiently researched, given its ease of implementation, most parents could be trained to use this approach at home.

Another consideration with repeated readings it that it only takes a few minutes to implement and yet results in immediate reading gains. Teachers could consider using this strategy when there are only a few minutes between transitioning from one classroom activity to another. 


\section{Delimitations}

In single subject research, the sample size is small by nature compared to other designs and therefore limits how its findings might be generalized. Since this study examined the effects of non-repeated and repeated readings on the reading skills of students with EBD, any replication would be required to be systematic and direct. Subsequently, since this study used sixth grade male students with EBD, these results cannot be generalized past this population in other grade levels with other disabilities. Another delimitation was the reading materials used in the study. Since the students were familiar with the basal reading program at the school, a supplemental reading program was used for this study. The passages from this program ranged from fiction to nonfiction and had the same readability level as the basal reader. Since different authors wrote the passages, this could have led to a preference by some students for certain passages over others.

Finally, since the research took place with students with EBD at a separate day school, their emotional and/or behavioral problems were sometimes apparent and may have interfered with the outcome of the study.

\section{Limitations}

There are certain limitations that need to be stated for this study. All the participants in this research study were male. Even though there is a vast overrepresentation of males in EBD programs (APA, 2000), there were attempts made to incorporate female participants in this study. However, the female students did not return permission forms, and parents/guardians did not allow participation when contacted by phone by the researcher. Therefore, the results of this study cannot be generalized to 
female students.

Another limitation of this study was that the participants received daily reading instruction. This may or may not have impacted the participants' performance during repeated reading. They received daily reading instruction from four different teachers (in addition to the researcher). Even though the teachers followed the specified scope and sequence dictated by the school's reading curriculum, the researcher did not observe the quantity or quality of their reading instruction. Therefore, its impact could not be considered.

\section{Suggestions for Future Research}

The results of this study suggest the need for future research. The demographics of the participants who participated in this study were restricted to sixth-grade male students with EBD. Their races included White and Black and their ethnicities included Hispanic and Non-Hispanic. Even though their races and ethnicities differed, it was still a small sample size for race and ethnicity. Participants with other characteristics such as gender, exceptionalities, reading abilities, and grade levels should also be considered for future research. Additionally, future research should document the type and scope of reading instruction that the participants are receiving in the classroom.

Future research should investigate the effects the combination of these conditions while having the students use peer tutoring (Barton-Arwood et al., 2005), track their own progress (Tam et al., 2006), or read with a capable peer tutor (Chard et al., 2002). Also, future research should investigate the effects of repeated readings over the course of one calendar school year and determine how these effects grow over an extended period of time. 
Furthermore, additional research is needed to compare the effects of repeated readings, non-repeated readings, and equivalent non-repeated readings. Prior to this study, no other study was found that compared these three conditions measuring fluency, errors per minute, and literal comprehension performances in one study. This is vital to empirically address those who propose that fluency acquired during repeated readings is due to increased reading practice other than repetition (Kuhn \& Stahl 2003; Pressley, 2006). It would be useful if additional research included the collection of repeated readings practice trial data for fluency and errors, as was done in this study.

Even though this study examined the effects of repeated and two non-repeated readings conditions with students with $\mathrm{EBD}$, there is still a need for additional research. Since the sample size is small by the nature of the single-subject design used in this study generalization of its findings is limited. Subsequently, direct and systematic replications are merited.

\section{Summary}

The results of this study demonstrated that repeated readings had a favorable outcome on the reading abilities of students with EBD. That is, overall repeated readings resulted in a higher mean number of correct words per minute (with the exception of one participant during the standard phase in which the mean repeated readings WCPM was essentially the same as equivalent non-repeated readings), fewer errors per minute, and more correct answers to literal comprehension questions. The positive differences in the effects of repeated readings and the two non-repeated readings conditions were more demonstrative during the enhanced condition with participants were reading under more rigorous circumstances. Additionally, this study compared non-repeated and equivalent 
non-repeated readings with mixed results across the dependent variables. In examining group means for fluency and errors, non-repeated readings had a better outcome than equivalent non-repeated readings in both standard and enhanced phases. Comprehension had contradictory results between the phases.

This study adds to the limited research of repeated readings and students with EBD by demonstrating the effect of repeated reading with this population, as well as examining the effects of repeated readings on WCPM and EPM during each repeated reading practice trial. Also, this study lends further credence to using repeated readings along with a structured reading program to assist students with EBD who are struggling readers (e.g. Alber-Morgan, et al., 2007; Scott \& Shearer-Lingo; Staubitz, et al., 2005; 2002; Strong et al., 2004). Additionally, this study adds value to the limited number of studies found that controlled the time that students spend reading (Alber-Morgan et al., 2007; Mathes and Fuchs, 1993; Nelson et al., 2004) and/or the number of words read in the equivalent non-repeated and repeated readings conditions (e.g., Ardoin et al., 2007; Homan et al., 1993; Rashotte \& Torgesen, 1985; Therrien et al., 2008; Van Bon et al., 1991).

Since repeated readings resulted in the best outcomes of all conditions, teachers and/or qualified school personnel should consider using repeated readings as individualized instruction with their students or when moving students to more challenging reading given its results during the enhanced phase of this study. Additionally, consideration should be given to parents implementing a repeated readings program at home given its ease of implementation. Parents could take a few minutes each night and have their child repeatededly read their favorite part of a story and then ask 
them questions about the story.

When looking at the delimitations of this study and given the nature of single subject design research, additional research is needed to generalize these results.

Additionally, any replication of this study would have to be systematic and direct. Future research should include participants with other characteristics such as gender, exceptionalities, reading abilities, and grade levels. Moreover, these results could not be generalized past this population in other grade levels with other disabilities and since a supplemental reading program was used for this study, this could have led to a preference by some students for certain passages over others. Finally, the students' emotional and/or behavioral problems were sometimes apparent and may have interfered with the outcome of the study.

Limitations for this study included the fact that all the participants were boys; therefore, the results of this study cannot be generalized to female students. Another limitation of this study was that the participants received daily reading instruction from four reading teachers (five including the researcher) and this may or may not have impacted the participants' performance during reading.

In sum, future research is needed to compare the effects of repeated and equivalent non-repeated readings since no other study was found that compared these two conditions for all of the three dependent variables used in this study in one comprehensive study. Furthermore, it would be useful if additional research included the collection of repeated readings practice trial data for fluency and errors, as was done in this study, to further analyze the immediate effects of repeatedly reading a passage, and compare any differences in reading fluency and errors made across each of the three 
practice trials during the repeated readings sessions. Finally, this study showed that repeated readings can have positive effects on students with EBD and therefore should be considered as an aid in the classroom to assist these students with improving their reading abilities. 


\section{References}

Abidin, R. R., \& Robinson, L. L. (2002). Stress, biases, or professionalism: What drives teachers' referral judgments of students with challenging behaviors? Journal of Emotional and Behavioral Disorders, 10, 204-212.

Adams, M.J. (1990). Beginning to read: Thinking and learning about print. Cambridge, MA: MIT Press.

Al-Otaiba, S., \& Rivera, M.O. (2006). Individualized guided oral reading fluency instruction for students with emotional and behavioral disorders. Intervention in School and Clinic, 41(3), 144-149.

Alber-Morgan, S. R., Ramp, E. M., Anderson, L. L., \& Martin, C. M. (2007). Effects of repeated readings, error correction, and performance feedback on the fluency and comprehension of middle school students with behavior problems. The Journal of Special Education, 41, 17-30.

American College Testing Program. (2006). Ready for college and ready for work: Same or different. Retrieved from http://www.act.org/research/ policymakers/reports/workready.html

American Psychiatric Association (2000). Diagnostic and statistical manual of mental disorders $\left(4^{\text {th }}\right.$ ed., text revision). Washington, DC: Author.

Anderson, J.A., Kutash, K., \& Duchnowski, A.J. (2001). A comparison of the academic progress of students with EBD and students with LD. Journal of Emotional and Behavioral Disorders, 9, 106-115.

Applegate, M.D., Quinn, K.B., \& Applegate, A.J. (2002). Levels of thinking required by comprehension questions in informal reading inventories. The Reading Teacher, 56(2), 174-180.

Ardoin, S. P., McCall, M., \& Klubnik, C. (2007). Promoting generalization of oral reading fluency: Providing drill versus practice opportunities. Journal of Behavioral Education, 16(1), 55-70.

Atkinson, T.S., Wilhite, K.L., Frey, L.M., \& Williams, S.C. (2002). Reading instruction for the struggling reader: Learning disabilities or emotional/behavioral disorders. Preventing School Failure, 46(4), 158-162.

Barbetta, P.M., Heron, T.E., \& Heward, W.L. (1993a). Effects of active student response during error correction on the acquisition, maintenance, and generalization of sight words by students with developmental disabilities. Journal of Applied Behavior Analysis, 26(1), 111-119. 
Barbetta, P. M., Heward, W. L., \& Bradley, D.M. (1993b). Relative effects of wholeword and phonetic-prompt error correction on the acquisition and maintenance of sight words by students with developmental disabilities. Journal of Applied Behavior Analysis, 26, 99-110.

Barley, Z., Lauer, P. A., Arens, S. A., Apthorp, H. A., Englert, K. S., Snow, D., \& Akiba, M. (2002). Helping at-risk students meet standards: A synthesis of evidence-based classroom practices. Aurora, CO: Mid-Continent Research for Education and Learning.

Barton-Arwood, S.M., Wehby, J.H., \& Falk, K.B. (2005). Reading instruction for elementary-age students with emotional and behavioral disorders: Academic and behavioral outcomes. Exceptional Children, 72(1),7-27.

Becker, W.C., \& Carnine, D.W. (1980). Direct instruction. In B.B. Lahey \& A.E. Kazdin (Eds.), Advances in clinical child psychology (pp. 429-473), New York, NY: Plenum.

Begeny, J. C., Daly, E. J., III, \& Valleley, R. J. (2006). Improving oral reading fluency through response opportunities: A comparison of phrase drill error correction with repeated readings. Journal of Behavioral Education, 15(4), 229-235.

Begeny, J. C.,\& Martens, B.K. (2006). Assisting low-performing readers with a groupbased reading fluency intervention. School Psychology Review, 35(1), 91-107.

Blumberg, S.J., Olson, L., Frankel, M.R. Osborn, L., Rinath, K.P. \&Giambo, P. (2003). Design and operation of the national survey of children. Retrieved from http://www.cdc.gov/nchs/data/sereis

Bos, C.S., Coleman, M., \& Vaughn, S. (2002). Reading and students with E/BD. What do we know and recommend? In K. L. Lane, F. M. Gresham, \& T.E. O'Shaughnessy (Eds.), Interventions for children with or at risk for emotional and behavioral disorders (pp. 87-103). Boston, MA: Allyn \& Bacon.

Brown, B. V., \& Bogard, K. (2007). Pre-kindergarten to 3rd grade (PK-3) school-based resources and third grade outcomes. Retrieved from http://www.childtrendsdatabank.org/PDF/PKtoThree.pdf

Brown, B.W. (1991). How gender and socioeconomic status affect reading and math achievement. Economics of Education Review, 10(2), 343-357. 
Bryant, D.P., Vaughn, S., Linan-Thompson, S., Ugel, N., Hamff, A., \& Hougen, M. (2000). Reading outcomes for students with and without reading disabilities in general education middle-school content area classes. Learning Disability Quarterly, 23, 238-252.

Bullis, M., \& Yovanoff, P. (2006). Idle hands: Community employment experiences of formerly incarcerated youth. Journal of Emotional and Behavioral Disorders, 14, $71-85$.

Bursuck, W.D., \& Damer, M. (2007). Reading instruction for students who are at risk or have disabilities. Boston, MA: Pearson Education, Inc.

Campbell, K. U., \&Mercer, C. (1994). Great leaps reading. Micanopy, FL: Diarmuid.

Carnine, D. W., Silbert, J., Kame'enui, E. J., \& Tarver, S. G. (2004).Direct instruction reading (4th ed.). Upper Saddle River, NJ: PrenticeHall/Merrill.

Carr, E. G., Taylor, J.C., \& Robinson, S. (1991). The effects of sever behavior problems in children on the teaching behavior of adults. Journal of Applied Behavior Analysis, 24, 523-535.

Chard, D.J., Ketterlin-Geller, L.R., Baker, S.K., Doabler, C., \& Apichatabutra, C. (2009). Repeated reading interventions for students with learning disabilities: Status of the evidence. Exceptional Children 75(3),263-281.

Chard, D. J., Vaughn, S., \& Tyler, B. (2002). A synthesis of research on effective interventions for building reading fluency with elementary students with learning disabilities. Journal of Learning Disabilities, 35, 386-406.

Cochran, L., Feng, H., Cartledge, G., \& Hamilton, S. (1993). The effects of cross-age tutoring on the academic achievement, social behaviors, and self-perceptions of low-achieving African-American males with behavioral disorders. Behavioral Disorders, 18, 292-302.

Coleman, M., \& Vaughn, S. (2000). Reading interventions for students with emotional and behavioral disorders. Behavioral Disorders, 25(2), 93-104.

Cooper, J., Heron, T., \& Heward, W. (2007). Applied behavior analysis (2nd ed.). Upper Saddle River, NJ: Pearson/Merrill-Prentice Hall.

Council for Exceptional Children. (2007). Behavior disorders/emotional disturbances. Retrieved from http://www.cec.sped.org

Coutinho, M. (1986). Reading achievement of students identified as behaviorally disordered at the secondary level. Behavioral Disorders, 11, 200-207. 
Dictionary.com. (2008). Retrieved from

http://dictionary.reference.com/search?r=2\&q=Mispronunciation

Dawson, L. Venn, M.L., \& Gunter, P.L. (2000). The effects of teacher versus computer reading models. Behavioral Disorders, 25(2), 105-113.

Drevno, G.E., Kimball, J.W., Possi, M.K., Heward, W.L., Gardner, R., III, \& Barbetta, P.M. (1994). Effects of active student response during error correction on the acquisition, maintenance, and generalization of science vocabulary by elementary students: A systematic replication. Journal of Applied Behavior Analysis, 27, 179-180.

Ehri, L.C. (1995). Stages of development in learning to read words by sight. Journal of Research in Reading, 18, 116-125.

Elbaum, B., Vaughn, S., Hughes, M. T., \& Moody, S. W. (2000). How effective are oneto-one tutoring programs in reading for elementary students at risk for reading failure? A meta-analysis of the intervention research. Journal of Educational Psychology, 92, 605-619.

Epstein, M.H., Kinder, D., \& Bursuck, B. (1989). The academic status of adolescents with behavioral disorders. Behavioral Disorders, 14, 157-165.

Florida Department of Education. (2008). Florida comprehensive assessment test: Student performance results demographic report, 2000-2007. Retrieved from http://www.fcatresults.com/demog/

Freeland, J. T., Skinner, C. H., Jackson, B., McDaniel, C. E., \& Smith, S. (2000). Measuring and increasing silent reading comprehension rates: Empirically validating a repeated readings intervention. Psychology in the Schools, 37, 415429.

Fry, E., Fountoukidis, D., \& Polk, J. (1985). The new reading teacher's book of lists (2nd ed.). Englewood Cliffs, NJ: Prentice-Hall.

Fuchs, L. S., \& Fuchs, D. (1992). Identifying a measure for monitoring student reading progress. School Psychology Review, 21, 45 - 58.

Fuchs, L. S., Fuchs, D., \& Hosp, M. K. (2001). Oral reading fluency as an indicator of reading competence: A theoretical, empirical, and historical analysis. Scientific Studies of Reading, 5(3), 239-256. 
Fuchs, D., Fuchs, L. S., Thompson, A., Svenson, E., Yen, L., Otaiba, S. A., et al. (2001). Peer-assisted learning strategies in reading: Extensions for kindergarten, first grade, and high school. Remedial and Special Education, 22, 15-21.

Gibb, G.S., \& Wilder, L.K. (2003). Using functional analysis to improve reading instruction for students with learning disabilities and emotional/behavioral disorders. Preventing School Failure, 46, 152-157.

Good, R. H., \& Kaminski, R. A. (Eds.). (2002). Dynamic indicators of basic early literacy skills: DIBELS (6th ed.). Eugene, OR: Institute for Development of Educational Achievement.

Greenbaum, P.E., Dedrick, R.F., Friedman, R.M., Kutash, K., Brown, E.C., Lardieri, S.P., et Al. (1996). National Adolescent and Child Treatment Study (NACTS): Outcomes for children with serious emotional and behavioral disturbance. Journal of Emotional and Behavioral Disorders, 4, 130-146.

Greenwood, C.R., Delquadri, J., \& Hall, R.V. (1989). Longitudinal effects of classwide peer tutoring. Journal of Educational Psychology, 81, 371-383

Gunter, P.L., Jack, S.L., Shores, R.E., Carrell, D.E., \& Flowers, J. (1993). Lag sequential analysis as a tool for functional analysis of student disruptive behavior in classrooms. Journal of Emotional and Behavioral Disorders, 1, 138-148.

Heward, W.L. (1994). Three "low-tech" strategies for increasing the frequency of active student responding during group instruction. In R. Gardner, D. Sainato, J. Cooper, T. Heron, W. Heward, J. Eshleman, \& T. Grossi (Eds.). Behavior analysis in education: Focus on measurably superior instruction (pp. 173-197). Belmont, CA: Brooks-Cole.

Heward, W.L. (1996). Everyone participates in this class: Using response cards to increase active student response. Teaching Exceptional Children, 28(2), 4-10.

Hinshaw, S.P. (1992). Externalizing behavior problems and academic underachievement in childhood and adolescence: Casual relationships and underlying mechanisms. Psychological Bulletin, 111, 127-155.

Hitchcock, C. H., Prater, M. A., \& Dowrick, P. W. (2004). Reading comprehension and fluency: Examining the effects of tutoring and video self-modeling on first-grade students with reading difficulties. Learning Disability Quarterly, 27, 89-103.

Homan, S. P., Klesius, J. P., \& Hite, C. (1993). Effects of repeated readings and nonrepetitive strategies on students' fluency and comprehension. Journal of Educational Research ,87(2), 94-99. 
Huby, H.S. (2001). Encouraging active student participation. College Teaching, 49(4), 141.

Ishii-Jordan, S.R.(2000). Behavioral interventions used with diverse students. Behavioral Disorders, 25, 299-309.

Jerome, A., \& Barbetta, P.M. (2005). The effect of active student responding during computer-assisted instruction on social studies learning by students with learning disabilities. Journal of Special education Technology, 20(3), 13-23.

Kauffman, J.M. (2005). Characteristics of children's behavior disorders (7th ed.). Columbus, $\mathrm{OH}$ : Merrill.

Kauffman, J. M. (2001). Characteristics of emotional and behavioral disorders in children and youth. (7th ed.). Upper Saddle River, NJ: Merrill/ Prentice Hall.

Kostwewicz, D.E., \&Kubina, R.M. (2008). The national reading panel guidepost: A review of reading outcome measures for students with emotional and behavioral disorders. Behavioral Disorders, 33(2),62-74.

Kuhn, M.R., \& Stahl, S.A. (2003). Fluency: A review of developmental and remedial practices. Journal of Educational Psychology, 95(19), 3-21.

LaBerge, D.,\& Samuels, S. J. (1974). Toward a theory of automatic information processing in reading. Cognitive Psychology, 6, 293-323.

Landa, K. G., \& Barbetta, P. M. (2010). Effects of repeated readings on reading abilities of english language learners with specific learning disabilities. Manuscript in progress.

Landrum, T.J., \& Kauffman, J.M. (2003). Emotionally disturbed, education of. In J.W. Guthrie (Ed.), Encyclopedia of education (2nd ed., pp.726-728). New York, NY: MacMillan Reference.

Landrum, T.J., Tankersley, M., \& Kauffman, J.M. (2003). What is special about special education of students with emotional and behavioral disorders? Journal of Special Education, 37, 148-156.

Lane, K.L., Barton-Arwood, S.M., Nelson, R.J., \& Wehby, J. (2008). Academic performance of students with emotional and behavioral disorders served in a selfcontained setting. Journal of Behavioral Education, 17(1), 43-62. doi:10.1007/s 10864-007-9050-1 
Lane, K. L., Wehby, J. H., \& Cooley, C. (2006). Teacher expectations of student's classroom behavioracross the grade span: Which social skills are necessary for success? Exceptional Children, 72, 153-167.

Lane, K. L., Wehby, J. H., Little, M. A., \& Cooley, C. (2005a). Academic, social, and behavioral profilesof students with emotional and behavioral disorders educated in self-contained classrooms and self-contained schools: Part I—are they more alike than different?Behavior Disorders, 30, 349-361.

Lane, K. L., Wehby, J. H., Little, M. A., \& Cooley, C. (2005b). Students educated in selfcontained classes and self-contained schools: Part II-How do they progress over time?Behavior Disorders, 30, 363-374.

Lazarus, B. D., \& Callahan, T. (2000). Attitudes toward reading expressed by elementary school students diagnosed with learning disabilities. Reading Psychology, 21, 271282.

Le Vasseur, V.M., Macaruso, P., \& Shankweiler, D. (2008). Promoting gains in reading fluency: A comparison of three approaches. Read Writ (21)3, 205-230.

Levy, S., \& Chard, D. (2001a). Research on reading instruction for students with emotional and behavioural disorders. International Journal of Disability, Development, and Education, 48, 429-444.

Levy, S., \& Chard, D.J. (2001b). Using functional analysis to improve reading instruction for students with learning disabilities and emotional/behavioral disorders. International Journal of Disability, Development and Education, 48, 429-444.

Linan-Thompson, S., Vaughn, S., Hickman-Davis, P., \& Kouzekanani, K. (2003). Effectiveness of supplemental reading instruction for second-grade English language learners with reading difficulties. Elementary School Journal, 103, 221238.

Lingo, A.S., Slaton, D.B., \& Jolivette, K. (2006). Effects of corrective reading on the reading abilities of classroom behaviors of middle school students with reading deficits and challenging behavior. Behavioral Disorders, 31(3), 265-283.

Locke, W.R.,\& Fuchs, L.S. (1995). Effects of peer-mediated reading instruction on the on-task behavior and social interaction of children with behavior disorders. Journal of Emotional and Behavioral Disorders, 3, 92-99.

Maheady, L., Mallette, B., Harper, G.F., \& Sacca, K. (1991). Heads together: A peer mediated option for improving the academic achievement of heterogeneous learning groups. Remedial and Special Education, 12(2), 25-33. 
Malanga, P.R., \&Sweeney, W.J. (2008). Increasing active student responding in a university applied behavior analysis course: The effect of daily assessment and response cards in end of week quiz scores. Journal of Behavioral Education, 17(2),187-199.

Manset-Williamson, G., \& Nelson, J. M. (2005). Balanced, strategic reading instruction for upper-elementary and middle school students with reading disabilities: A comparative study of two approaches. Learning Disability Quarterly, 28, 59-74.

Mathes, P.G., \& Fuchs, L.S. (1993). Peer-mediated reading instruction in special education resource rooms. Learning Disabilities Research and Practice, 8, 233243.

Miami-Dade County Public Schools. (2007). Guide to completing an individual LEP student plan: Elementary

Miller, A.D., Hall, S.W., \& Heward, W.L. (1995). The effects of sequential 1-minute trials with and without inter trail feedback on general and special education students' fluency with main facts. Journal of Behavioral Education, 5, 319-345.

Mooney, P., Epstein, M. H., Reid, \& Nelson, J. R. (2003). Status of and trends in academic intervention inresearch for students with emotional disturbance.Remedial and Special Education, 24, 273-287.

Narayan, J.S., Heward, W.L., Gardner, R. III, Courson, F.H., \& Omness, C. (1990). Using response cards to increase student participation in an elementary classroom. Journal of Applied Behavior Analysis, 23, 483-490.

National Dissemination Center for Children with Disabilities. (2007). Disability info: emotional disturbance. Retrieved from http://www.nichcy.org/pubs/factshe/fs5txt.htm

National Reading Panel. (2000). Teaching children to read: An evidence-based assessment of the scientific research literature on reading and its implications for reading instruction. Washington, DC: National Institute of Child Health and Development.

Nelson, J. S., Alber, S. R., \& Gordy, A. (2004). Effects of systematic error correction and repeated readings on the reading accuracy and proficiency of second-graders with disabilities. Education \& Treatment of Children, 27, 186-198.

Nelson, J. R., Babyak, A., Gonzalez, J., E., \& Benner, G. H. (2003). An investigation of the characteristicsof K-12 students with comorbid emotional disturbance and significant language deficits served inpublic schools. Behavioral Disorders, 29, 25 33. 
Nelson, J.R., Brenner, G.J., Lane, K., \& Smith, B.W. (2004). An investigation of the academic achievement of K-12 students with emotional and behavioral disorders in public schools settings. Exceptional Children, 71, 59-73.

Ojwaya, J. A. (2008). Effects of repeated reading and sequential reading on oral reading fluency and sight word knowledge (Unpublished master's thesis). Miami University, Oxford, $\mathrm{OH}$.

Pattillo, S. T., Heller, K. W., \& Smith, M. (2004). The impact of a modified repeatedreading strategy paired with optical character recognition on the reading rates of students with visual impairments. Journal of Visual Impairment and Blindness, $98,28-46$.

Peak, J.,\& Dewalt, M. (1994). "Reading achievement: effects of computerized reading management and enrichment. Journal of School Research and Information 12(1), $31-34$.

Pressley, M. (2006, April 29). What the future of reading research could be. Paper presented at the International Reading Association's Reading Research 2006, Chicago, IL.

Pressley, M., Gaskins, I., \& Fingeret, L. (2006). Instruction and development of reading fluency in struggling readers. In S.J. Samuels \& A.E. Farstrup (Eds.), What research has to say about fluency instruction (pp.47-69). Newark, DE: International Reading Association.

Rashotte, C.A., \&Torgenson, J.K., (1985). Repeated reading and reading fluency in learning disabled children. Reading Research Quarterly, (20)2, 180-188.

Rasinski, T. V. (2000). Speed does matter in reading. Reading Teacher, 54, 146-151.

Rasinski, T. V., \& Padak, N. (2004). Effective reading strategies: Teaching children who find reading difficult (3rd ed.). Upper Saddle River, NJ: Pearson Education.

Reid, R., Gonzalez, J.E., Nordness, P.D., Trout, A., \& Epstein, M.H. (2004). A metaanalysis of the academic status of students with emotional/behavioral disturbance. The Journal of Special Education, 38, 130-144.

Rittner, B., \& Dozier, C.D. (2000). Effects of court-ordered substance abuse treatment in child protective services. Social Work, 45, 131-140.

Rivera, M.O., Al-Otaiba, S., \& Koorland, M.A. (2006). Reading instruction for students with emotional and behavioral disorders and at risk of antisocial behaviors in primary grades: Review of literature. Behavioral Disorders, 31(3), 312-322. 
Roshette, C. A., \& Torgesen, J. K. (1985). Repeated reading and reading fluency in learning disabled children. Reading Research Quarterly, (20)2, 180-188.

Roswell, F.G., Chall, J.S., Curtis, M.E., \& Kearns, G. (2005). Diagnostic assessment of reading. Rolling Meadows, IL: Riverside Publishing.

Ruhl, K.L., \& Berlinghoff, D.H. (1992). Research on improving behaviorally disordered students; academic performance: A review of the literature. Behavioral Disorders, 17, 178-190.

Samuels, S. J. (1979). The method of repeated readings. The Reading Teacher, 32, $403-$ 408.

Samuels, S. J., \& Flor, R. F. (1997). The importance of automaticity for developing expertise in reading. Reading and Writing Quarterly, 13, 107-121.

Samuels, S. J., \& Wu, Y. (in press). The effects of immediate feedback on reading achievement. Manuscript submitted for publication. University of Minnesota.

Samuels, S.J., \& Wu, Y. (2004). How the amount of time spent on independent reading affects reading achievement: A response to the National Reading Panel (Unpublished manuscript). Minneapolis, MN: University of Minnesota, Department of Educational Psychology.

Scott, T.M., \& Shearer-Lingo, A. (2002). The effects of reading fluency instruction on the academic and behavior success of middle school students in a self-contained EBD classroom. Preventing School Failure, 46, 167-173.

Skinner, C.H., Belifore, P.J., Mace, H.W., Williams-Wilson, S., \& Johns, G.A. (1997). Altering response topography to increase response efficiency and learning rates. School Psychology Quarterly, 12, 54-64.

Snow, C. E., Burns, M. S., \& Griffin, P. (Eds.). (1998). Preventing reading difficulties in young children. Washington, DC: National Academy Press.

Stahl, S. A., \& Heubach, K. M. (2005). Fluency-oriented reading instruction. Journal of Literacy Research, 37, 25-60.

Staubitz, J.E., Cartledge, G., Yurick, A.L. \& Lo, Y. (2005). Repeated reading for students with emotional or behavioral disorders: Peer-and trainer-mediated instruction. Behavioral Disorders, 31(1), 51-54. 
Stoddard, K., Valcante, G., Sindelar, P. T., O'Shea, L., \& Algozzine, B. (1993). Increasing reading rate and comprehension: The effects of repeated readings, sentence segmentation, and intonation training. Reading Research and Instruction, 32, 53-65.

Stokes, T. F., \& Baer, D. M. (1977). An implicit technology of generalization. Journal of Applied Behavior Analysis, 10, 349-367.

Stromquist, N.P. (2008). The political benefits of adult literacy: Presumed and real effects. International Multilingual Research Journal, 2, 88-101.

Strong, A., Wehby, J.H., Falk, K.B., \& Lane, K.L. (2004). The impact of a structured reading curriculum and repeated reading on the achievement of junior high students with emotional and behavioral disorders. School Psychology Review, $3(4), 561-584$.

Sutherland, K.S., Alder, N., \& Gunter, P.L. (2003). The effect of varying rates of opportunities to respond to academic requests on the classroom behavior of students with EBD. Journal of Emotional and Behavioral Disorders, 11(4), 239248.

Sutherland, K.S., \& Singh, N.N. (2004). Learned helplessness and students with emotional or behavioral disorders: Deprivation in the classroom. Behavioral Disorders, 29, 169-181.

Sutherland, K.S., \& Wehby, J.H. (2001). Exploring the relation between increased opportunities to respond to academic requests and the academic and behavioral outcomes of students with emotional and behavioral disorders: A review.

Remedial and Special Education, 22, 113-121.

Tam, K. Y., Heward, W. L., \& Heng, M. A. (2006). A reading instruction intervention program for English-language learners who are struggling readers. The Journal of Special Education, 40, 79-93.

Taylor, B. M., Pearson, P. D., Peterson, D. S., \& Rodriguez, M. C. (2003). Reading growth in high-poverty classrooms: The influence of teacher practices that encourage cognitive engagement in literacy learning. The Elementary School Journal, 104(1), 3-28.

Therrien, W., Wickstrom, K., \& Jones, K. (2006). Effect of a combined repeated reading and question generation intervention on reading achievement. Learning Disabilities Research and Practive, 21(2), 89-97. 
Therrien, W.J., Ojwaya, J.A., Wickstrom, K.F., \& Jones, K.J. (2008). Comparison of the effects of repeated reading and sequential reading in fluency and word acquisition. Balanced Reading Instruction, 15(1), 27-38.

Therrien, W. J., \& Kubina, R. M. (2006). Developing reading fluency with repeated reading. Intervention in School \& Clinic, 41, 156-160.

Torgenson, J.K. (2002). The prevention of reading difficulties. Journal of School Psychology, 40, 7-26.

Trout, A. L., Nordness, P. D., Pierce, C. D., \& Epstein, M. H. (2003). Research on the academic status ofchildren with emotional and behavioral disorders: A review of the literature from 1961 to 2000.Journal of Emotional and Behavioral Disorders, 11, 198-210.

U.S. Department of Education. (2001). Twenty-third annual report to Congress on the implementation of the Individuals with Disabilities Act. Washington, DC: Author.

U.S. Department of Education. (2005). Institute of Education Sciences, National Center for Education Statistics, Long term trends: Reading. Retrieved from http://nces.ed.gov/nationsreportcard/ltt/results2004

U.S. Department of Education. (2006). Twenty-sixth annual report to Congress on the implementation of the Individuals with Disabilities Education Act. Washington, DC: Author.

U.S. Department of Education, National Center for Education Statistics. (2004). The condition of education 2004 (NCES 2004-077). Washington DC: U.S. Government Printing Office.

Vadasay, F., \& Sanders, E.A. (2008). Repeated reading intervention: Outcomes and interactions with readers' skills and classroom instruction. Journal of Educational Psychology, 100(2), 272-280.

Valencia, S. W., \& Pearson, P. D. (1986). Reading assessment: Time for a change. The Reading Teacher, 40, 726-732.

Vallely, R.J., \& Shriver, M.D. (2003). An examination of the effects of repeated readings with secondary students. Journal of Behavioral Education, 12, 55-76.

Vaughn, S., Levy, S., Coleman, M. and Bos, C.S. (2002). Reading instruction for students with ld and ebd: A synthesis of observational studies. The Journal of Special Education, 36(1), 2-13. 
Vincent, E.A. (2009). Effects of repeated reading and sequential reading on fluency acquisition (Unpublished manuscript). Miami University, Oxford, $\mathrm{OH}$.

Von Bon, W.H.J., Boksebeld, L.M., Font Freide, T.A.M, \& Van Den Hurk, A.J.M. (1991). A comparison of three methods of reading-while- listening. Journal of Learning Disabilities, 24(8), 471-476.

Wagner, M., \& Cameto, R. (2004). The characteristics, experiences, and outcomes of youth withemotional disturbances.NLTS2 Data Brief, 3(2).

Walker, H.M., Ramsey, E., \& Gresham, F.M. (2004). Antisocial behavior in school: Evidence- based practices (2nd ed.). Belmont, CA: Wasworth.

Webby, J.H., Lane, K.L., \& Falk, K.B. (2003). Academic instruction for students with emotional and behavioral disorders. Journal of Emotional and Behavioral Disorders, 11, 194-197.

Weinstein, G., \& Cooke, N. L. (1992). The effects of two repeated reading interventions on generalization of fluency. Learning Disability Quarterly, 15, 21-28.

Wexler, J., Vaughn, S., Edmonds, M., \& Reutebuch, C.K. (2008). A synthesis of fluency interventions for secondary struggling readers. Reading and Writing: An Interdisciplinary Journal, 21(4), 317-347.

Woodcock, R.W., Mather, N., \& Shrank, K.S. (2001). Woodcock-Johnson III Diagnostic Reading Battery (3rd ed.). Rolling Meadows, IL: Riverside Publishing

Woods, M., \& Moe, A. (2007). Analytical reading inventory (8th ed.). Upper Saddle River, NJ: Prentice Hall.

Yell, M.L. (1992). A comparison of three-instructional approaches on task attention, interfering behaviors, and achievement of students with emotional and behavioral disorders. Dissertation Abstracts International, 53 (09), 3174. (University Microfilms No. 9236987) 
APPENDIX A

PARENT/GUARDIAN CONSENT FORM 


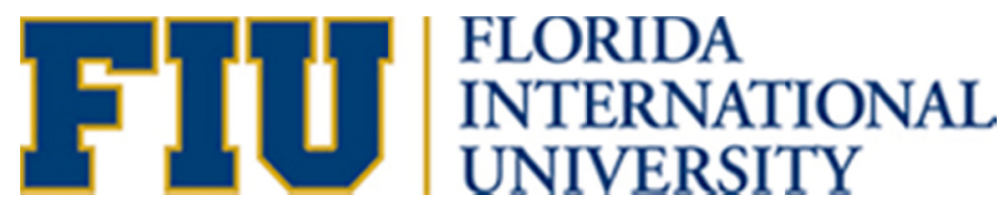

\section{CONSENT TO PARTICIPATE IN A RESEARCH STUDY}

Your child, , is being considered for participation in a research study. The investigator of this study is Raul Escarpio and he is a student at Florida International University (FIU). The study will involve students reading below grade level. Your child's participation will require 20 minutes of his or her regular tutoring time.

If you permit your child to be a part of the study, we will integrate the activities into the first 20 minutes of his or her regularly scheduled tutoring time. The research method is similar to what is done during a regular tutoring session. It involves reading a short passage and answering questions about the passage. The exception will be that the researcher will be collecting data on how many words per minute your child reads and how many questions he or she answers correctly at the end of each 20 minute session. The researcher does not expect any harm to your child by being in the study. If he or she becomes frustrated or upset at any point in the study he or she may ask to take a break. You may withdraw your child from the study at any time if you feel in any way uncomfortable. There is no cost to you for your child's participation in the study. This study will provide him or her with additional reading assistance.

The data collected will be identified by a pseudonym and not your child's name. All of the information is private and will not be shared with anyone unless required by law. The data will be presented in a graph like table. Your child may ask questions at any time. If you choose not to allow your child to participate no one will be upset with you.

If you would like more information about the research, you may contact Raul Escarpio at (305) 546-5501. You may also contact the faculty advisor at FIU, Dr. Patricia Barbetta at (305) 348-2552. If you would like to ask someone about being a subject in this study you may contact Dr. Patricia Price, the Chairperson of the FIU Institutional Review Board at 305-348-2618 or 305-348-2494.

Thank you for your time.

Raul Escarpio

Florida International University

If you have had all of your questions answered to your liking and you would like to be in the study, sign below. Your signature indicates that you will allow/deny your child participate in the in the study.

I give permission for (Print Child's Name) to participate in this study. to participate in this study. 


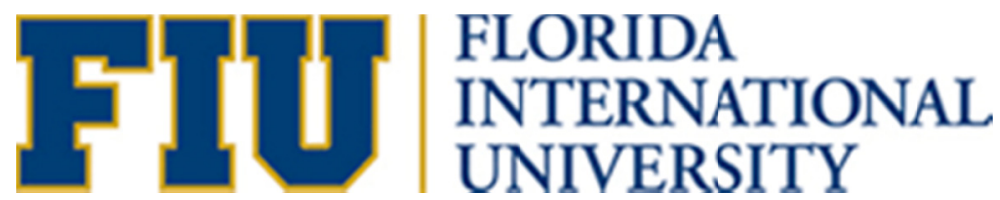

\section{CONSENTIMIENTO PARA TOMAR PARTE EN UN ESTUDIO DE INVESTIGACION}

Su hijo(a),

, ha sido tomado(a) en consideración para participar en un estudio de investigación. El investigador de este estudio es Raul Escarpio, quien es un estudiante al nivel doctoral en la Universidad Internacional de la Florida (FIU). El enfoque del estudio es de estudiantes que leen por debajo de sus respectivos grados escolares. La participación de su hijo(a) abarcara 20 minutos diarios que están incluidos en sus sesiones regulares de enseñanza suplementaria.

Si usted permite que su hijo(a) participe en este estudio, integraremos las actividades del estudio en los primeros 20 minutos de sus clases suplementarias. El método de investigación incluye una lectura corta y preguntas acerca del tema repasado durante la lectura. La única diferencia implementa supervisión por la investigadora cuya tarea será reunir data acerca del número de palabras leídas por minuto por su hijo(a) y el número de preguntas contestadas correctamente a la conclusión de cada sesión. La investigadora de este estudio no espera que ningún daño resulte contra su hijo(a) durante el transcurso del estudio Si su hijo(a) se encuentra incomodo(a) durante el lapso del estudio, él/ella podrá disculparse de su participación hasta que él/ella determine apropiado resumir su actividad. Usted puede retirar a su hijo(a) del estudio en cualquier momento si usted lo determina apropiado por cualquier razón. La participación de su hijo(a) en este estudio resultara en ningún costo de su parte. Este estudio esta diseñado con el propósito de proveer ayuda adicional en la lectura de su hijo(a).

La identidad de su hijo(a) se mantendrá estrictamente confidencial y solamente representada por un seudónimo en este estudio de investigación. Toda la información es completamente privada y no será compartida con terceras personas al menos que sea requerido por la ley. Los datos adquiridos en el estudio serán presentados en una forma gráfica y científica. Si por alguna razón usted decide no dejar la participación de su hijo(a) en este estudio de investigación, tenga en cuenta que no habrá ningún tipo de consecuencias negativas o perjudicará a su hijo(a). Adicionalmente, la voz de su hijo/a puede ser grabado/a come parte de este estudio.

Si usted necesita más información acerca de este estudio de investigación, puede llamar a Raul Escarpio al (305) 5465501, o a la Dra. Patricia Barbetta al (305) 348-2552, a su conveniencia. Si a usted le gustaría adquirir mas información acerca de este estudio incluyendo la participación de su hijo(a) puede comunicarse con la directora de los estudios sancionados por el Institutional Review Board (IRB), la Dra. Patricia Price, al (305) 348-2618 o al (305) 3482494.

Gracias por su atención.

\section{Raul Escarpio}

Florida International University

Si usted se encuentra satisfecho(a) con el contenido de este consentimiento y todas sus preguntas han sido adecuadamente contestadas y está de acuerdo en la participación de su hijo(a) en este estudio de investigación por favor tome el tiempo de firmar en la línea de abajo. Su firma también indica que usted permitirá a su hijo(a) en participar en el estudio.

Yo doy permiso para

(Imprimir nombre del niño/a) que participe en el estudio.

Firma del Padre/Tutor

Fecha

Yo NO doy permiso para

(Imprimir nombre del niño/a) que participe en el estudio.

Firma del Padre/Tutor

Florida International University
University Park, Miami, Florida 33199


APPENDIX B

PARTICIPANT ASSENT FORM 


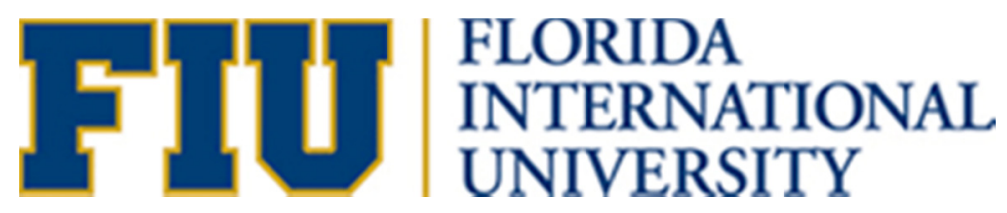

ASSENT TO PARTICIPATE IN A RESEARCH STUDY

Title: Comparison of Sequential and Repeated Readings on Reading Abilities of Students With Emotional And/Or Behavioral Disorders

My name is Raul Escarpio and I am a student at Florida International University (FIU). You and some of your classmates are being asked to participate in a research study. This study will look at whether reading something one time or three times helps you to read it faster and understand it better. Being part of this study will give you a chance to practice your reading with me as your tutor.

Your parent/guardian must give you permission to take part in the study. If you do take part, you will be meeting with me for 20 minutes a day. We will meet in school.

1. You will read a short passage one time or three times.

2. You will answer questions about the passage.

3. I will record the reading and questions.

4. I will listen to the recordings. This will help me count how many words you have read and how many questions you are answering correctly.

There is no charge for being a part of this study. Reading the passages will not harm you in any way. If you get tired or upset, you may ask for a break. I only want you to do your best. Taking part in this study will not help or hurt your grades. You or your parent can ask to stop taking part in the study at any time.

None of the information I collect will have your name on it. Only I will know which ones are your scores. I will write about them in my research paper using a letter (such as student " $A$ "). If you choose not to take part no one will be upset with you.

If you have any questions you can ask anytime. You and your parents may contact me at (305) 546-5501. You may also contact my teacher at FIU, Dr. Patricia Barbetta at (305) 348-2552. If you or your parent feels that you are not being treated fairly in this study, you may contact Dr. Patricia Price, the Chairperson of the FIU Institutional Review Board at 305-348-2618 or 305348-2494.

If you would like to be in the study, sign below. You will get a copy of this form.

\begin{tabular}{ccc}
\hline Sign Here & & Date \\
\cline { 1 - 1 } & & Date
\end{tabular}


APPENDIX C

TREATMENT FIDELITY FORM 
Equivalent Non-Repeated Reading

Treatment Fidelity Form

Participant Pseudonym:

Observer Filling Out This Form:

Date of Session:

Time:

Date of Completion of This Form: Time:

Passage \#: __ Passage Topic:

Number of Words in Passage:

Directions: Check off whether the researcher performs the following tasks. 


\begin{tabular}{|c|c|c|c|c|c|c|c|c|c|}
\hline \multicolumn{10}{|c|}{ Vocabulary Practice } \\
\hline \multirow{2}{*}{\multicolumn{2}{|c|}{ Description of Procedures }} & \multicolumn{5}{|c|}{ New Words } & \multicolumn{3}{|c|}{ Implemented? } \\
\hline & & Word 1 & Word 2 & Word 3 & Word 4 & Word 5 & N/A & Yes & No \\
\hline 1. & $\begin{array}{l}\text { The researcher asks the participant: } \\
\text { "Can you read the word on the card?" }\end{array}$ & & & & & & & & \\
\hline 2. & $\begin{array}{l}\text { (If participant cannot read the word) } \\
\text { The researcher states the word. }\end{array}$ & & & & & & & & \\
\hline 3. & $\begin{array}{l}\text { The researcher asks the participant "Can } \\
\text { you use the word in a sentence?" }\end{array}$ & & & & & & & & \\
\hline 4. & $\begin{array}{l}\text { If the participant can use the word in a } \\
\text { sentence, the researcher says, "correct." }\end{array}$ & & & & & & & & \\
\hline 5. & $\begin{array}{l}\text { After stating that the participant is } \\
\text { correct the researcher moves on to the } \\
\text { next word. }\end{array}$ & & & & & & & & \\
\hline 6. & $\begin{array}{l}\text { (If the participant cannot use the word } \\
\text { in a sentence) The researcher reads the } \\
\text { definition from the back of the card. }\end{array}$ & & & & & & & & \\
\hline 7. & $\begin{array}{l}\text { The researcher asks the participant to } \\
\text { use the word in a sentence. }\end{array}$ & & & & & & & & \\
\hline 8. & $\begin{array}{l}\text { (If the participant cannot use the word in a } \\
\text { sentence) The researcher uses the word in a } \\
\text { sentence. }\end{array}$ & & & & & & & & \\
\hline & & & & & & & & & \\
\hline & & & & & & & & & \\
\hline
\end{tabular}




\begin{tabular}{|c|c|c|c|c|}
\hline \multicolumn{5}{|c|}{ Equivalent Non-Repeated Reading-Error Correction-Fluency Assessment } \\
\hline \multicolumn{2}{|r|}{ Description of Procedures } & \multicolumn{3}{|c|}{ Implemented? } \\
\hline & & N/A & Yes & No \\
\hline 1. & The researcher tells the participant to read the passage. & & & \\
\hline 2. & $\begin{array}{l}\text { During this reading, when the participant makes an error, the researcher immediately states the } \\
\text { word correctly. }\end{array}$ & & & \\
\hline 3. & The researcher prompts the participant to repeat the word aloud. & & & \\
\hline 4. & $\begin{array}{l}\text { (After the participant repeats the word) The researcher prompts the participant to repeat the } \\
\text { sentence containing the word. }\end{array}$ & & & \\
\hline 5. & $\begin{array}{l}\text { Following the reading of the passage, the researcher prompts the participant to read each word } \\
\text { read incorrectly in isolation. }\end{array}$ & & & \\
\hline 6. & $\begin{array}{l}\text { The researcher prompts the participant to read the passage again from the beginning for one } \\
\text { minute for the fluency assessment. }\end{array}$ & & & \\
\hline
\end{tabular}




\begin{tabular}{|c|c|c|c|c|}
\hline \multicolumn{5}{|c|}{ Comprehension Questions } \\
\hline \multirow{2}{*}{\multicolumn{2}{|c|}{ Description of Procedures }} & \multicolumn{3}{|c|}{ Implemented? } \\
\hline & & \multirow{2}{*}{$\mathrm{N} /$} & \multirow{2}{*}{ Yes } & \multirow{2}{*}{ No } \\
\hline 1. & $\begin{array}{l}\text { (After the fluency assessment) The researcher asks the participant the first literal } \\
\text { comprehension question. }\end{array}$ & & & \\
\hline 2. & The researcher gives the participant five seconds to respond. & & & \\
\hline 3. & The researcher asks the participant the second literal comprehension question. & & & \\
\hline 4. & The researcher gives the participant five seconds to respond. & & & \\
\hline 5. & The researcher asks the participant the third literal comprehension question & & & \\
\hline 6. & The researcher gives the participant five seconds to respond. & & & \\
\hline 7. & The researcher asks the participant the fourth literal comprehension question. & & & \\
\hline 8. & The researcher gives the participant five seconds to respond. & & & \\
\hline 9. & The researcher asks the participant the fifth literal comprehension question. & & & \\
\hline 10. & The researcher gives the participant five seconds to respond. & & & \\
\hline 11. & $\begin{array}{l}\text { The researcher issues a closing statement in which he commends the participant } \\
\text { for working hard during the session }\end{array}$ & & & \\
\hline
\end{tabular}


Non-Repeated Reading

Treatment Fidelity Form

\section{Participant Pseudonym:}

Observer Filling Out This Form:

Date of Session:

Time:

Date of Completion of This Form: Time:

Passage \#: ___ Passage Topic:

Number of Words in Passage:

Directions: Check off whether the researcher performs the following tasks. 


\begin{tabular}{|c|l|c|c|}
\hline \multicolumn{3}{|c|}{ Equivalent Non-Repeated Reading-Error Correction-Fluency Assessment } \\
\hline \multicolumn{2}{|c|}{ Description of Procedures } & Implemented? \\
\cline { 2 - 4 } & \multicolumn{1}{|c|}{$\begin{array}{c}\text { N/ } \\
\text { A }\end{array}$} & $\begin{array}{c}\text { Ye } \\
\text { S }\end{array}$ & No \\
\hline 1. & The researcher tells the participant to read the passage. & & \\
\hline 2. & $\begin{array}{l}\text { During this reading, when the participant makes an error, the researcher immediately } \\
\text { states the word correctly. }\end{array}$ & & \\
\hline 3. & The researcher prompts the participant to repeat the word aloud. & & \\
\hline 4. & $\begin{array}{l}\text { (After the participant repeats the word) The researcher prompts the participant to } \\
\text { repeat the sentence containing the word. }\end{array}$ & & \\
\hline 5. & $\begin{array}{l}\text { Following the reading of the passage, the researcher prompts the participant to read } \\
\text { each word read incorrectly in isolation. }\end{array}$ & & \\
\hline 6. & $\begin{array}{l}\text { The researcher prompts the participant to read the passage again from the beginning } \\
\text { for one minute for the fluency assessment. }\end{array}$ & & \\
\hline
\end{tabular}




\begin{tabular}{|c|c|c|c|c|}
\hline \multicolumn{5}{|c|}{ Comprehension Questions } \\
\hline \multicolumn{2}{|r|}{ Description of Procedures } & \multicolumn{3}{|c|}{ Implemented? } \\
\hline & & $\mathrm{N} / \mathrm{A}$ & Yes & No \\
\hline 1. & $\begin{array}{l}\text { (After the fluency assessment) The researcher asks the participant the first literal } \\
\text { comprehension question. }\end{array}$ & & & \\
\hline 2. & The researcher gives the participant five seconds to respond. & & & \\
\hline 3. & The researcher asks the participant the second literal comprehension question. & & & \\
\hline 4. & The researcher gives the participant five seconds to respond. & & & \\
\hline 5. & The researcher asks the participant the third literal comprehension question & & & \\
\hline 6. & The researcher gives the participant five seconds to respond. & & & \\
\hline 7. & The researcher asks the participant the fourth literal comprehension question. & & & \\
\hline 8. & The researcher gives the participant five seconds to respond. & & & \\
\hline 9. & The researcher asks the participant the fifth literal comprehension question. & & & \\
\hline 10 & The researcher gives the participant five seconds to respond. & & & \\
\hline 11 & $\begin{array}{l}\text { The researcher issues a closing statement in which he commends the participant for } \\
\text { working hard during the session }\end{array}$ & & & \\
\hline
\end{tabular}


Repeated Reading

Treatment Fidelity Form

Participant Pseudonym:

Observer Filling Out This Form:

Date of Session: ___ Time:

Date of Completion of This Form: ___ Time:

Passage \#: __ Passage Topic:

Number of Words in Passage:

Directions: Check off whether the researcher performs the following tasks. 


\begin{tabular}{|c|c|c|c|c|c|c|c|c|c|}
\hline \multicolumn{10}{|c|}{ Vocabulary Practice } \\
\hline \multirow{2}{*}{\multicolumn{2}{|c|}{ Description of Procedures }} & \multicolumn{5}{|c|}{ New Words } & \multicolumn{3}{|c|}{ Implemented? } \\
\hline & & Word 1 & Word 2 & Word 3 & Word 4 & Word 5 & $\mathrm{~N} / \mathrm{A}$ & Yes & No \\
\hline 1. & $\begin{array}{l}\text { The researcher asks the } \\
\text { participant: "Can you read the } \\
\text { word on the card?" }\end{array}$ & & & & & & & & \\
\hline 2. & $\begin{array}{l}\text { (If participant cannot read the } \\
\text { word) The researcher states the } \\
\text { word. }\end{array}$ & & & & & & & & \\
\hline 3. & $\begin{array}{l}\text { The researcher asks the } \\
\text { participant "Can you use the } \\
\text { word in a sentence?" }\end{array}$ & & & & & & & & \\
\hline 4. & $\begin{array}{l}\text { If the participant can use the } \\
\text { word in a sentence, the } \\
\text { researcher says, "correct." }\end{array}$ & & & & & & & & \\
\hline 5. & $\begin{array}{l}\text { After stating that the participant } \\
\text { is correct the researcher moves } \\
\text { on to the next word. }\end{array}$ & & & & & & & & \\
\hline 6. & $\begin{array}{l}\text { (If the participant cannot use the } \\
\text { word in a sentence) The } \\
\text { researcher reads the definition } \\
\text { from the back of the card. }\end{array}$ & & & & & & & & \\
\hline 7. & $\begin{array}{l}\text { The researcher asks the } \\
\text { participant to use the word in a } \\
\text { sentence. }\end{array}$ & & & & & & & & \\
\hline 8. & $\begin{array}{l}\text { (If the participant cannot use the } \\
\text { word in a sentence) The }\end{array}$ & & & & & & & & \\
\hline
\end{tabular}




\begin{tabular}{|c|c|c|c|c|}
\hline \multicolumn{5}{|c|}{ Repeated Reading-Error Correction-Fluency Assessment } \\
\hline & & \multicolumn{3}{|c|}{ Implemented? } \\
\hline & & $\mathrm{N} / \mathrm{A}$ & Yes & No \\
\hline 1. & The researcher tells the participant to read the passage. & & & \\
\hline 2. & $\begin{array}{l}\text { During this initial reading, when the participant makes an error, the researcher immediately } \\
\text { states the word correctly. }\end{array}$ & & & \\
\hline 3. & The researcher prompts the participant to repeat the word aloud. & & & \\
\hline 4. & $\begin{array}{l}\text { (After the participant repeats the word) The researcher prompts the participant to repeat the } \\
\text { sentence containing the word. }\end{array}$ & & & \\
\hline 5. & $\begin{array}{l}\text { Following the initial reading of the passage, the researcher prompts the participant to read } \\
\text { each word read incorrectly in isolation. }\end{array}$ & & & \\
\hline 6. & $\begin{array}{l}\text { The researcher prompts the participant to read the passage a second time from the } \\
\text { beginning. }\end{array}$ & & & \\
\hline 7. & The researcher prompts the participant to read the passage a third time from the beginning. & & & \\
\hline 8. & $\begin{array}{l}\text { The researcher prompts the participant to read the passage again from the beginning for one } \\
\text { minute for the fluency assessment. }\end{array}$ & & & \\
\hline
\end{tabular}




\begin{tabular}{|l|l|l|l|}
\hline \multicolumn{2}{|c|}{ Comprehension Questions } & \multicolumn{2}{l|}{ Implemented? } \\
\cline { 3 - 4 } & \multicolumn{1}{|c|}{ N/A } & Yes & No \\
\hline 1. & $\begin{array}{l}\text { (After the fluency assessment) The researcher asks the participant the first literal } \\
\text { comprehension question. }\end{array}$ & & \\
\hline 2. & The researcher gives the participant five seconds to respond. & & \\
\hline 3. & The researcher asks the participant the second literal comprehension question. & & \\
\hline 4. & The researcher gives the participant five seconds to respond. & & \\
\hline 5. & The researcher asks the participant the third literal comprehension question & & \\
\hline 6. & The researcher gives the participant five seconds to respond. & & \\
\hline
\end{tabular}


APPENDIX D

\section{INTEROBSERVER AGREEMENT FORM}


Inter-Observer Agreement (IOA) Form

Participant Identification Letter:

Passage \#:___ Passage Topic:

Session Date:

Directions: This sheet compares the data collected by the researcher with the data collected by the second observer. Using the data sheets independently completed by the researcher and the observer, do a word for word comparison of their marks in each of the following three categories.

$\underline{\text { Fluency Assessment }}$

\# of words agreed:

\# of words disagreed:

Types of Errors

\# of errors agreed:

\# of errors disagreed:

$\underline{\text { Literal Comprehension Question Assessment }}$

\# of questions agreed:

\# of questions disagreed:

\section{TOTAL}

Number of Agreements:

Number of Disagreements

IOA Formula

\# Agreements __ $\div$ \# Disagreements $\_\times 100=\ldots \% \mathrm{IO}$ 
APPENDIX E

\section{DATA COLLECTION FORM}




\section{Data Collection Form}

Participant Identification Letter:

Person Completing This Form (Check One):

Researcher

Second Observer, Name:

Session Date: Time:

Study Phase: (Check One)

Non-Repeated Reading Equivalent Non-Repeated Reading

Repeated Readings

Date of Completion of This Form: Time:

\section{$\underline{\text { Types of Errors }}$}

Directions: Directly on the passage below mark each error in reading with a slash (/). Above each slash, use the following abbreviations to identify the type of error. Place a slash with the word STOP above it in order to identify where the student stopped reading at one minute.

O- Omission

A- Addition

M- Mispronunciation

$\mathrm{H}$ - Hesitation more than $5 \mathrm{sec}$

Fluency Assessment:

Directions: Count the number of words read in one minute of reading by counting the words until the word STOP above.

Number of Words Correct per Minute:

\section{Literal Comprehension Question Assessment}

Directions: Mark each of the following questions to determine if the participant's response corresponds to the basal reader's key.

\begin{tabular}{|l|l|l|}
\hline \multicolumn{1}{|c|}{ Questions } & Correct & Incorrect \\
\hline 1. Type Question Here & & \\
\hline 2. Type Question Here & & \\
\hline 3. Type Question Here & & \\
\hline 4. Type Question Here & & \\
\hline 5. Type Question Here & & \\
\hline
\end{tabular}


Passage \#:

Passage Topic:

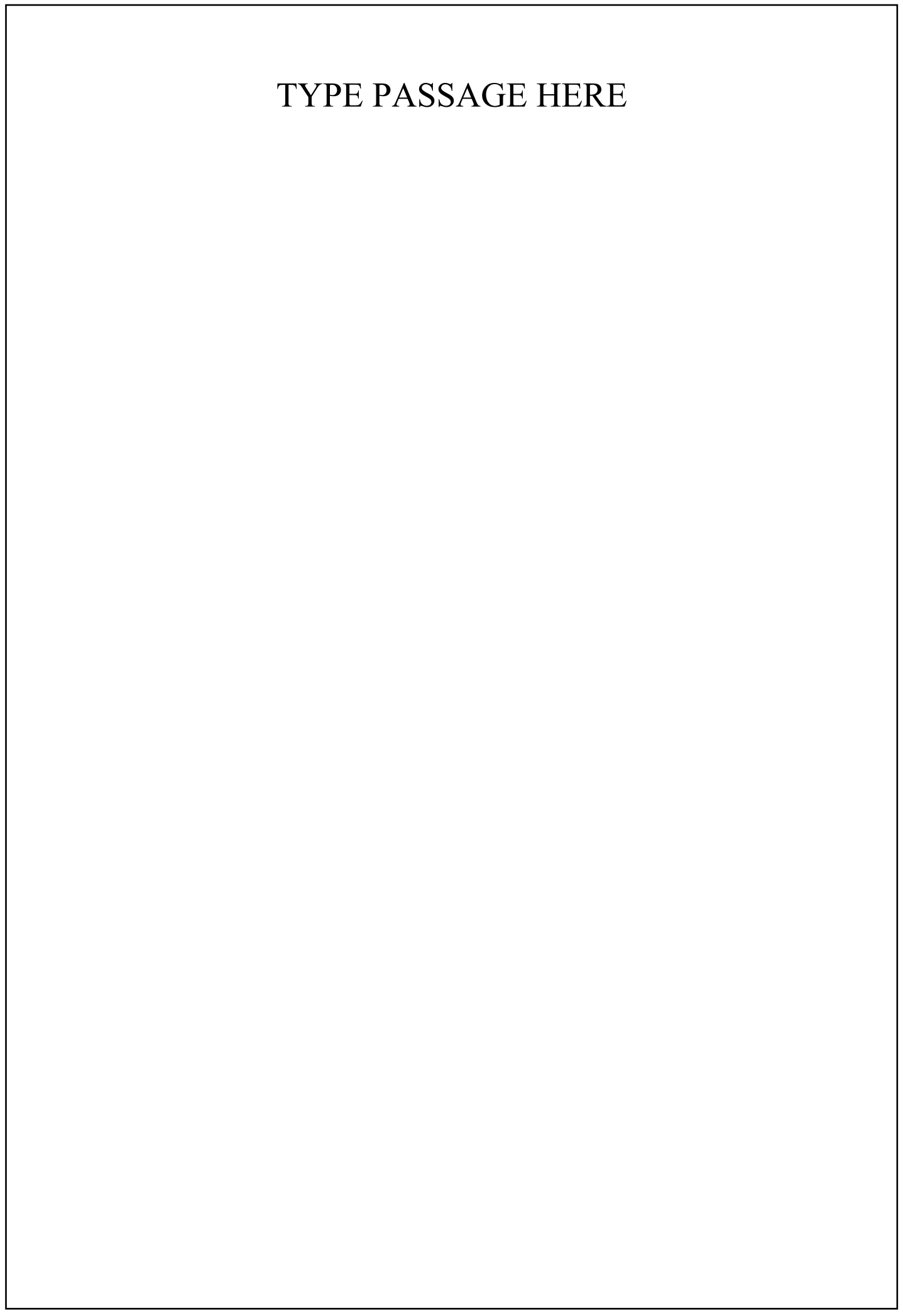


APPENDIX E

FLASHCARDS OF CHALLENGING WORDS 
blowhole

A hole at the top of the head that allows whales to breathe. 
APPENDIX G

\section{LITERAL COMPREHENSION QUESTIONS}




\section{Swimming with the Pod}

1. How do whales call to each other?

2. Who was speeding toward the shore as the family followed?

3. With whom do whales swim beneath?

4. What do scientists think keeps the whales' body clean?

5. What does a female cousin slap against the water? 
VITA

\section{RAUL ESCARPIO}

1999

1999-2009

2006

2009-Present

2005-2007
B.S., Elementary Education

Nova Southeastern University

Ft. Lauderdale, Florida

Elementary and Exceptional Student Education Teacher Ben Sheppard Elementary

Hialeah, Florida

M.S., Early Childhood Special Education and

Pre-K Disabilities

University of Miami

Coral Gables, Florida

Elementary Teacher and Team Leader

Ruth Owens Krusé Educational Center

Miami, Florida

Educational Specialist

Miami-Dade County Public Schools

Miami, Florida

Graduate Assistant College of Education

Florida International University

Miami, Florida

\section{PUBLICATIONS AND PRESENTATIONS}

Escarpio, R. (2007). Review of Foundations of special education leadership: Administration, assessment, placement, and the law. Journal of Educational Administration, 46, 122-124.

Escarpio, R. (2007, October). Effective inclusion of all students with behavioral disorders: Best practices in teaching. Workshop presented at the annual meeting of the Florida Council for Exceptional Children, Ft. Lauderdale, Florida.

Escarpio, R., \& Salazar, M. (2007, November). Creating a sense of competence and confidence for novice teachers through mentoring and coaching. Poster session presented at the annual meeting of the Council for Exceptional Children, Teacher Education Division, Milwaukee, Wisconsin.. 
Valle-Riestra, D. \& Escarpio, R. (2007, November). Teaching cultural responsiveness in a redesigned early childhood assessment course. Workshop presented at the annual meeting of the Council for Exceptional Children, Teacher Education Division, Milwaukee, Wisconsin.

Nevin, A., Malian, I., Moores-Abdool, W., Marshall, D., Voight, J., Salazar, M.,Gonzalez, L., Escarpio, R., \& Liston, A. (2008, January). A multi-site mixed method study of paraeducators in inclusive classrooms: Pilot study results \& preliminary analysis of national survey data. Paper presented at the meeting of the Hawaii International Higher Education Conference, Honolulu, Hawaii.

\section{CURRENT MEMBERSHIPS}

National Association for the Education of Young Children Council for Exceptional Children (Teacher Education Division, Council for Children with Behavior Disorders, Division of Early Childhood)

AWARDS

Mathematics Teacher of the Year, Ben Sheppard Elementary, Miami-Dade County Public Schools, 2003

Beginning Teacher of the Year - Ben Sheppard Elementary, Miami-Dade County Public Schools, 1999 